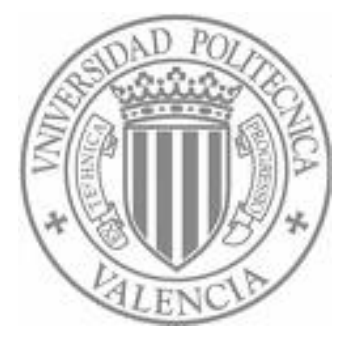

Universidad Politécnica de Valencia

Departamento de Tecnología de Alimentos

Consejo Superior de Investigaciones Científicas

Instituto de Agroquímica y Tecnología de Alimentos

\title{
INFLUENCIA DE TRATAMIENTOS TÉRMICOS EN LA CALIDAD Y ESTABILIDAD DEL PURÉ DE FRESA (Fragaria $x$ ananassa, cv Camarosa)
}

Memoria presentada por:

Oswaldo Osorio Mora

Para optar al grado de

Doctor por la Universidad Politécnica de Valencia

Valencia, España, Julio 2008 

Los doctores Nuria Martínez Navarrete, Catedrática de Universidad del Departamento de Tecnología de Alimentos de la Universidad Politécnica de Valencia, Gemma Moraga Ballesteros, Profesora Titular de Escuela Universitaria del mismo Departamento, y José Vicente Carbonell Talón, Profesor de Investigación del Instituto de Agroquímica y Tecnología de Alimentos (IATA) del Consejo Superior de Investigaciones Científicas:

AUTORIZAN a D. Oswaldo Osorio Mora, con Documento de Identificación Español NIE X1731097-W y Cédula de Ciudadanía Colombiana 7.554.798 de Armenia a que presente el trabajo que lleva como título: "INFLUENCIA DE TRATAMIENTOS TÉRMICOS EN LA CALIDAD Y ESTABILIDAD DEL PURÉ DE FRESA" y que se ha realizado bajo su dirección, para optar al grado de Doctor por la Universidad Politécnica de Valencia.

Y para que conste a los efectos oportunos, firman el presente escrito en Valencia, a 1 de Julio de 2008. 



\section{DEDICACIÓN ESPECIAL}

\section{A DIOS QUIEN SIEMPRE ESTUVO AHÍ.}

A MIS PADRES, LUIS Y MIRIAN. MIS HERMANAS YICEL Y MARCELA. A TODOS MIS FAMILIARES QUE FALTARON Y A LOS QUE AÚN ESTÁN 



\section{AGRADECIMIENTOS}

Recapacito en el día en el que supe que tenía la posibilidad de realizar estos estudios y pensé que sólo tendría que agradecerle a la Universidad de Nariño y a sus directivas del momento en cabeza del Dr. Pedro Vicente Obando, pero ha pasado tanto tiempo y han pasado tantas cosas, que tendría que escribir otra memoria, recordando a todos aquellos que de una u otra manera me apoyaron en la culminación de esta meta.

En primer lugar, agradezco al Ministerio de Educación y Ciencia y al Fondo Europeo de Desarrollo Regional la financiación concedida, a través del proyecto AGL 2005-05994, para la realización de este trabajo.

A nivel humano, quiero agradecer en especial a algunas personas que hicieran parte de mi vida en España y de esta tesis.

Al Dr. José Vicente Carbonell, gran profesional y mejor persona, por su apoyo incondicional tanto profesional como personal. A todos los investigadores del laboratorio: al Dr. José M. Sendra, al Dr. Luis Izquierdo, a la Dra. Inmaculada Carbonell, al Dr. José Luís Navarro, al Dr. Quique Sentandreu (el capi, por su asesoría, apoyo y ponerme en línea con la investigación), quienes me apoyaron profesionalmente de alguna manera en la elaboración de esta tesis.

Quiero agradecer muy especialmente a mi compañera de laboratorio, la Dra. Virginia Bernabé, siento que llegó un poco tarde a mi vida. Hubiéramos hecho mil cosas más, con su ímpetu, profesionalismo y ganas de trabajar. Espero poder hacerlo en un futuro. $Y$ al Dr. Fernando Sanpedro de quien recibí gran apoyo y amistad.

A las Dras. Nuria Martínez N. y Gemma Moraga, de quienes recibí apoyo profesional y una gran asesoría. Las dos son increíbles profesionales y me siento orgulloso de haber sido su humilde tesista. 
A todos mis compañeros del IATA y de la UPV. Españoles y foráneos (que son muchos), quienes me apoyaron brindándome su amistad y asesoría cuando la necesité.

Más que un agradecimiento siento que debería brindar un abrazo y un mil gracias a todos mis compas Colombianos, los currrantes. Siento un gran orgullo de uds. Son personas fenomenales y muy honestas que estudian, trabajan y sacan familias adelante, muchos sin becas, y fuera de eso tienen tiempo para los amigos, y la diversión. De verdad mil gracias.

Un agradecimiento muy especial y un "sí, se puede" a Bivi y a Lorena por su gran amistad, espero de corazón que todos sus sueños se cumplan.

Y en la última etapa de esta tesis y de este camino conocí alguien muy especial y a quien debo agradecer su compañía y apoyo. Yohana, espero que siempre estés ahí.

Sólo me resta desearles a todos Buen Viento y Buena Mar. 
RESUMEN/SUMMARY/RESUM 



\section{RESUMEN.}

La tendencia actual de los consumidores a adquirir alimentos con alta calidad sensorial y alto valor nutritivo y funcional está haciendo que las industrias de procesado desarrollen tecnologías capaces de combinar estas propiedades con la innegociable seguridad alimentaria. En el caso de los zumos de frutas se trata de conseguir este objetivo combinando tratamientos mínimos con la conservación refrigerada del producto durante su periodo de vida comercial, que suele ser del orden de dos meses.

Se han descrito tratamientos suaves de pasteurización de zumos ácidos, como el de naranja, que cumplen este objetivo. En el caso de la fresa, no se ha encontrado ninguna referencia bibliográfica sobre tratamientos de este tipo. Por ello, el objetivo planteado en esta tesis ha sido el estudio del efecto de la intensidad del tratamiento térmico en diferentes propiedades relacionadas con la calidad y estabilidad nutritiva, funcional y sensorial del puré de fresa.

Los resultados obtenidos ponen de manifiesto que el tratamiento térmico más intenso $\left(90^{\circ} \mathrm{C}-2 \mathrm{~min}\right)$ conlleva un aumento de la viscosidad y del área relativa de histéresis, relacionado con un incremento de la fracción de pectina hidrosoluble. No obstante, también son las muestras estructuralmente más estables durante el almacenamiento. En cuanto a su aceptación sensorial, cambio en el color, contenido en antocianinas, vitamina $\mathrm{C}$ y actividad antirradical no hay diferencias entre los diferentes tratamientos térmicos aplicados. En el almacenamiento refrigerado se produce una pequeña pérdida de algunos parámetros de calidad, pero estas pérdidas son mucho más intensas si el puré de fresas se conserva a temperatura ambiente.

Como conclusión se sugiere obtener un puré de fresa estéril, mediante la técnica de envasado en caliente y posterior enfriamiento de los envases, por ser el tratamiento más seguro y de aplicación industrial más sencilla, y conservar el producto en refrigeración durante su vida comercial. 



\section{SUMMARY.}

Due to the tendency to consume foods showing high sensory quality and with high nutritious and functional values the food industry is developing technologies to make compatible these properties in the products with nourishing safety. In the case of acid juices this is usually achieved by combining minimum heat treatments with cold storage, having the juices a whole commercial life of about two months.

In strawberry no information exists about treatments of this type and, thus, the objective of this work is the study of the effects of heat treatment intensity on properties related with physical, nutritious, functional and sensory quality of strawberry puree.

The viscosity and the relative area of hysteresis, related with an increase of water-soluble pectin, increased in the samples receiving the most intense heat treatments $\left(90^{\circ} \mathrm{C}\right.$ for 2 minutes). However, these samples were also structurally more stable during storage. No significant differenced due to the intensity of heat treatment were detected in colour parameters in antocyanins or vitamin $\mathrm{C}$ contents and antiradical activity. During cold storage a small decrease was observed in some quality parameters after two month of storage, whereas the loss of quality was much more pronounced at room temperature.

According to the obtained results it is suggested the use of hot filling techniques (safer and simpler than aseptic canning) to preserve the strawberry puree and to store the product in refrigeration during its commercial life. 



\section{RESUM.}

La tendència actual dels consumidors a adquirir aliments amb una alta qualitat sensorial i un alt valor nutritiu i funcional provoca que les indústries de processament desenvolupen tecnologies capaces de combinar aquestes propietats amb la seguretat alimentària, que és innegociable. En el cas dels sucs de fruites, es tracta d'aconseguir aquest objectiu combinant tractaments mínims amb la conservació refrigerada del producte durant el període de vida comercial, que sol ser d'uns dos mesos.

S'han descrit tractaments suaus de pasteurització de sucs de molt àcids, com el de taronja, que compleixen aquest objectiu. En el cas de la maduixa, no s'ha trobat cap referència bibliogràfica sobre tractaments d'aquest tipus. Per això, l'objectiu plantejat en aquesta tesi ha sigut estudiar l'efecte de la intensitat del tractament tèrmic en diferents propietats relacionades amb la qualitat i l'estabilitat nutritiva, funcional i sensorial del puré de maduixa. Els resultats obtinguts posen de manifest que el tractament tèrmic més intens $\left(90^{\circ} \mathrm{C}, 2 \mathrm{~min}\right)$ comporta un augment de la viscositat i de l'àrea relativa d'histèresi, augment relacionat amb un increment de la fracció de pectina hidrosoluble. No obstant això, les mostres sotmeses a aquest tractament també són estructuralment més estables durant l'emmagatzematge. Quant a l'acceptació sensorial, el canvi en el color, el contingut en antocianines i vitamina C i l'activitat antiradical, no hi ha diferències entre els diferents tractaments tèrmics aplicats. En l'emmagatzematge refrigerat es produeix una petita pèrdua en alguns paràmetres de qualitat, però aquestes pèrdues són molt més intenses si el puré de maduixa es conserva a temperatura ambient.

Com a conclusió se suggereix obtenir un puré de maduixa estèril, mitjançant la tècnica d'envasament en calent i refredament posterior dels envasos, per ser aquest el tractament més segur i d'aplicació industrial més senzilla, i conservar el producte en refrigeració durant la vida comercial d'aquest. 

ÍNDICE 



\section{ÍNDICE DE CONTENIDOS}

Pág.

I. Introducción 3

I.1. Conceptos y definiciones 6

I.1.1. La fresa 6

I.1.2. Variedades, producción y procesado 9

I.1.3. Objetivos de la pasteurización 13

I.1.4. Efecto del tratamiento térmico sobre la calidad nutricional y organoléptica de purés de frutas

I.2. Estado actual del tema y antecedentes de nuestra investigación

II. Objetivos y plan de trabajo

II.1. Objetivos generales

II.2. Objetivos específicos

II.3. Plan de trabajo

III. Materiales y métodos 43

III.1. Materia prima y procesado 43

III.2. Análisis realizados 48

III.2.1. Azúcares 48

III.2.2. Actividad del agua 48

III.2.3. Humedad 49

III.2.4. Determinación del pH 49

III.2.5. Determinación de los ${ }^{\circ}$ Brix 49

III.2.6. Acidez $\quad 50$

III.2.7. Índice de madurez 50

III.2.8. Color 50

III.2.9. Reología 51

III.2.10. Análisis sensorial $\quad 52$

III.2.11. Actividades enzimáticas 53

III.2.11.1. Actividad polifenoloxidasa 53 
III.2.11.2. Actividad peroxidasa 54

III.2.11.3. Actividad pectinmetilesterasa $\quad 55$

III.2.12. Antocianinas, vitamina C y actividad antirradical 55

III.2.12.1. Antocianidinas $\quad 55$

III.2.12.2. Ácido ascórbico y vitamina C 58

$\begin{array}{ll}\text { III.2.12.3. Actividad antirradical } & 59\end{array}$

III.2.13. Microbiología $\quad 61$

IV. Resultados y Discusión $\quad 67$

IV.1. Caracterización del puré de fresa fresco 67

IV.1.1. Macrocomponentes y propiedades fisicoquímicas del puré $\begin{array}{ll}\text { de fresa fresco } & 67\end{array}$

IV.1.2. Comportamiento reológico del puré de fresa fresco 68

$\begin{array}{ll}\text { IV.1.3. Color del puré de fresa fresco } & 71\end{array}$

$\begin{array}{ll}\text { IV.1.4. Actividad enzimàtica } & 72\end{array}$

IV.1.4.1. Pectinmetilesterasa $\quad 72$

$\begin{array}{lll}\text { IV.1.4.2. } & \text { Peroxidasa } & 73\end{array}$

$\begin{array}{lll}\text { IV.1.4.3. Polifenoloxidasa } & 74\end{array}$

IV.1.5. Contenido en antocianidinas 76

IV.1.6. Contenido en vitamina C 77

$\begin{array}{ll}\text { IV.1.7. Actividad antirradical } & 79\end{array}$

IV.2. Efecto del tratamiento térmico y del almacenamiento en la actividad enzimàtica del puré de fresa 85

IV.2.1. Pectinmetilesterasa 85

$\begin{array}{ll}\text { IV.2.2. Peroxidasa } & 87\end{array}$

IV.2.3. Polifenoloxidasa 89

IV.3. Efecto del tratamiento térmico y del almacenamiento en el contenido de antocianinas, vitamina $\mathrm{C}$ y actividad antirradical

IV.3.1. Efecto del tratamiento térmico y del almacenamiento en el Contenido de antocianidinas

IV.3.2. Efecto del tratamiento térmico y del almacenamiento en el contenido de vitamina $\mathrm{C}$ 
IV.3.3. Efecto del tratamiento térmico y del almacenamiento en la actividad antirradical

IV.4. Efecto del tratamiento térmico y del almacenamiento en aspectos de calidad sensorial, color y reología del puré de fresa

IV.4.1. Efecto del tratamiento térmico y del almacenamiento en el comportamiento reológico

IV.4.2. Efecto del tratamiento térmico y del almacenamiento en la calidad sensorial

IV.4.3. Efecto del tratamiento térmico y del almacenamiento en el color

IV.5. Aspectos microbiológicos del puré de fresa

IV.5.1. Determinación de la flora mesófila, hongos y levaduras en puré de fresa

IV.5.2. Cinéticas de inactivación por calor de Lactobacillus plantarum en suero de puré de fresa 
INDICE DE FIGURAS

Pág.

Figura I.1. Evolución de la forma, tamaño y color de la fresa durante la maduración.

Figura I.2. Evolución de la producción de fresa en Europa y España.

Figura I.3. Modelo intercambiador de placas. 15

$\begin{array}{ll}\text { Figura I.4. Estructura del ácido poligalacturónico. } & 20\end{array}$

Figura I.5. Esquema de acción de las enzimas pécticas 21

Figura I.6. Reacciones de pardeamiento en las que interviene la polifenoloxidasa. 22

Figura III. 1. Llegada de la fresa a planta piloto. 44

Figura III. 2. Pasadora de tornillo sinfín. $\quad 44$

Figura III. 3. Fracción de desecho y fracción pulposa para

alimentación al proceso de desaireado. $\quad 45$

Figura III. 4. Pasteurizador de placas APV Ibérica júnior. 46

Figura III. 5. Envasado en cámara de flujo laminar y esterilización de los Frascos $\quad 47$

Figura IV.1.1. Reograma del puré de fresa fresca inicial. $\quad 69$

Figura IV.1.2. Descenso del pH con el tiempo de incubación enzimática. $\quad 73$

Figura IV.1.3. Evolución de la actividad enzimática POD $\Delta$ Abs/ $\Delta$ t. 73

Figura IV.1.4. Evolución de la actividad enzimática PPO $\Delta$ Abs/ $\Delta t \quad 75$

Figura IV.1.5. Cromatograma de antocianinas en puré de fresa. 76

Figura IV.1.6. Cromatogramas de purés de fresa mostrando

el pico del ácido ascórbico antes y después de la conversión

de ácido dehidroscórbico a ascórbico.

Figura IV.1.7. Representación de la disminución de la concentración de DPPH en función del tiempo de reacción de los diferentes volúmenes de muestra.

Figura IV.1.8. Representación actividad antirradical y de las 
diferencias $y_{0}-y_{i}$ para diferentes volúmenes de muestra

Figura IV.2.1. Actividad PME del puré de fresa fresco y de los tratados térmicamente.

Figura IV.2.2. Medida espectrofotométrica de la actividad POD en fresa 88

Figura IV.2.3. Efectos del tratamiento térmico en la POD. 88

Figura IV.2.4. Actividad PPO a tiempo cero. 90

Figura IV.3.1. Variación del contenido total en pelargonidina

y cianidina (en $\mathrm{mg} / 100 \mathrm{~g}$ ) según el tratamiento a que ha sido sometida la muestra.

Figura IV.3.2. Variación del contenido total de pelargonidina y de cianidina en función del tiempo de almacenamiento a $3^{\circ} \mathrm{C}$. y $21^{\circ} \mathrm{C}$.

Figura IV.3.3. Variación del contenido en ácido ascórbico y vitamina $\mathrm{C}$ (en $\mathrm{mg} / \mathrm{g}$ ) en función del tratamiento térmico a que ha sido sometido el puré de fresa.

Figura IV.3.4. Variación del contenido en vitamina $\mathrm{C}$ y ácido ascórbico en función del tiempo de exposición de la muestra a una temperatura de $90^{\circ} \mathrm{C}$.

Figura IV.3.5. Variación del contenido en vitamina $\mathrm{C}$ y ácido ascórbico en función del tiempo de almacenamiento a $3^{\circ} \mathrm{C}$.y a $21^{\circ} \mathrm{C}$.

Figura IV.4.1. Comportamiento reológico del puré de fresa fresca y tratado térmicamente.

Figura IV.5.1. Ajuste al modelo de Weibull.de las curvas de supervivencia de $L$. plantarum inoculado en suero de fresa 


\section{INDICE DE TABLAS}

Tabla I.1. Tratamientos térmicos usados en la conservación de alimentos.

Tabla IV.1.1. Características iniciales del puré de fresa

Tabla IV.1.2. Valores medios del índice de consistencia (k), índice de flujo (n) y área relativa de histéresis de las muestras de puré de fresa fresca.

Tabla IV.I.3. Efecto de la desaireación en el color del puré de fresa.

Tabla IV.1.4. Resumen de las actividades enzimáticas encontradas en el puré de fresa fresco.

Tabla IV.1.5. Concentraciones de los picos mostrados en la figura IV.1.6. $\quad 77$

Tabla IV.1.6. Concentraciones de los picos mostrados en la figura IV.1.7. $\quad 77$

Tabla IV.2.1. Actividad PME del puré de fresa

Tabla IV.2.2. Valores de actividad POD del puré de fresa almacenado a $3^{\circ} \mathrm{C}$.

Tabla IV.2.3. Valores de actividad PPO del puré de fresa almacenado a 3 y $21^{\circ} \mathrm{C}$.

Tabla V.3.1. Actividad antirradical (milimoles / $L$ equivalentes de ácido ascórbico) del puré de fresa con distintos tratamientos térmicos y condiciones de almacenamiento.

Tabla IV.4.1. Índice de consistencia (K), índice de comportamiento al flujo (n) y área relativa de histéresis de las muestras de puré de fresa tratadas térmicamente.

Tabla IV.4.2. Resultados del test de ordenación comparando la aceptabilidad del puré fresco y el tratado térmicamente.

Tabla IV.4.3. Resultados del test de ordenación comparando la aceptabilidad del puré de fresa pasteurizado y almacenado a $3^{\circ} \mathrm{C}$

Tabla IV.4.4. Resultados del test de ordenación comparando 
la aceptabilidad del puré de fresa envasado en caliente y almacenado a $3^{\circ} \mathrm{C}$ y a $21^{\circ} \mathrm{C}$.

Tabla IV.4.5. Efecto del tratamiento térmico en las Coordenadas de color $\mathrm{CIEL} \mathrm{a}^{*} \mathrm{~b}^{*}$ y en los atributos de color croma $\left(\mathrm{C}^{*}\right)$ y tono $\left(\mathrm{h}^{*}\right)$ del puré de fresa.

Tabla IV.4.6. Efecto del almacenamiento en las coordenadas de color

CIEL*a*b* y en los atributos de color croma $\left(C^{*}\right)$ y tono $\left(h^{*}\right)$ del puré de fresa.

Tabla IV.5.1. Recuento de mohos, levaduras y mesófilos durante el almacenamiento del puré de fresa a 3 y $21^{\circ} \mathrm{C}$ durante 60 días.

Tabla IV.5.2. Valor de los parámetros del modelo de Weibull y Bigelow en las curvas de supervivencia de L. plantarum en el suero de fresa. 



\section{INTRODUCCIÓN}





\section{INTRODUCCION.}

En general los alimentos son perecederos, por lo que necesitan ciertas condiciones de tratamiento, conservación y manipulación. Su principal causa de deterioro es el ataque por diferentes tipos de microorganismos (bacterias, levaduras y mohos) y enzimas. Esto tiene implicaciones económicas evidentes, tanto para los fabricantes como para distribuidores y consumidores. Se calcula que más del $20 \%$ de todos los alimentos producidos en el mundo se pierden por acción de los microorganismos.

El deterioro de un alimento es toda modificación del mismo que, según la conformidad con los hábitos, costumbres y diferencias individuales, hace que no resulte apropiado para el consumo humano. Es un concepto relativo y está ligado a hábitos y costumbres de los pueblos. Muchos alimentos deteriorados no dañan a la salud, pero sus características organolépticas pueden estar alteradas y no ser apetecibles para los consumidores. Por otra parte, algunos alimentos alterados pueden resultar muy perjudiciales para la salud del consumidor. Existen por ello razones para evitar la alteración de los alimentos.

La tecnología de la conservación de alimentos ha avanzado en el desarrollo de una serie de innovaciones y tendencias, buscando métodos de conservación eficiente, obtención de alimentos seguros, nutritivos y con calidad sensorial. De las nuevas tecnologías de conservación y/o transformación de alimentos destacan, entre otras, las altas presiones hidrostáticas (Harte et al., 
2003; Guerrero-Beltran et al., 2005; Guerrero-Beltran et al., 2006;; Penna et al., 2006; Raso et al., 1998; San Martin et al., 2002; Sepulveda-Ahumada et al., 2000), los pulsos eléctricos (Barbosa-Canovas et al., 1998; Bendicho et al., 2002; Bendicho et al., 2005; Cortes et al., 2006; Estrada-Giron et al., 2005; FernandezMolina et al., 2005; Fernandez-Molina et al., 2005), los ultrasonidos (BarbosaCanovas y Rodriguez, 2002; Lopez et al., 1994), las radiaciones ionizantes (Guerrero-Beltran y Barbosa-Canovas, 2006; Guerrero-Beltran y BarbosaCanovas, 2005; Guerrero-Beltran y Barbosa-Canovas, 2004; Song et al., 2007), las atmósferas modificadas (Garcia et al., 1998) y los envases "inteligentes". Todas estas tecnologías presentan ventajas y limitaciones en su aplicación industrial además de requerir un marco legal que regule su uso. Por ello, el uso del método de conservación por tratamientos térmicos, sigue siendo el proceso usado por la mayoría de las industrias procesadoras, tanto por su eficiencia como por su sencillez.

En los zumos de frutas existen factores causales físicos, químicos y biológicos que intervienen en su descomposición o deterioro. Entre los más destacados tenemos el deterioro por enzimas que origina cambios en el sabor, color y textura del mismo. Los procesos alimentarios antes descritos incluyen tratamientos para inactivar parcial o totalmente estos enzimas. Los tratamientos térmicos aplicados para la inactivación de enzimas producen, en mayor o menor extensión, la inactivación de microorganismos que, además, se encuentran en un medio de pH bajo que limita su crecimiento. 
La aplicación sistemática de estos tratamientos en alimentos supuso, en su momento, un enorme avance en la lucha contra muchas enfermedades de transmisión alimentaría. No obstante, los tratamientos térmicos no son buenos aliados de las propiedades sensoriales y nutritivas de los alimentos. Si aumentamos la intensidad del tratamiento térmico (sea utilizando mayores temperaturas o tiempos de aplicación más largos) podemos esperar una mayor destrucción de los enzimas y microorganismos presentes, pero también una mayor alteración del aroma, del sabor y de algunos nutrientes del alimento. Por ello, cuando se establecen los tratamientos térmicos más adecuados para un determinado producto se busca siempre un compromiso entre la inactivación enzimàtica/ microbiológica y la calidad organoléptica/nutritiva del mismo.

Por otro lado, una de las cualidades beneficiosas de las frutas cada vez más valorada por los consumidores es su actividad o propiedades antioxidantes. Generalmente, un antioxidante se puede definir como aquella sustancia natural o artificial con capacidad para neutralizar y proteger a un sistema biológico frente a radicales libres, tales como los radicales de oxígeno, los de nitrógeno y los radicales lipídicos. En este sentido, en la medida en que los tratamientos térmicos afecten a los compuestos responsables de su actividad antioxidante, el beneficio del alimento para la salud del consumidor va a verse también comprometido. En el caso de las frutas, la vitamina $\mathrm{C}$ y los fenoles parecen ser los compuestos que más contribuyen a su actividad antioxidante. 


\section{I.1. CONCEPTOS Y DEFINICIONES.}

\section{I.1.1. La Fresa.}

Las frutas son productos de gran interés en el comercio mundial y constituyen importantes fuentes de ingreso en numerosos países, especialmente en el mundo en desarrollo. Su creciente consumo en los países desarrollados deriva, en parte, del convencimiento de que son buenas para la salud. Numerosos consumidores pueden elegir hoy, a lo largo de todo el año, entre una variedad mucho más amplia de frutas que la que tenían a su disposición en tiempos pasados. Sin embargo, no sólo podemos conseguir las fruta frescas, sino también una serie de productos derivados de ellas.

Las fresas o frutillas son varias especies de plantas rastreras del género Fragaria, nombre que se relaciona con la fragancia que posee ("fraga", en latín), cultivadas por su fruto comestible. Las variedades cultivadas comercialmente son por lo general híbridos en especial Fragaria $x$ ananassa, que ha reemplazado casi universalmente a la especie silvestre, Fragaria vesca, por el superior tamaño de sus frutos.

La fresa pertenece a la familia de las rosáceas. Es una planta perenne que produce brotes nuevos cada año. Presenta una roseta basal de donde surgen las hojas y los tallos florales, ambos de la misma longitud. Los tallos florales no presentan hojas. En su extremo aparecen las flores de cinco pétalos blancos, 
cinco sépalos y numerosos estambres. Los pecíolos de las hojas son pilosos. Cada uno soporta una hoja compuesta con tres foliolos ovales dentados. Éstos son verde brillantes por el haz y más pálidos por el envés, que manifiesta una nervadura muy destacada y una gran pilosidad. De la roseta basal surgen también otro tipo de tallos rastreros que producen raíces adventicias de donde nacen otras plantas.

La fresa es en realidad un engrosamiento del receptáculo floral. Contrario a la creencia popular no es el fruto de la planta, sino una modificación carnosa del tallo cuya función es contener dentro de ella los frutos de la planta. Por lo tanto es una infrutescencia. Cada fresa alberga entre 150 y 200 'pepitas', que son los auténticos frutos.

La fresa silvestre es originaria de Europa, concretamente de la región de los Alpes. El fresón, considerado una variedad de fresa, proviene de dos especies americanas que se mezclaron a su llegada a Europa. En la Edad Media se le atribuyeron diversas propiedades terapéuticas contra las infecciones de garganta, fiebre y problemas renales. Parece que la fresa comenzó a ser cultivada en Francia en el siglo XV y algo más tarde en España. Durante el siglo XIX se crearon numerosos híbridos, pero es en el siglo $\mathrm{XX}$ cuando se produce la explotación de la fresa a gran escala.

La fresa que conocemos actualmente fue introducida en Europa por los primeros colonos de Virginia. Con la llegada de la fresa de Virginia en el siglo XIX, se obtuvieron nuevas variedades que ganaron en tamaño pero que perdieron en sabor. Más tarde se realizaron cruces entre ésta y una variedad chilena lo cual 
compensó la balanza, consiguiendo una fresa grande y sabrosa. Este híbrido es el antepasado de todas las variedades que se consumen actualmente.

Hoy día las más comercializadas son fresas y fresones de cultivo intensivo que, gracias a los invernaderos, pueden comprarse durante todo el año, aunque su mejor época es en los meses de primavera hasta julio, en función de la variedad (Otterbacher y Skirvin, 1978).

Durante la maduración, el fruto va perdiendo color blanquecino (Figura I.1) a la vez que va incrementando su tamaño entre un 23 a 57\%, habiendo prácticas postcosecha que pueden influenciar el cambio de color del fruto. Cuando la fresa alcanza la madurez comercial es cuando se encuentran potenciados el color, aroma y sabor característicos.

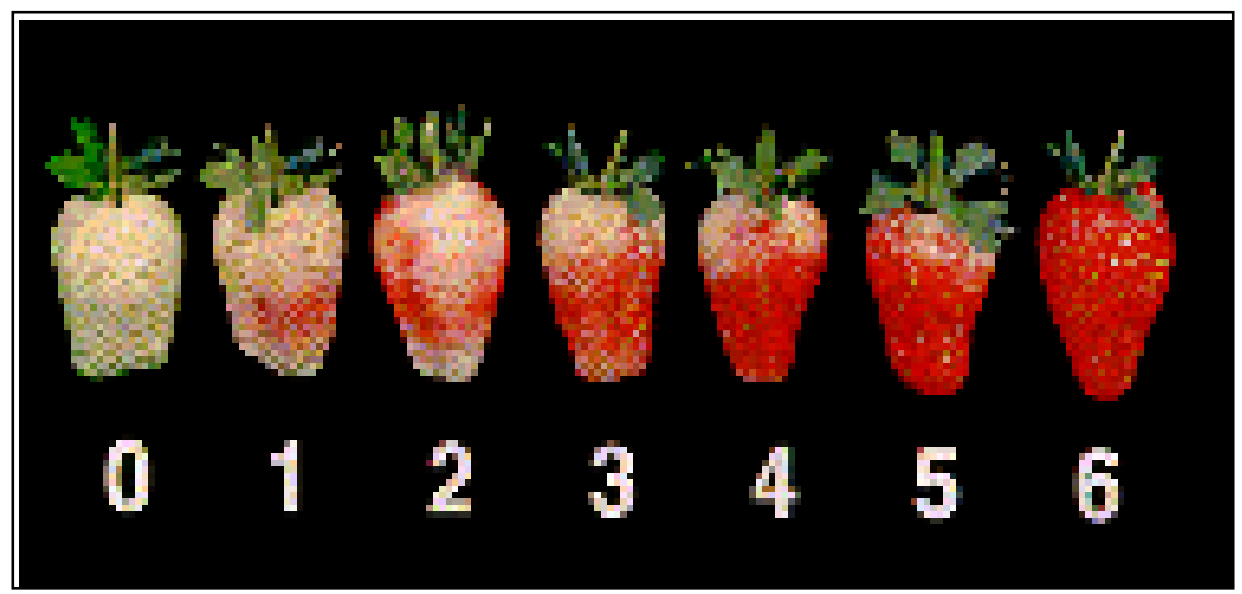

Figura I.1. Evolución de la forma, tamaño y color de la fresa durante la maduración. 
Desde el punto de vista de sus propiedades nutritivas y funcionales, en comparación con el resto de frutas, contiene una cantidad moderada de hidratos de carbono (alrededor del $5 \%$ de su peso y fundamentalmente son fructosa y glucosa) y su valor calórico es bajo. Destaca su aporte de vitamina C, con un porcentaje incluso superior en ocasiones al que posee la naranja, y antocianinas (flavonoides), sustancias ambas de acción antioxidante y, por lo tanto, con un claro papel funcional. Además tiene un importante contenido de ácidos orgánicos, entre ellos, el cítrico, málico, oxálico y salicílico (de acción anticoagulante y antiinflamatoria). También es rica en minerales como el potasio y el magnesio, entre otros. Su contenido en fibra es moderado.

\section{I.1.2. Variedades, producción y procesado.}

Las condiciones ambientales de la provincia de Huelva, España, la convierten en la zona más productiva de fresas y fresones. Las fresas que más se comercializan en España son las de la variedad "Reina de los Valles". En cuanto a los fresones, la más conocida es la variedad Camarosa, de origen californiano. Esta variedad supone un elevado porcentaje de la producción total de fresones de la provincia de Huelva y se caracteriza por ser un fruto de gran tamaño, muy precoz, de color extremadamente brillante, de buen sabor y firmeza. Otras variedades de cultivo de fresón en Huelva son: Tudla, Oso Grande, Cartuno y Carisma. 
La evolución de la producción desde 1970 hasta el 2005 ha sido la siguiente: en $1970,11.000 \mathrm{~T}$; en $2000,315.000 \mathrm{~T}$ y en $2005,358.000 \mathrm{~T}$. La figura I.2 muestra con mayor detalle esta evolución tanto en Europa como en España.
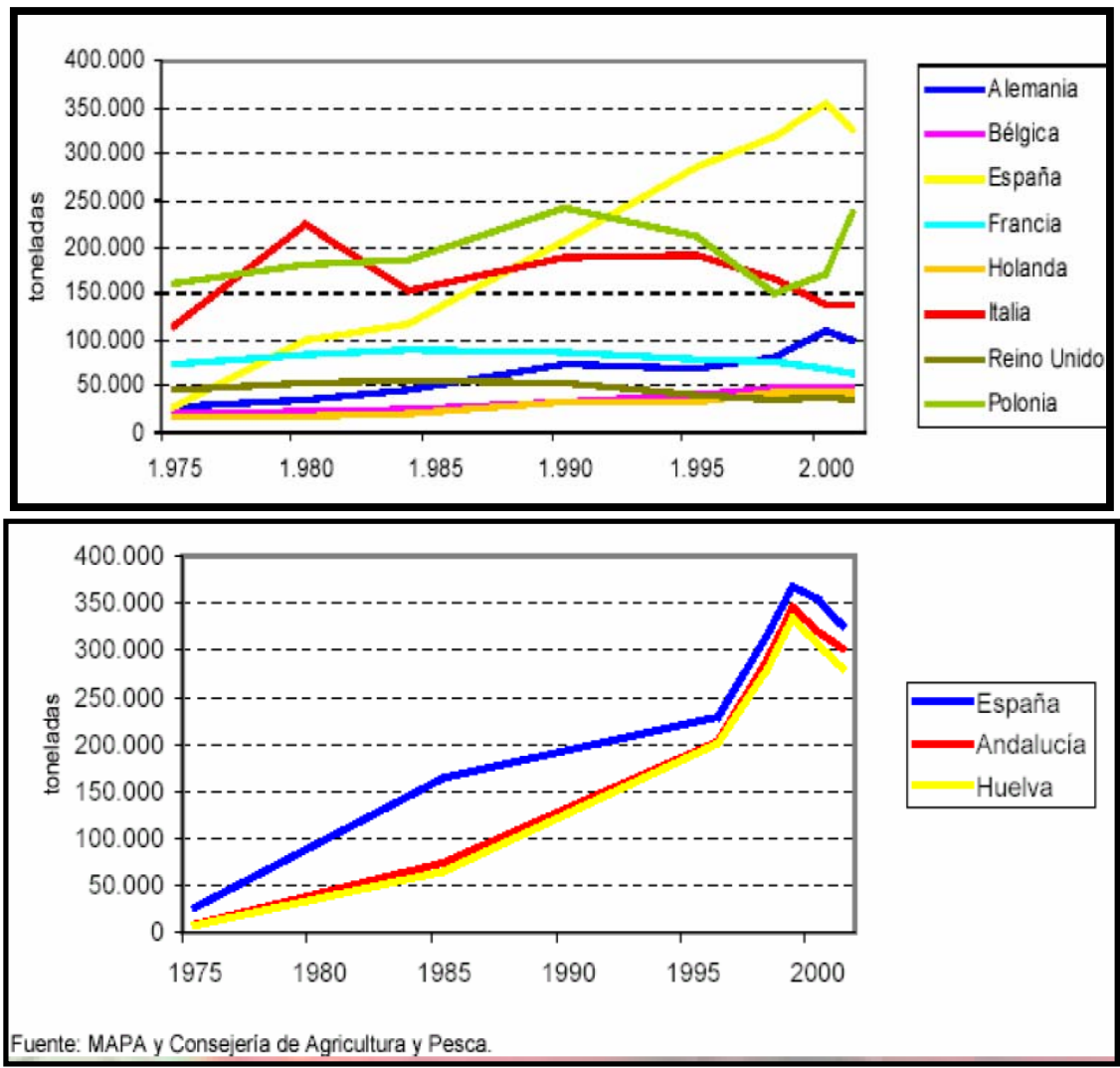

Figura I.2. Evolución de la producción de fresa en Europa y España.

Las diferencias en forma y tamaño de los frutos de los diferentes cultivares dependen de su fisiología, aunque la forma del fruto está determinada por el genotipo, clima, prácticas agrícolas, posición en la planta, etc. Así, los frutos 
pueden ser de diferente forma: cónico, cónico alargado, redondeado, esferoides, reniformes, etc. (Brazanti, 1989). En cualquier caso, desde el punto de vista de su procesado, una característica importante de la fresa es su escasa generación de residuos (pedúnculos y sépalos) y su gran porcentaje de conversión en pulpa o puré (rendimientos sobre el $85 \%$ a nivel industrial). La separación del pedúnculo puede producirse con la extracción de una parte del corazón que a veces saca también una parte de la pulpa, lo que reduce el valor comercial de los frutos (Brazanti, 1989).

Los zumos constituyen la principal vía de industrialización de las frutas. Prácticamente no existe ningún país del mundo que no tenga una industria elaboradora de zumos. Sin embargo, a menos que sean tratados correctamente y envasados asépticamente, estos productos tienen grandes riesgos de deterioro. Por tanto, los sistemas de conservación, los envases asépticos, la maquinaria para manejarlos y los sistemas de distribución son la base para obtener un producto de calidad.

En España, el Real Decreto 1650/1991 (BOE de 8 de noviembre de 1991) recoge la Reglamentación Técnico Sanitaria para la elaboración y venta de zumos de frutas y de otros productos similares. En el artículo 2 del Titulo Primero se define al puré, pulpa o cremogenado como el producto susceptible de fermentación pero no fermentado obtenido mediante molturación o tamizado de la parte comestible de frutas enteras o peladas sin eliminar el zumo.

Las pulpas de frutas como elaborados casi integrales (salvo hueso, semillas y otras partes duras o defectuosas), con consistencia cremosa, han 
alcanzado una gran importancia económica en la industria alimentaría actual, mostrando un gran futuro comercial ya que son la base a partir de la cual se elaboran una amplia gama de productos finales como son:

- Los zumos de frutas con pulpa y los néctares de frutas.

- Mermeladas.

- Alimentos infantiles.

El uso de las pulpas o purés como base para la elaboración de los productos mencionados anteriormente presenta una serie de ventajas bien definidas frente al método tradicional de utilizar la fruta como materia prima, ya que permite:

- Reducir costes de almacenamiento, por reducción de volumen.

- Reducir costes de transporte.

- Ampliar el tiempo de conservación, ya que puede ser tratado a fin de reducir las posibles causas de alteración.

Los productos procesados de fresa tales como puré, néctar, jugo y concentrado están también comercialmente disponibles. La aplicación de procesos de pasteurización al puré de fresa permitiría obtener un producto de alta calidad para la formulación de zumos y bebidas o para otros usos (por ejemplo, yogurt, helados, etc.), pero no existen antecedentes bibliográficos sobre el producto. Con respecto a la producción de zumos de fresa solo se ha encontrado una empresa productora en España que se ha decantado por este producto. Del resto de empresas inscritas en la Asociación Española de Fabricantes de Zumos, sólo 
algunas de ellas fabrican jugos multifruta donde incluyen a la fresa como una de las frutas integrantes (www.asozumos.org).

\section{I.1.3. Objetivos de la pasteurización.}

La actividad microbiana y enzimàtica de los zumos y purés de frutas son los principales responsables de su deterioro. Por lo tanto, la aplicación de tratamientos térmicos tendrá como objetivo reducir y controlar ambas actividades. No obstante, tratamientos térmicos muy intensos pueden dar lugar al desarrollo de aromas y sabores extraños, así como al deterioro del color y valor nutritivo y funcional del producto. En este sentido, últimamente están apareciendo en el mercado zumos de frutas pasteurizados por tratamientos "alta temperatura-corto tiempo" que, aunque requieren del almacenamiento del producto en refrigeración para garantizar su estabilidad y seguridad durante aproximadamente dos meses, mantienen mejores características sensoriales.

La pasteurización se usa en un sentido amplio en tecnología de alimentos para designar cualquier tratamiento térmico cuyo objetivo sea la destrucción de la mayor parte de las formas vegetativas de los microorganismos capaces de alterar los alimentos o de interferir con el desarrollo de fermentaciones indeseables. Normalmente se aplican temperaturas que oscilan entre 55 y $90^{\circ} \mathrm{C}$, variando los tiempos de exposición para conseguir el objetivo deseado (destrucción de microorganismos y enzimas que afecten a la seguridad y calidad del alimento en el 
tiempo de vida útil), afectando lo menos posible a la composición, el sabor y el valor nutritivo del líquido. El proceso se llama así en honor del químico francés Louis Pasteur, quien lo ideó en 1865 con el fin de inhibir la fermentación del vino y de la leche.

Los equipos en los que generalmente se realiza este proceso en la industria alimentaría son los intercambiadores de placas. Estos pueden ser de placas con juntas, PHE (plate heat exchangers), o de placas soldadas, BHE (brazed heat exchangers). Ambos diseños se conocen indistintamente como intercambiadores compactos. Los PHE consisten en un conjunto de placas metálicas corrugadas montadas entre dos placas, una fija (bastidor) y otra móvil (de presión). Este paquete de placas, a su vez, es soportado por dos barras guía, una superior y otra inferior que apoyan sobre una columna o pedestal. El sellado entre placas se efectúa mediante juntas elastoméricas quienes a su vez dirigen los fluidos por canales alternos. Las placas contienen orificios que permiten y dirigen el flujo de los fluidos. El conjunto de placas es comprimido mediante espárragos que aseguran el apriete y estanqueidad entre las mismas. Las conexiones de entrada y salida se localizan en la placa fija del bastidor salvo en el caso de que haya más de un paso, donde se utilizan ambas placas del bastidor. Los PHE son llamados también intercambiadores de placas y marcos (plate and frame) por su similitud constructiva con los filtros prensas. La Figura I.3 Muestra un esquema típico del equipo que se asemeja, a nivel piloto, al usado en nuestra investigación. 


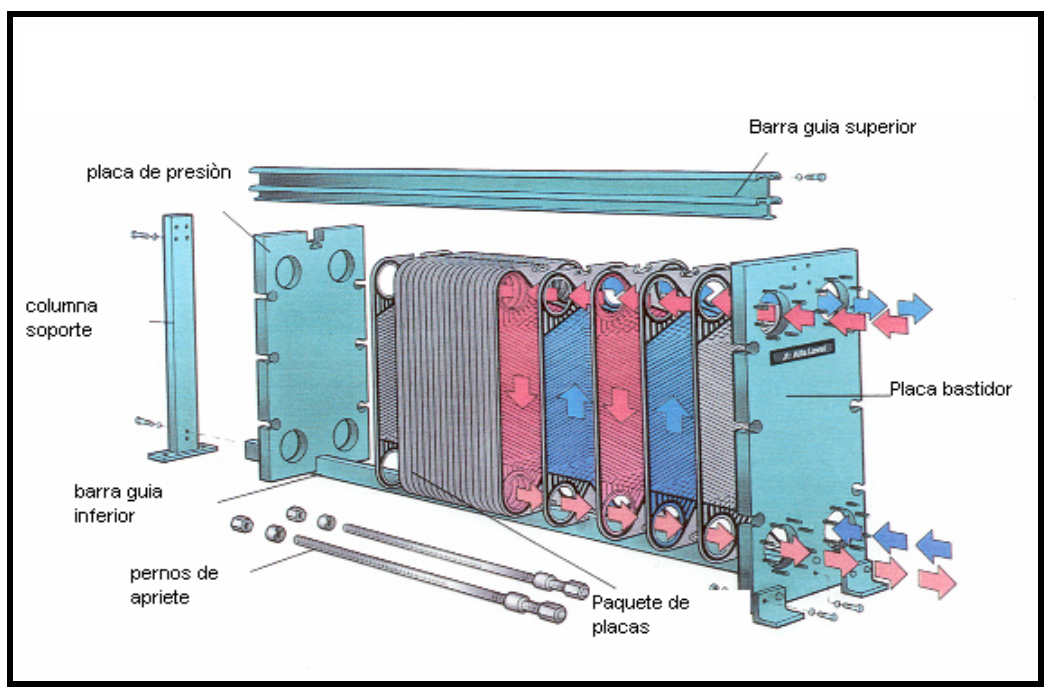

Figura I.3. Modelo intercambiador de placas.

Como se ha mencionado anteriormente, el binomio temperatura-tiempo a aplicar en un proceso de pasteurización va a depender del objetivo perseguido y la vida útil que se quiera dar al producto.

El uso de temperaturas elevadas provoca en las poblaciones microbianas un progresivo y ordenado descenso de su tasa de crecimiento debido a la muerte de un número de células tanto más elevado cuanto más prolongado sea el tiempo de exposición. Los factores que afectan a la termorresistencia, además del tipo de microorganismo, son el número de células existente, la fase del crecimiento en que se encuentran y las condiciones del medio en el que se efectúa el calentamiento. Las esporas bacterianas son muy resistentes a las temperaturas extremas. Algunas pueden incluso sobrevivir tratamientos de varios minutos a 
$120^{\circ} \mathrm{C}$ y horas a $100^{\circ} \mathrm{C}$. No obstante, la mayoría de sus formas vegetativas, al igual que las levaduras y los hongos, mueren tras unos minutos a $70-80^{\circ} \mathrm{C}$ y ninguno resiste más que una exposición momentánea a $100^{\circ} \mathrm{C}$. Por otra parte, cuanto más elevada sea la carga microbiana inicial, tanto más tardará una población en alcanzar un determinado valor de reducción de la población, por lo que un buen proceso debe diseñarse considerando la carga microbiana en el producto fresco. El uso de prácticas defectuosas que permitan una excesiva multiplicación microbiana antes de su aplicación puede comprometer seriamente el éxito de un tratamiento térmico.

El tipo de microorganismo presente en un alimento depende principalmente del pH y de la actividad del agua. En los alimentos ácidos, como lo pueden ser los zumos o purés de fruta ( $\mathrm{pH}$ menor o igual a 4,5), los microorganismos que crecen se controlan fácilmente con un tratamiento térmico de pasteurización suave. Sin embargo, se debe tener en cuenta algunos microorganismos alterantes de este tipo de productos, entre ellos algunas bacterias esporuladas como el Clostridium pasteurianum el cual no se desarrolla a $\mathrm{pH}$ inferior a 3,7 y que afecta a frutas y tomates enlatados; bacterias no esporuladas como el Lactobacillus brevis y Lactobacillus mesenteroides y pleofructi, que se destruyen con tratamiento térmico a menos de $100^{\circ} \mathrm{C}$; las levaduras que presentan escasa resistencia al calor, pero que producen fermentación en productos ácidos con escaso tratamiento térmico; y los mohos como Byssochlamis fulva que afecta a frutas enlatadas y embotelladas y es responsable de la desintegración de frutas por descomposición del material 
péctico. En fresas se encuentra el Byssochlamys nivea y Aspergillus que son termoresistentes y afectan a las fresas enlatadas (Garcia-Alonso, 2005).

Con respecto a la inactivación enzimàtica, la efectividad del tratamiento depende igualmente de las variables del tratamiento (tiempo, temperatura, $\mathrm{pH}$ ), de la composición del alimento y del tipo de enzima.

Las enzimas son esenciales porque catalizan numerosas reacciones metabólicas en las plantas, sin embargo continúan actuando después de la recolección. Esto hace que sean las principales responsables de la pérdida de calidad de los alimentos (sabor, aroma, color, textura y valor nutritivo). Para obtener alimentos de buena calidad y de larga vida útil, es pues necesario inactivarlas. El tratamiento térmico es el procedimiento mas utilizado para este fin.

La peroxidasa (POD) está en todos los animales y plantas y probablemente en algunos microorganismos. No existe como una única enzima en frutas y hortalizas sino que se encuentra en forma de un número discreto de isoenzimas, las isoperoxidasas. La POD es una enzima capaz de reaccionar con numerosos compuestos por lo que es difícil correlacionar los cambios producidos después de la recolección con reacciones químicas especificas (Robinson, 1991). Se sabe que probablemente está involucrada en reacciones de degradación de flavonoides (Schreier, 1985). La POD está dentro del grupo de las enzimas oxirreductasas y descomponen el peroxido de hidrógeno en presencia de un dador de hidrógeno. Ya desde 1994 Whitaker clasificó a las peroxidasas en POD que contienen hierro y las POD con flavoproteínas. En vegetales la más estudiada ha sido la del rábano (Robinson, 1991). La POD puede producir un gran número de 
reacciones separadas, por lo que tienen un grado de versatilidad muy elevado en comparación con otras enzimas. Es capaz de catalizar reacciones peroxidativas, oxidativas, catalíticas e hidroxilaciones utilizando un sustrato oxidante y uno reductor. El agente oxidante puede ser un peróxido o un peroxiácido, $\mathrm{RO}=\mathrm{COOH}$, principalmente peroxido de hidrogeno (Robinson, 1991). A partir de los sustratos naturales, incluyendo compuestos fenólicos presentes en frutas, se pueden formar gamas muy amplias de productos a través de reacciones que incluyen radicales libres. En condiciones donde se utilizan compuestos fenólicos, sólo es importante la reacción peroxidativa (Whitaker, 1994) y ésta se da con sustratos como guayacol, resorcinol, p-cresol o p-fenilendiamina, entre otros. Esta última está dentro de las aminas aromáticas con función cromófora, que son cristales de color que varían del blanco al malva y que ha sido utilizado en la determinación espectrofotometrica de la POD en fresa por autores como Begoña de Ancos et al., (2007); Cano et al., (1997); Garcia-Palazon et al., (2004).

Los métodos espectrofotométricos han sido los mas usados para cuantificar la actividad de esta enzima desde que lo propusieron en 1954 Maehly y Chance (1954). Para determinar la actividad de esta enzima se puede medir la cantidad de producto formado o la de $\mathrm{H}_{2} \mathrm{O}_{2}$ consumido. Para ello hay que controlar muy bien la concentración del oxidante y del dador además de la temperatura y tiempo de reacción (Saunders et al.,1964).

La POD ha sido considerada la enzima más termorresistente en vegetales (Martens et al., 2001) y de hecho fue y ha sido utilizada como índice de eficacia 
del escaldado en muchos productos que han sido procesados y se van a congelar (Ganthavorn y Powers, 1988).

Otra enzima importante es la pectinmetilesterasa (PME). Al hacer una revisión bibliográfica sobre la acción de esta enzima en el puré o zumo de fresa y en particular en el efecto de esta enzima en la calidad de purés o zumos pasteurizados-enfriados de esta fruta, no se encontraron estudios relacionados. Sin embargo, en otros zumos de fruta de contenido similar de acidez y de azúcar, tales como jugos de naranja, se han encontrado recomendaciones en las que para ajustar las condiciones del tratamiento térmico, la inactivación de enzimas es fundamental, siendo primordial la actividad PME (Irwe y Olson I., 1994; Kimball D.A., 1999). Estos autores consideran aceptable una actividad residual del $10 \%$ para jugos pasteurizados enfriados.

Las pectinas son polisacáridos constituidos principalmente de ácido poligalacturónico (Figura I.4) con parte de los grupos metoxilados. La PME es una enzima presente en la pared celular vegetal que causa la eliminación de grupos metoxilo de las pectinas y produce radicales carboxílicos libres. Una vez alcanzada el grado crítico de esterificación, los cationes divalentes (especialmente el $\mathrm{Ca}^{2+}$ ) pueden unirse a grupos carboxílicos libres pertenecientes a las cadenas adyacentes de la pectina. Por lo tanto, la actividad de la PME implicará cambios en las características reològicas del zumo y de los purés de fruta (Baker y Cameron, 1999). 


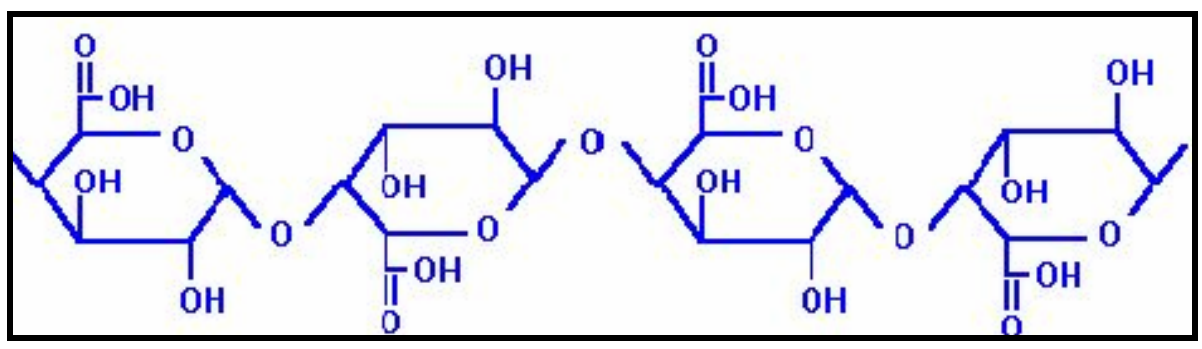

Figura I.4. Estructura del ácido poligalacturónico.

No obstante, esta enzima péctica actúa junto con otras (Figura I.5) entre las que se encuentran poligalacturonasas (PG), que hidrolizan los enlaces glicosidicos próximos a un grupo carboxilo libre, y pectinliasas $(\mathrm{PL})$, que rompen los enlaces glucosídicos próximos a un grupo metil éster (Pilnik y Rombouts, 1978).

En zumos cítricos los macropolímeros insolubles formados por la actividad PME y que se han relacionado con la ruptura de la nube característica de estos productos, conducen a la clarificación del zumo (Joslyn y Pilnik, 1961). Por otro lado, en puré de tomate se ha detectado que la actividad poligalacturonasa y la de la PME está relacionada con un descenso de la viscosidad (Krebbers et al., 2003; Plaza et al., 2003; Vercet et al., 2002). 


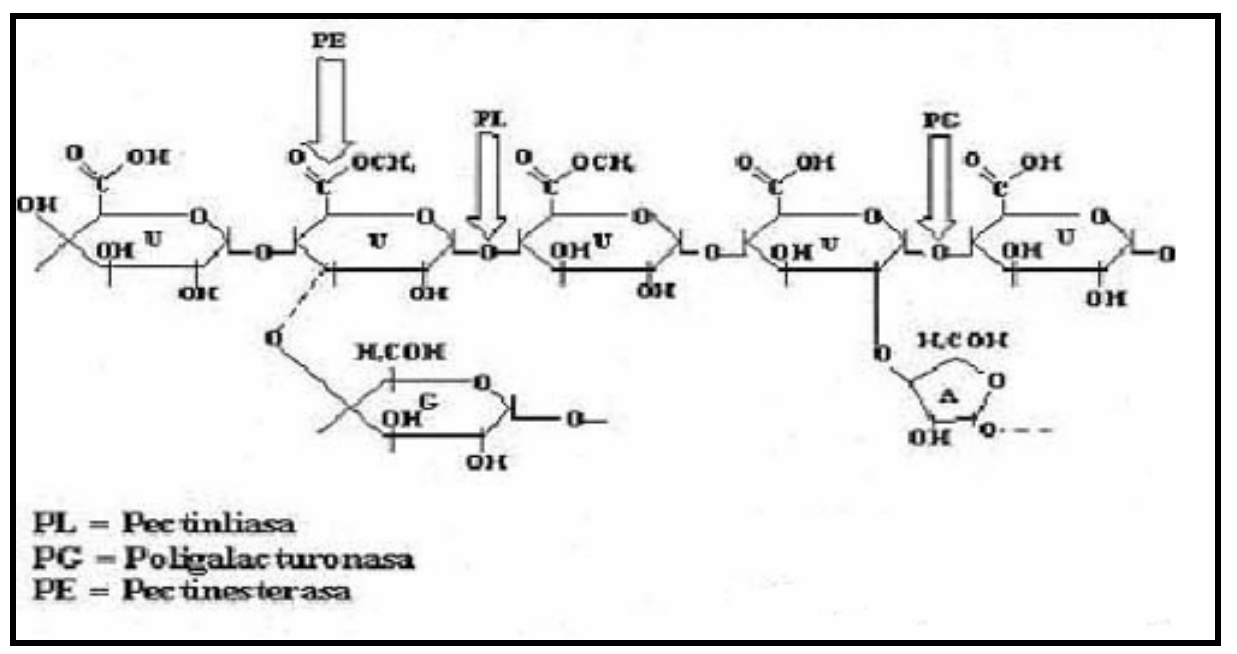

Figura I.5. Esquema de acción de las enzimas pécticas.

La pectina soluble en oxalato representa la mayor fracción péctica en fresa, lo cual no es usual en otras frutas tal como la manzana (Contreras et al., 2005). Esta fracción de pectina de baja esterificación puede favorecer la unión del calcio (Sirisomboon et al., 2001). En este sentido la actividad PME tal vez no sea la actividad más importante en fresa. Sin embargo, su acción puede dar lugar a cambios en el comportamiento reológico que podrían manifestarse en una inestabilidad del producto durante el almacenamiento.

Por otra parte, las polifenoloxidasas (PPO) están involucradas en el pardeamiento enzimático, provocando el oscurecimiento de algunos vegetales ricos en compuestos fenólicos durante su elaboración o almacenamiento. La figura I.6 muestra la reacción de formación de productos pardos y en las dos primeras etapas de esta reacción intervienen las polifenoloxidasas, métaloenzimas que 
contienen aproximadamente un $0,2 \%$ de cobre. En ellas el oxigeno molecular actúa como aceptor de hidrogeno. Su pH óptimo es de 5,5.

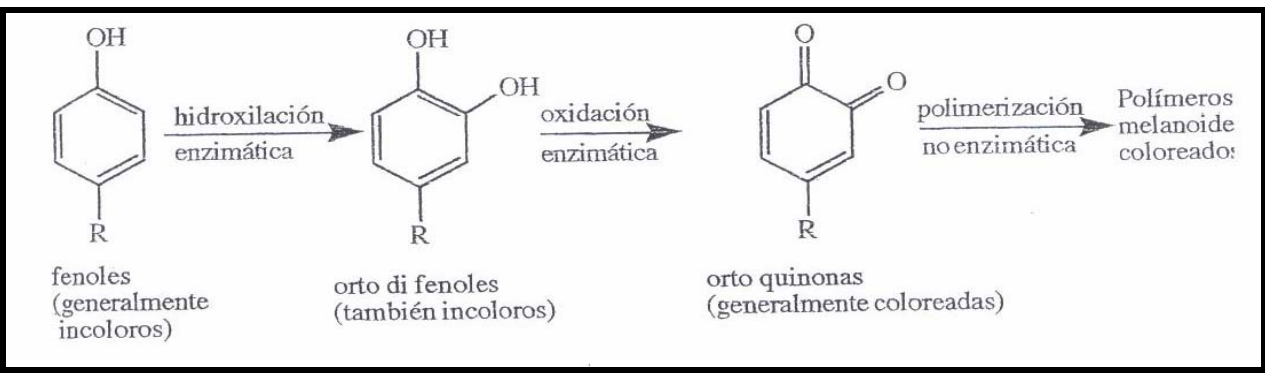

Figura I.6. Reacciones de pardeamiento en las que interviene la polifenoloxidasa.

Para inhibir el pardeamiento se recurre a distintos tratamientos, dependiendo del tipo de producto que se desee obtener. Entre estos tratamientos está el escaldado con vapor o con agua hirviendo, inmersión en agua ligeramente acidulada con ácido ascórbico (reduce las quinonas recién formadas) o tratamientos con $\mathrm{SO}_{2}$ o bisulfitos (Hernando et al., 2007).

\section{I.1.4. Efecto del tratamiento térmico sobre la calidad nutricional y organoléptica de purés de frutas.}

Los métodos de conservación tradicionales de alimentos basados en tratamientos térmicos (escaldado, pasteurización o esterilización) conllevan en muchas ocasiones, como ya se ha comentado, una disminución de la calidad 
nutricional y organoléptica del alimento. Este aspecto, unido al hecho de que el consumidor demanda alimentos cada vez más frescos y naturales que además de tener una vida útil prolongada mantengan sus cualidades nutricionales y sensoriales, ha llevado a perfeccionar los tratamientos térmicos existentes, ya que cuanto más intenso es el tratamiento térmico aplicado, mayores son los cambios indeseables ocasionados. Por ello, cuando se establecen los tratamientos térmicos más adecuados para un determinado producto se busca siempre ese compromiso entre la calidad microbiológica, la organoléptica y la nutritiva del mismo que se mencionaba anteriormente.

Desde el punto de vista de la calidad nutricional, como consecuencia del tratamiento térmico aplicado, se pierden vitaminas termolábiles, como la vitamina C, además de otros compuestos como antocianinas y compuestos fenólicos presentes en la fresa (Klopotek et al., 2005). Estos autores reportan una disminución en la capacidad antioxidante total de la fruta como consecuencia de su procesado.

Por otro lado, el uso de temperaturas elevadas favorece las reacciones de pardeamiento no enzimático (Anese et al., 2002) dando lugar a compuestos altamente reactivos que pueden reaccionar con algunas vitaminas, oxidándolas, y producir complejos oscuros que modifican el color, aroma y sabor de la fruta.

Existen referencias de la degradación aerobia de la vitamina $C$ en las cuales, si se aplica calor se produce el ácido 2,3- dicetogulónico, a partir del cual se producen descarboxilaciones y deshidrataciones formándose finalmente ácido furoico. Este compuesto interviene en la reacción de Maillard, o puede intervenir 
en condensaciones con otras moléculas de su misma naturaleza dando complejos oscuros coloreados, por ejemplo, en zumos donde no se ha eliminado bien el oxígeno.

En la degradación anaerobia de la vitamina $\mathrm{C}$, en medios muy ácidos y con aplicación de calor se produce el ácido 2-cetogulónico, a partir del cual se produce el furfural que es intermediario de las reacciones de pardeamiento no enzimático, oscureciéndose finalmente el producto. En los zumos, a pesar de estar bien envasados, si hay un $\mathrm{pH}$ muy ácido se puede dar color oscuro y envase abombado ya que se desprende $\mathrm{CO}_{2}$ en la secuencia de reacciones.

En el caso de la fresa, la pérdida del color rojo intenso de la fruta, ocasionada por estas reacciones o por la pérdida de antocianinas como consecuencia del tratamiento térmico, da lugar a importantes pérdidas de calidad. Además, durante el almacenamiento pueden ocurrir cambios indeseables en el color del producto por efecto de la actividad polifenoloxidasa o peroxidasa residual (Chisari et al., 2007) que serán función de la temperatura de almacenamiento. De todos los factores estudiados, el control de la temperatura de almacenamiento es el que incrementa de forma significativa la estabilidad del color.

Otro parámetro de calidad importante que puede verse modificado por el tratamiento térmico es la viscosidad del zumo. Esta propiedad reológica depende de la cantidad de sólidos totales, la cantidad de sólidos solubles, el tamaño de partícula y la temperatura (Ahmed et al., 2004). El tratamiento térmico puede afectar a estos factores, como por ejemplo, modificando la fracción de pectina soluble presente en la fruta, cambiando de esta manera la viscosidad del producto 
(Dutta et al., 2006). Por otra parte, durante el almacenamiento en refrigeración, la actividad residual de la pectinmetilesterasa podría influir en el comportamiento reológico del producto.

Aunque no se han encontrado referencias bibliográficas sobre el efecto de la intensidad del tratamiento térmico en la evaluación sensorial de purés de fresa tratados térmicamente, en otros zumos de frutas semejantes como los de cítricos, un tratamiento de pasteurización suave es preferido por el consumidor frente a los tratamientos más intensos como el de esterilización, a pesar de que su vida comercial el más corta y se requiere su almacenamiento en refrigeración.

\section{I.2. Estado actual del tema y antecedentes de nuestra investigación.}

Cada vez es mayor la preocupación de consumidores, procesadores y productores por obtener alimentos más sanos y seguros (Bello, 2005). Además, los consumidores están interesados en conocer con exactitud la composición de los alimentos y el efecto de los ingredientes de la dieta en su salud, bienestar y en la prevención de enfermedades (Cano et al., 2005).

Numerosos estudios epidemiológicos asocian el consumo de una dieta rica en productos de origen vegetal con una menor predisposición a padecer ciertas enfermedades degenerativas como cáncer (Potter, 1996, Jang et al., 1997; Michels et al., 2000) y enfermedades cardiovasculares (Rimm et al., 1996) (Liu, 2002) (Pace-Asciak et al., 1995; Divisi et al., 2006). Por tanto, el consumidor 
valora positivamente aquellos alimentos vegetales que no sólo le proporcionan nutrientes indispensables para la vida (carbohidratos, proteínas, vitaminas, grasas, etc.) sino que además posean sustancias con un posible efecto protector para su salud, conocidos como compuestos fitoquímicos o bioactivos (antocianinas, flavonoides, etc.) (Prior y Cao, 2000).

Por otro, lado las frutas y hortalizas deben ser procesadas y conservadas por conveniencia y razones económicas, lo que implica numerosos cambios desde la cosecha hasta su consumo. Durante las operaciones de acondicionamiento, procesamiento y almacenamiento se producen cambios que afectan a las propiedades nutritivas y funcionales de estos alimentos. En los países más industrializados surgen tecnologías de conservación de alimentos orientadas a minimizar el impacto de los procesos sobre el valor nutritivo, calidad sensorial y propiedades funcionales de los mismos. Se producen "alimentos vegetales mínimamente procesados" (Gonzalez-Aguilar et al., 2004), denominación que hace referencia a la aplicación de una tecnología que, combinada con otras, ayudan a mantener las características propias del alimento fresco original, además de mejorar su vida comercial en términos microbiológicos, sensoriales y nutricionales.

De los métodos físicos, los tratamientos térmicos son, en la mayoría de los casos, los escogidos para la conservación de los zumos y otros alimentos perecederos. Como ya se ha comentado, el tratamiento térmico tiene una larga tradición al ser un método económico y eficiente en el logro de la inactivación 
microbiana y enzimática (Diels et al., 2005); (Bahceci y Acar, ; Bower y Daeschel, 1999; van Asselt y Zwietering, 2006).

Los tratamientos térmicos tradicionalmente aplicados a los alimentos son los procesos de esterilización, aunque en alimentos de alta acidez se aplican también procesos de pasteurización. En la tabla I.1 se describen los parámetros de los principales procesos térmicos aplicados.

Tabla I.1. Tratamientos térmicos usados en la conservación de alimentos.

\begin{tabular}{lcc}
\hline Tratamiento & Temperatura ${ }^{\circ} \mathrm{C}$ & Tiempo \\
\hline Termización & $63-65$ & $15-30 \mathrm{~s}$ \\
Pasteurización HTST ${ }^{\mathrm{a}}$ & $72-75$ & $15-20 \mathrm{~s}$ \\
Pasteurización LTLT $^{\mathrm{b}}$ & $63-65$ & $30 \mathrm{~min}$ \\
$\begin{array}{l}\text { Ultrapasteurización } \\
\text { Esterilización en envase }\end{array}$ & $125-138$ & $2-4 \mathrm{~s}$ \\
& $115-120$ & $20-30 \mathrm{~min}$ \\
$\begin{array}{l}\text { Esterilización UHT } \\
\end{array}$ & $138-150$ & $1-4 \mathrm{~s}$ \\
\hline $\begin{array}{l}\text { a Iniciales de High Temperature ShortTime } \\
\text { b Iniciales de Low Temperature Long Time } \\
\text { c Iniciales de Ultra High Temperature. }\end{array}$
\end{tabular}

Los procesos de esterilización pretenden la destrucción de los microorganismos presentes en los alimentos y la inactivación total de los enzimas, mientras que en los procesos de pasteurización se trata de destruir los 
microorganismos patógenos y reducir la actividad enzimàtica a niveles compatibles con la conservación refrigerada del producto durante su periodo de vida útil. En este sentido, en los productos pasteurizados se debe poner atención a la posible contaminación de algunos microorganismos que los alteran, entre ellas, algunas bacterias esporuladas y no esporuladas, levaduras y mohos.

Una combinación que se utiliza cada vez con mayor frecuencia en zumos, purés y derivados de frutas es la aplicación de tratamientos térmicos muy suaves y la conservación refrigerada de los mismos. El tratamiento térmico suave reduce considerablemente el impacto de las altas temperaturas sobre la calidad de los alimentos, manteniendo en alto grado sus propiedades nutritivas y sensoriales, mientras que la conservación refrigerada confiere a los alimentos así tratados la estabilidad necesaria para su comercialización.

Las actividades enzimáticas residuales en zumos pasteurizados pueden producir pardeamiento, clarificación, decoloración y aparición de sabores y aromas extraños.

\footnotetext{
El pardeamiento enzimático provoca el oscurecimiento de algunos productos naturales vegetales ricos en compuestos fenolicos durante su elaboración o almacenamiento, y se debe a la actuación de las polifenoloxidasas. Una alta concentración de polifenoles en el tejido vegetal puede dar lugar a pardeamientos más intensos, pero los polifenoles, por sus propiedades antioxidantes son muy beneficiosos para la salud, y el pardeamiento enzimático puede evitarse o reducirse aplicando tratamientos adecuados (Luh et al., 1967; Chang et al., 2000).
} 
Sólo se ha encontrado un trabajo sobre la reducción de la actividad PPO en fresa por tratamiento térmico. Dalmadi et al. (2006) estudiaron su inactivación térmica y el pH óptimo de actividad, encontrando un valor de 5 para esta enzima en fresa variedad Elsanta. Según este estudio, un tratamiento de 10 minutos a $55^{\circ} \mathrm{C}$ reduce la actividad PPO de un extracto a $\mathrm{pH} 7$ en un $50 \%$ y estos enzimas se inactivan completamente con un tratamiento a $65^{\circ} \mathrm{C}$ durante 10 minutos.

En otras especies vegetales se observan comportamientos análogos. Chutintrasria y Noomhorm (2006) estudiaron la inactivación térmica de la PPO en puré de piña tratado en intervalos de temperatura entre $40^{\circ} \mathrm{C}$ y $90^{\circ} \mathrm{C}$ con exposición entre 10 y 30 minutos, encontrando que se obtiene una reducción del $60 \%$ a $70-75^{\circ} \mathrm{C}$ durante 5 minutos, a $65^{\circ} \mathrm{C}$ durante $10-25$ minutos y a $60^{\circ} \mathrm{C}$ durante 30 minutos. Weemaes et al. (1997) estudiaron la influencia del pH en la cinética térmica de inactivación en la PPO en extracto de champiñón, encontrando que la estabilidad de la PPO aumenta a pH superior a 6,5 y el mismo grupo (Weemaes et al., 1998) también estudió la cinética de inactivación de la PPO en mango, combinando tratamientos de altas presiones con temperaturas moderadas $\left(62^{\circ} \mathrm{C}\right)$.

Las peroxidasas son enzimas que catalizan la oxidación de un amplio número de sustratos orgánicos, utilizando el poder oxidante del peróxido de hidrógeno. Es uno de los grupos de enzimas más termorresistentes; una inactivación parcial de la peroxidasa puede dar lugar a alteraciones oxidativas que pueden traducirse en pérdidas de color, modificaciones del sabor, y aparición de sabores extraños de los alimentos, existiendo muchas diferencias entre unas especies vegetales y otras. Existen pocos trabajos sobre el comportamiento 
térmico de las POD de fresa. Civello et al. (1995) purificaron y determinaron algunas de las propiedades de la POD de fresa, encontrando que la máxima actividad se produce a $\mathrm{pH} 6,0$ y una temperatura de $30^{\circ} \mathrm{C}$. Además observaron que un tratamiento a $60^{\circ} \mathrm{C}$ durante 5 minutos reduce la actividad al $20 \%$ de la inicial y con 20 minutos a la misma temperatura la actividad disminuye hasta niveles inferiores al 5\%. En un trabajo reciente, Begoña de Ancos et al. (2007) estudiaron la inactivación de la POD de fresa en un tratamiento con microondas y observaron que, en las mismas condiciones de aplicación (850 w durante 60 segundos) la actividad POD de la fresa se reduce sólo en un $8 \%$ mientras que en otros frutos como kiwi y papaya la reducción es del orden del $60 \%$. El mismo grupo de trabajo también investigó anteriormente la inactivación enzimática de un puré de fresa por tratamiento conjunto de altas presiones y temperatura, sugiriendo como conclusión un tratamiento a $230 \mathrm{MPa}$ y $43^{\circ} \mathrm{C}$ (Cano et al., 1997).

Las pectinmetilesterasas constituyen un grupo de enzimas pectolíticos que catalizan la desmetoxilación de las pectinas. Los iones divalentes del medio (fundamentalmente iones $\mathrm{Ca}^{2+}$ ) se unen a los grupos carboxilo liberados y hacen de puente entre cadenas de pectina, creándose macromoléculas de pectato cálcico insolubles. La precipitación de estas macromoléculas arrastra a otros componentes coloidales de zumos y purés, lo que da lugar a una clarificación del medio (Joslyn y Pilnik, 1961). En productos como purés de fresa y zumos de naranja, donde la turbidez es un factor de calidad del producto, la actividad PME da lugar a una pérdida de aceptación del producto por los consumidores. 
No se han encontrado referencias bibliográficas sobre la actividad PME en purés de fresa y su comportamiento frente a tratamientos térmicos. Una gran parte de los trabajos sobre actividad PME se han llevado a cabo en zumos de naranja y mandarina, frutos que por su composición y pH (alrededor de 3,5) cabe considerar próximos a la fresa. En los zumos cítricos, los tratamientos de pasteurización se ajustan para inactivar suficientemente este grupo de enzimas, más termorresistentes que los microorganismos contaminantes, dado el bajo $\mathrm{pH}$ del medio (Kimball, 1999). Carbonell et al. (2006) estudiaron la actividad PME, en diferentes zumos de frutos cítricos, encontrando diferencias entre la actividad PME y su termorresistencia entre los diferentes zumos y constatando que con tratamientos térmicos suaves (por ejemplo $74^{\circ} \mathrm{C}$ durante 10 segundos) se reduce su actividad de zumos de Clementina Nules hasta un 6,5\% de la inicial. Estos tratamientos térmicos suaves apenas modifican el sabor característico de los zumos frescos (Sentandreu et al., 2005).

Los tratamientos térmicos de pasteurización influyen en mayor o menor grado en las características físico-químicas y organolépticas del producto. Un aspecto fundamental a considerar es la reología del puré de fresa y su posible cambio de comportamiento reológico cuando se somete a tratamientos térmicos y/o almacenamiento. Existen muchas referencias sobre el comportamiento reológico de purés de frutas (Labuza y Simon, 1969; Moreira, 1976; Ngaseppam et al., 2000; Vidal y Gasparetto, 2000; Krokida et al., 2001;Curcio et al., 2001; Juszczak y Fortuna, 2003; Rosa et al., 2004), pero en ellas no se aborda el caso del puré de fresa. Dos trabajos (Juszczak y Fortuna, 2003; Rosa et al., 2004) 
estudian el comportamiento reológico de zumos clarificados de fresa, pero este producto tiene obviamente un comportamiento reológico muy diferente del de un puré integral.

Los diversos estudios han demostrado que la aceptación de un producto por parte del consumidor depende en buena medida de su apariencia y, por tanto, también de su color. Realmente, el color es la primera sensación que se percibe y la que determina el primer juicio sobre su calidad. Es también un factor importante dentro del conjunto de sensaciones que aporta el alimento y tiende, a veces, a modificar subjetivamente otras sensaciones como el sabor y el olor.

Algunas características del color de la fresa han sido estudiadas utilizando medidas objetivas del mismo (Abers y Wrolstad, 1979; Bakker et al., 1994; Bakker et al., 1992; Castro et al., 2002; Duhard et al., 1997; Garcia-Viguera et al., 1999) pero no se han encontrado referencias sobre cómo evolucionan los parámetros de color cuando los purés de fresa se someten a tratamientos térmicos suaves y se almacenan posteriormente a temperatura ambiente o en refrigeración.

El análisis sensorial ha demostrado ser un instrumento de suma eficacia para el control de calidad y aceptabilidad de un alimento. Se ha definido como una disciplina científica usada para medir, analizar e interpretar las reacciones percibidas por los sentidos de las personas hacia ciertas características de un alimento como son su sabor, olor, color y textura. El resultado de este complejo de sensaciones captadas e interpretadas es usado para medir la calidad de los alimentos. Dentro de las principales características sensoriales de los alimentos destacan: el olor, que es ocasionado por las sustancias volátiles liberadas del 
producto, las cuales son captadas por el olfato; el color, que es el resultado de la interacción de la luz con la materia, percibida por la vista; la textura, que es una de las características primarias que conforman la calidad sensorial, no tiene una definición sencilla porque es el resultado de la acción de estímulos de distinta naturaleza. Algunas características sensoriales de la fresa han sido estudiadas por diversos autores, pero no en puré sino en otros productos derivados como yogur (Gambaro et al., 2001), zumo (Golaszewski et al., 1998) y mermeladas (Spayd y Morris, 1981). No se han detectado referencias bibliográficas sobre la evaluación sensorial de purés de fresa tratados térmicamente.

Por otra parte, en cualquier producto destinado a consumo humano debe conocerse la flora microbiana presente y su comportamiento frente a los procesos térmicos. No se han encontrado referencias bibliográficas sobre la flora microbiana del puré de fresa y su comportamiento en procesos térmicos moderados, pero por similitud de $\mathrm{pH}$ con el zumo de naranja (Torres et al, 2008) no cabe esperar que aparezcan problemas microbiológicos en los productos tratados.

La gama de zumos pasteurizados refrigerados está aumentando continuamente, debido a la alta calidad y razonable estabilidad de estos zumos. No existen purés pasteurizados de fresa y además de su interés por las propiedades sensoriales, nutritivas y funcionales de este producto, su elaboración permitiría una valiosa salida para los destríos de la confección del fruto en fresco. El producto también tiene interés como producto semielaborado para la fabricación de yogurs, helados y productos de pastelería. El tema tiene interés científico, económico y social y forma parte del programa de investigación del Departamento 
de Tecnología de Alimentos y del Instituto Universitario de Ingeniería de Alimentos para el Desarrollo de la Universidad Politécnica de Valencia y está muy relacionado con las actividades del grupo de zumos del Instituto de Agroquímica y Tecnología de Alimentos, del Consejo Superior de Investigaciones Científicas.

Los objetivos del trabajo se ajustan perfectamente a los de la convocatoria del Plan Nacional de Investigación Científica, Desarrollo e Innovación Tecnológica 2004-2007. Dentro del Programa Nacional de Recursos y Tecnologías Agroalimentarias se centran en el objetivo general b) "Obtención y elaboración de productos agroalimentarios de calidad, seguros y saludables", Area de Ciencia y Tecnología de Alimentos, objetivos científico-técnicos 11 (Procesos de elaboración y conservación de alimentos), subobjetivos 11.1 (Modelización, diseño, optimización y validación de nuevos procesos) y 11.7 (Desarrollo de prototipos y equipos para la industrialización de productos agroalimentarios).

La tesis presente está enmarcada dentro del proyecto AGL-2005-05994 financiado por el Ministerio de Educación y Ciencia, por el Fondo Europeo de Desarrollo Regional y por el programa Agroalimed de la Generalitat Valenciana. Pretende establecer las características físicas, químicas y sensoriales del puré de fresa y su estabilidad respecto al tratamiento térmico y almacenamiento. Se han utilizado el bagaje de conocimientos previos adquiridos en la investigación de zumos de naranja y mandarina para aplicarlos en un producto similar, el puré de fresa, que hasta el momento ha sido objeto de escasos estudios científicos. 


\section{OBJETIVOS Y PLAN DE TRABAJO}





\section{OBJETIVOS Y PLAN DE TRABAJO.}

\section{II.1. OBJETIVO GENERAL.}

El objetivo de esta tesis ha sido el estudio del efecto de la intensidad del tratamiento térmico en diferentes propiedades relacionadas con la calidad y estabilidad nutritiva, funcional y sensorial del puré de fresa.

\section{II.2. OBJETIVOS ESPECÍFICOS.}

$>$ Caracterizar la materia prima.

$>$ Determinar la influencia del procesado térmico en la composición y en las propiedades físico-químicas, físicas y sensoriales de interés del puré de fresa, así como en su estabilidad durante el almacenamiento.

> Determinar las actividades enzimáticas (PPO, POD, PME) residuales en el puré de fresa en función de los distintos procesos térmicos aplicados.

$>$ Determinar el efecto del tratamiento térmico en las propiedades funcionales del puré de fresa.

> Seleccionar parámetros que puedan servir como indicadores de la perdida de calidad del puré de fresa durante su procesado y almacenamiento. 


\section{II.3. PLAN DE TRABAJO.}

Para conseguir los objetivos anteriores, se diseñó el plan de trabajo que se describe a continuación.

Obtención de la materia prima:

Se partió de lotes homogéneos de fresa fresca, la cual fue lavada y troceada antes de ser homogeneizada en forma de puré. Esto se realizó en una despulpadora o pasadora de tornillo sin fin y se recolectó en un tanque de acero inoxidable.

Tratamientos térmicos y almacenamiento:

La muestra obtenida fue sometida a un proceso de desaireación y se dividió en 4 lotes. Uno de ellos se caracterizó como producto fresco y cada uno de los otros tres se sometió a un tratamiento de pasteurización diferente: uno suave a $75^{\circ} \mathrm{C}$ durante 15 segundos, otro más severo a $90^{\circ} \mathrm{C}$ durante 20 segundos y otro a $90^{\circ} \mathrm{C}$ durante 2 minutos. El puré inmediatamente pasteurizado fue envasado en frascos de vidrio previamente esterilizados y ubicados dentro de una cámara de flujo laminar. El puré envasado se almacenó en cámaras a $3^{\circ} \mathrm{C}$ y los tratados más intensamente también a $22^{\circ} \mathrm{C}$. Se realizaron análisis tanto inmediatamente después de los tratamientos térmicos como a los 30 y 60 días de almacenamiento. Por su parte, el puré fresco fue analizado después del procesado. Una vez cumplidos los tiempos de almacenamiento, las muestras se congelaron a $-20{ }^{\circ} \mathrm{C}$ hasta proceder a realizar los análisis correspondientes. 
$>$ Caracterización del puré de fresa antes y después del tratamiento:

Se realizaron análisis de humedad, actividad del agua $\left(\mathrm{a}_{\mathrm{w}}\right), \mathrm{pH}$, contenido en azúcares mayoritarios, acidez total, vitamina C (ácido ascórbico y dehidroascórbico), antocianinas mayoritarias (cianidina y pelargonidina) y recuento de microorganismos viables totales y hongos y levaduras. Además se evaluó el color, el comportamiento reológico y la aceptación sensorial del aroma y sabor.

Se hicieron determinaciones de la actividad pectinmetilesterasa, peroxidasa y polifenoloxidasa, con el fin de establecer posibles relaciones entre la actividad enzimática residual y la pérdida de calidad del producto durante el almacenamiento.

Se evaluó la actividad antioxidante, uno de los principales papeles funcionales atribuidos a las frutas. 

III. MATERIALES Y MÉTODOS 



\section{MATERIALES Y MÉTODOS.}

\section{III.1 MATERIA PRIMA Y PROCESADO.}

Para este estudio se utilizó fresa (Fragaria $x$ ananassa) de la variedad Camarosa adquirida en un comercio de la ciudad de Valencia y procedente de Huelva. La fresa usada en los ensayos fue procesada en planta piloto 3 días después de haber sido cosechada. Las fresas tuvieron un calibre promedio $>20$ $\mathrm{mm}$, perteneciendo todas ellas a la categoría $1^{\text {a }}$. Se recibieron en la planta piloto del Instituto de Agroquímica y Tecnología de Alimentos (IATA) de Valencia donde se procesaron tal y como se describe a continuación.

La fruta llegó a la planta piloto en cajas de 2 kg (Figura III.1). Se lavó con agua corriente, se dejó escurrir y se introdujo en una pasadora de tornillo (tamiz con perforaciones de $0,7 \mathrm{~mm} \varnothing$ ) que, al tiempo que transforma el fruto en puré, retira pedúnculos y hojas (figura III.2).

El puré obtenido fue recogido y transvasado a un tanque de acero inoxidable. De aquí se separó un primer lote correspondiente al puré fresco sin desairear, que fue envasado en frascos de vidrio de $250 \mathrm{~mL}$ previamente esterilizados con vapor y al que se midió el color, antocianinas y vitamina C, según se describe más adelante. El resto del puré fue llevado a un equipo de concentración de película agitada, que operando a $25^{\circ} \mathrm{C}$ y una presión absoluta de $0,15 \mathrm{MPa}$ ), sirvió de desaireador. El producto obtenido se muestra en la figura III.3. 


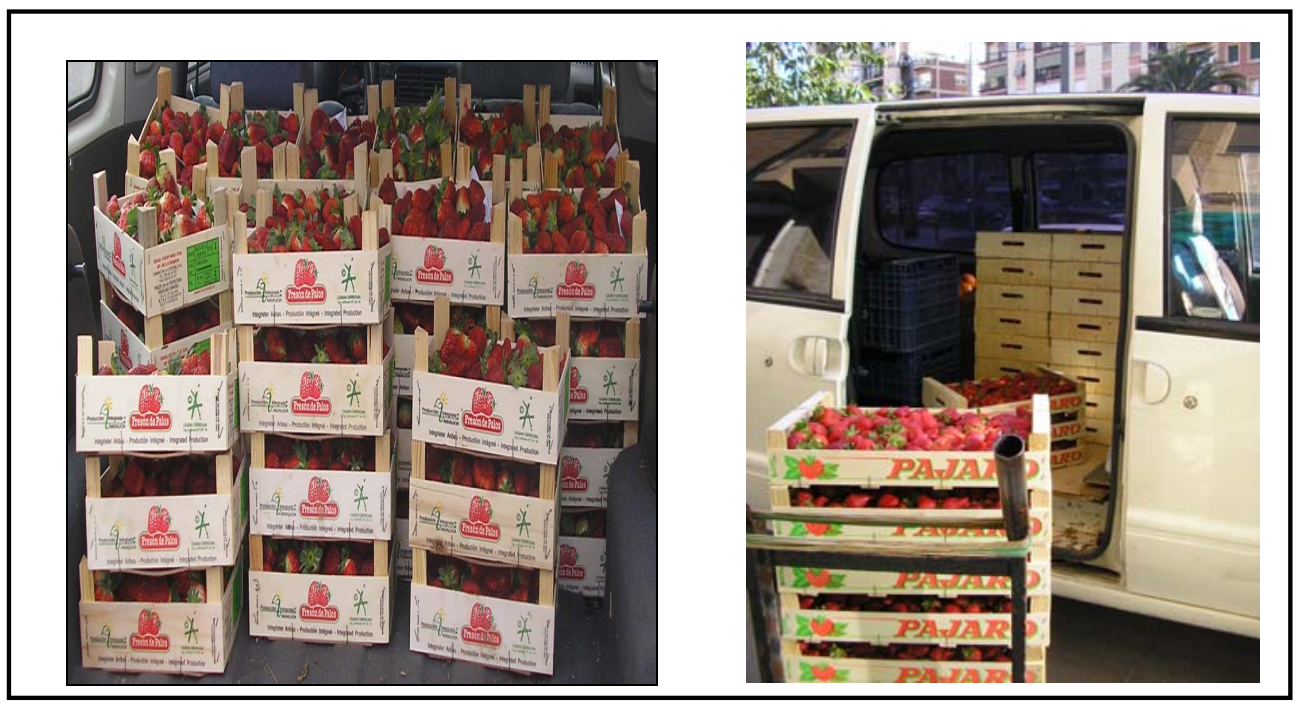

Figura III. 1. Llegada de la fresa a planta piloto.

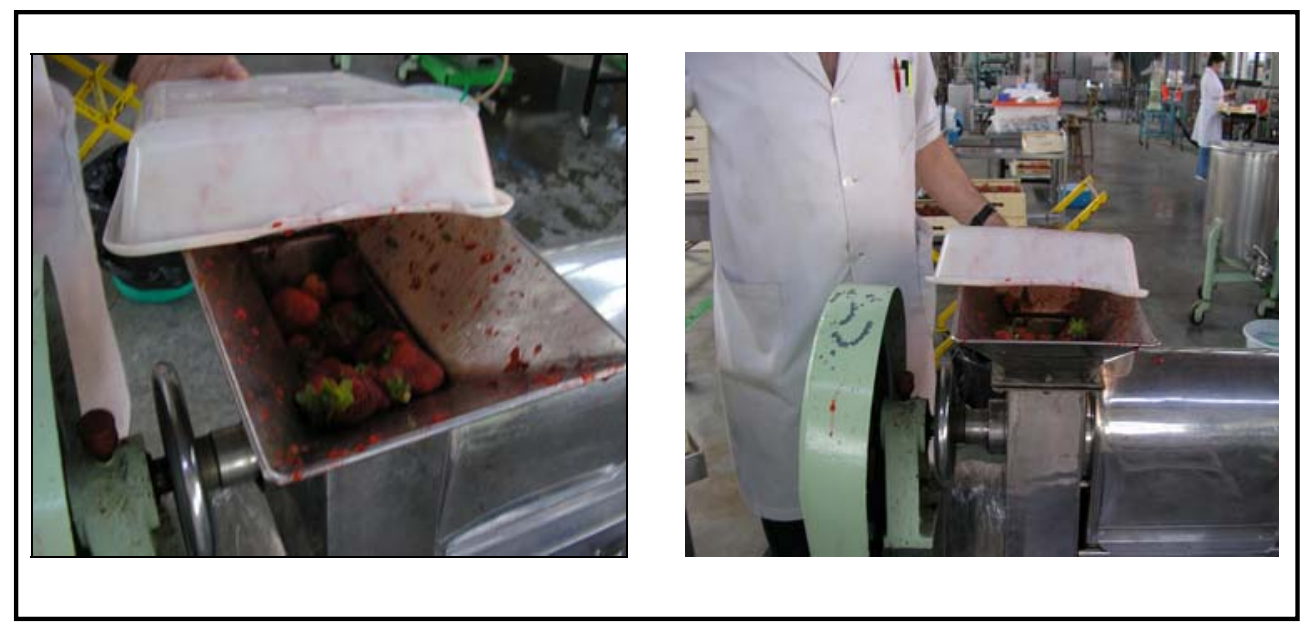

Figura III. 2. Pasadora de tornillo sinfín. 

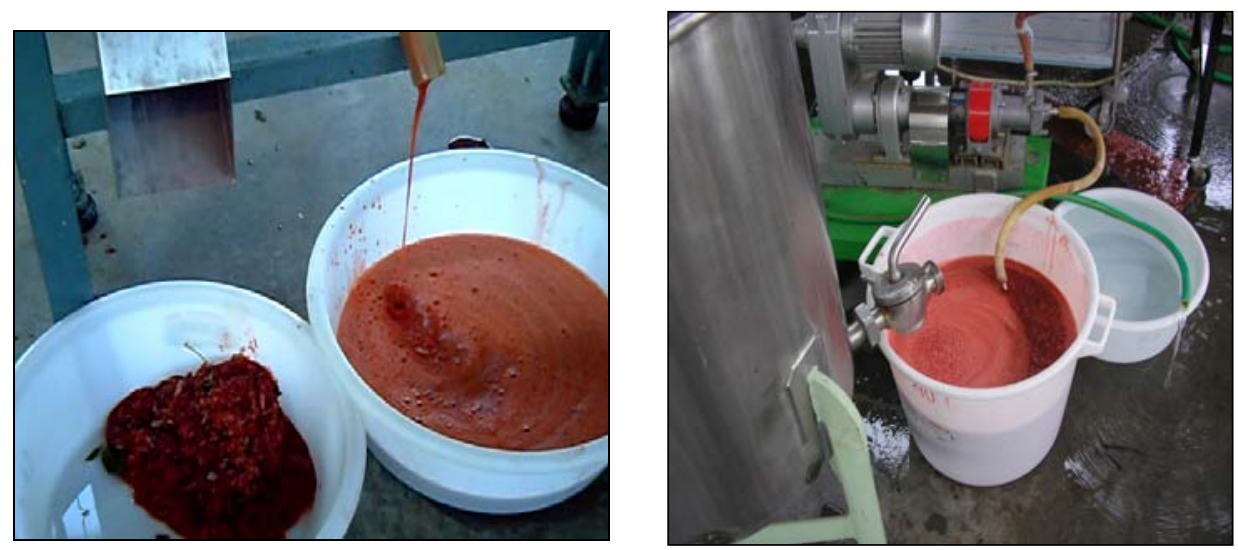

Figura III. 3. Fracción de desecho y fracción pulposa que será sometida al proceso de desaireado.

El puré desaireado se dividió en 4 lotes. El primero, correspondiente al puré fresco, fue envasado directamente en frascos de vidrio de $1 \mathrm{~L}$ y $250 \mathrm{~mL}$ previamente esterilizados. El segundo y tercer lote pasaron al tratamiento térmico, en un pasteurizador de placas (APV Ibérica S.A., modelo junior) (Figura III.4) alimentado por una bomba volumétrica helicoidal. Se ajustaron los caudales para cada tiempo de tratamiento, logrando así una diferenciación de tiempos de retención. El segundo lote se pasteurizó a $75^{\circ} \mathrm{C}$ durante 15 segundos y el tercer lote a $90^{\circ} \mathrm{C}$ durante 20 segundos.

El cuarto lote se envasó en caliente, a $90^{\circ} \mathrm{C}$, en tarros previamente precalentados para evitar su rotura por choque térmico. Tras el cierre, se les dio la vuelta a los tarros (para que el propio producto, ácido y caliente, esterilice también 
la tapa) y después de 2 minutos se enfriaron por inmersión en agua, primero en agua tibia (unos $45^{\circ} \mathrm{C}$ ) y luego con agua corriente.

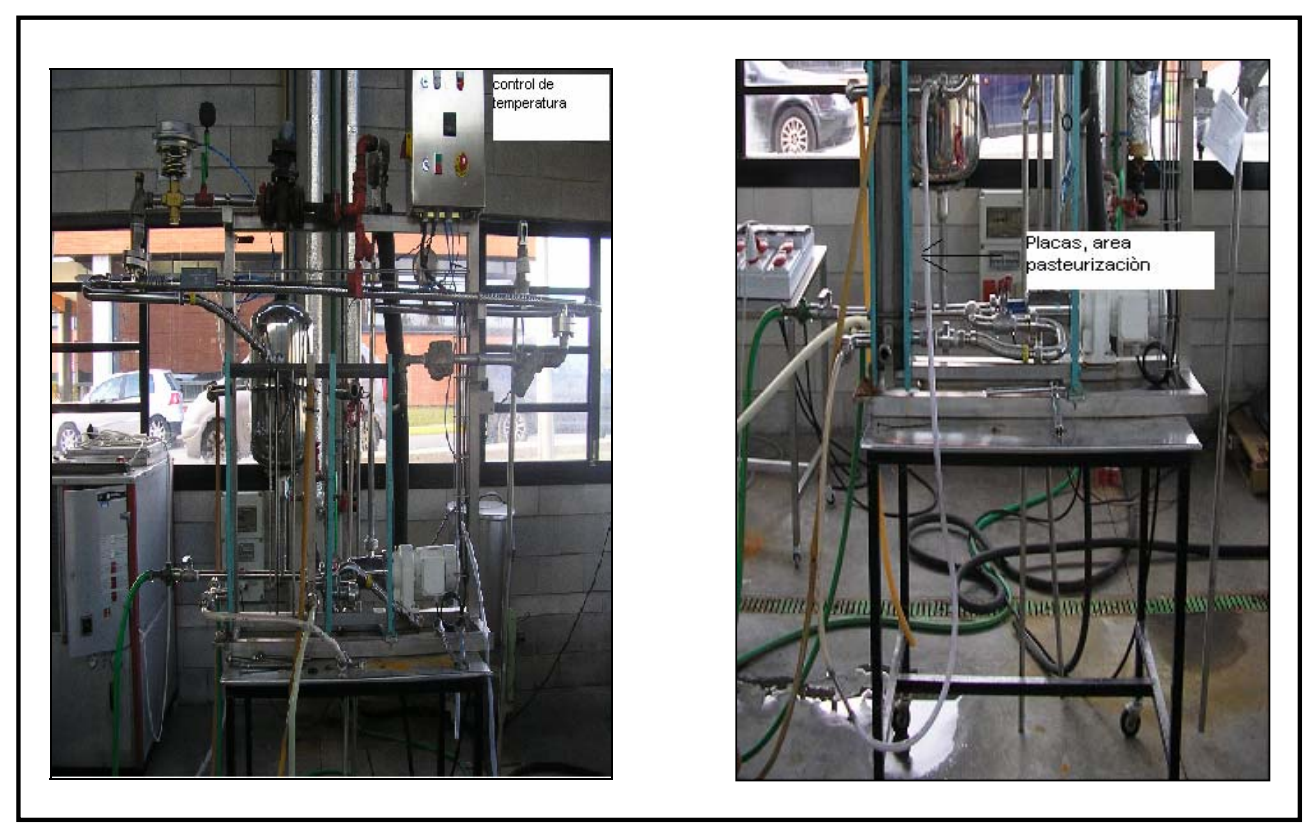

Figura III. 4. Pasteurizador de placas APV Ibérica júnior.

El envasado de cada una de las muestras tratadas térmicamente se llevó a cabo en una cámara de flujo laminar y en frascos de vidrio de 250 y $900 \mathrm{~mL}$ previamente esterilizados con vapor (Figura III.5). 

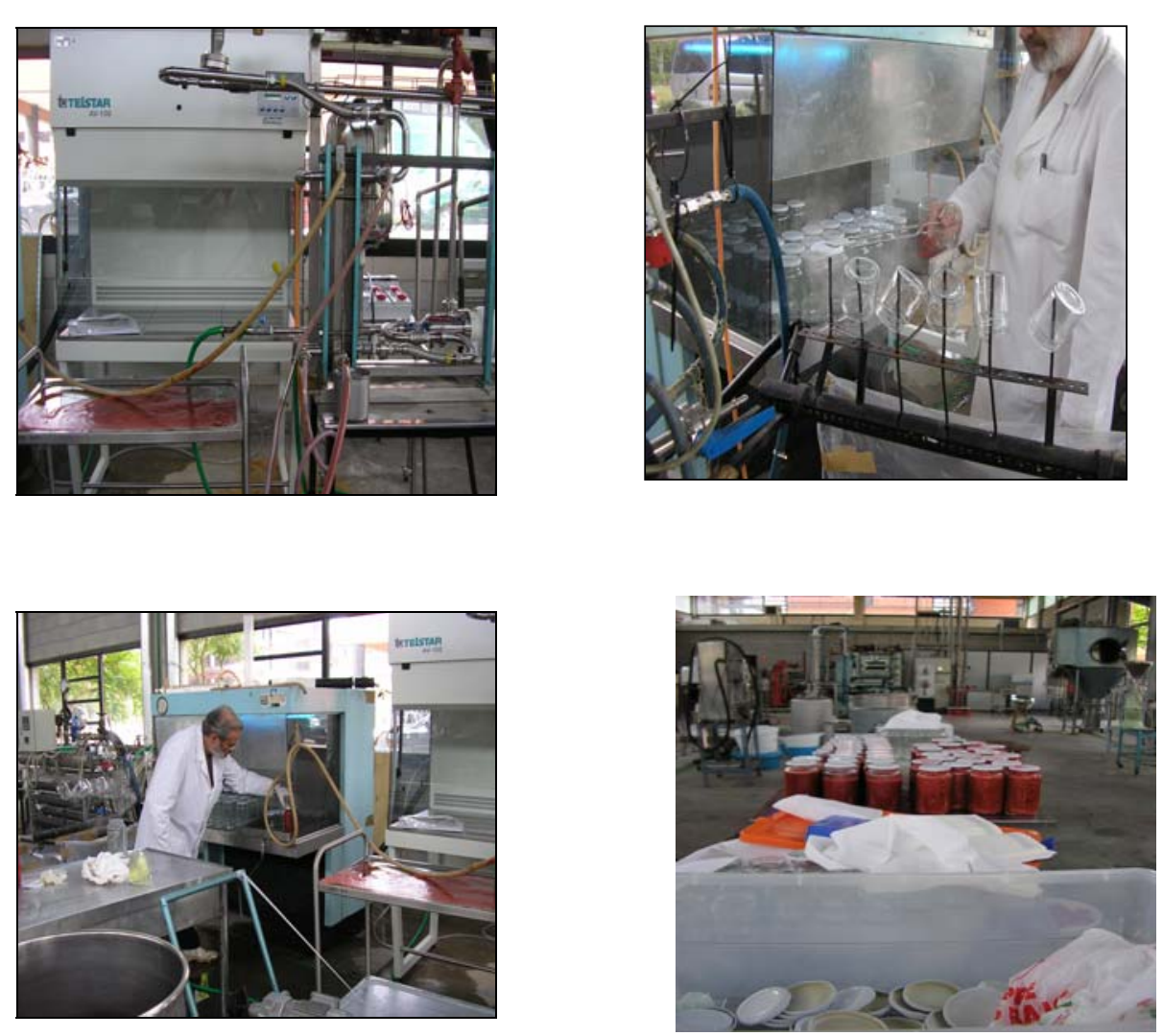

Figura III. 5. Envasado en cámara de flujo laminar y esterilización de los frascos

Finalmente los tarros de puré se almacenaron en una cámara de refrigeración a $3^{\circ} \mathrm{C}$ y, en el caso de las muestras del tercer y cuarto lote, también a $21-22^{\circ} \mathrm{C}$, durante un plazo máximo de dos meses. De aquí se tomaron las muestras para los análisis que se describen en el siguiente apartado. 


\section{III.2 ANALISIS REALIZADOS.}

\section{III.2.1. Azúcares.}

El análisis de azucares fue realizado usando un cromatógrafo iónico MIC9ADV (Metrohm Ltd, Swizerland) y detector de pulsos amperométricos. Se utilizó una columna Metrosep Carb 1-250 4.6x250 mm. Como fase móvil se usó $\mathrm{NaOH}$ $100 \mathrm{mM}$ con un flujo de $1 \mathrm{~mL} / \mathrm{min}$. El puré de fresa fue centrifugado a $5000 \mathrm{rpm}$ durante $15 \mathrm{~min}$, se tomaron $100 \mu \mathrm{L}$ del sobrenadante y se diluyeron en agua Meq hasta $25 \mathrm{~mL}$. De esta dilución se inyectó un volumen de $20 \mu \mathrm{l}$ en el cromatógrafo. Todas las muestras fueron analizadas por duplicado.

\section{III.2.2 Actividad del agua.}

La actividad del agua se determinó con un higrómetro de punto de rocío Aqualab modelo CX-3 con una sensibilidad 0,003 , calibrado previamente con una solución salina saturada $\left(\mathrm{K}_{2} \mathrm{Cr}_{2} \mathrm{O}_{7}, \mathrm{a}_{\mathrm{w}}=0,981\right)$. Se colocaron aproximadamente $5 \mathrm{~g}$ de muestra previamente homogeneizada en los recipientes plásticos dispuestos para dicho equipo. Las medidas se realizaron por triplicado. 


\section{III.2.3. Humedad.}

La humedad de las muestras se determinó, por triplicado, de acuerdo a la metodología estándar AOAC 20.013 (AOAC, 1980), pesando aproximadamente 5 $\mathrm{g}$ de muestra, mezclada con una cantidad proporcional de arena seca. El proceso de secado se llevó a cabo por medio de una estufa a vacío $(10 \mathrm{mmHg})$ modelo Vacioterm a $60^{\circ} \mathrm{C}$ hasta obtener peso constante. La diferencia de pesos antes y después del secado en la estufa en relación al peso inicial de muestra permite determinar la humedad, expresada como g agua/g muestra.

\section{III.2.4. Determinación del pH.}

Se realizó con un pHmetro Crison GLP 22, previamente calibrado con tampones a pH 4 y 7 . Las medidas se realizaron por triplicado.

\section{III.2.5. Determinación de los ${ }^{\circ}$ Brix.}

Los sólidos solubles de la fracción liquida de la fresa se determinaron, por triplicado, previa homogenización de la muestra en un Politrón a 8000 rpm. Se midieron los ${ }^{\circ}$ Brix usando un refractómetro (Atago Pocket, pal-1, Atago Co Ltd., Tokyo, Japan) a $20^{\circ} \mathrm{C}($ AOAC 932.12, AOAC, 1980). 


\section{III.2.6. Acidez.}

La acidez total fue medida, por triplicado, por valoración con $\mathrm{NaOH} 0,1 \mathrm{~N}$ hasta $\mathrm{pH} 8,1$ (Crison micropH 2001, España), partiendo de $10 \mathrm{~g}$ de muestra triturada (AOAC 942.15, AOAC, 1980). Los resultados se expresaron en porcentaje de ácido cítrico, por ser el mayoritario de la fresa.

\section{III.2.7. Índice de madurez.}

Este índice se calculó a partir de la relación entre los Brix y la acidez de la muestra.

\section{III.2.8. Color.}

El equipo para la medida del color fue un colorímetro Hunter Labscan II, utilizando como referencia el iluminante D65, observador $10^{\circ}$. Las medidas fueron tomadas por triplicado sobre un diafragma de apertura de $13 \mathrm{~mm}$. Aproximadamente $80 \mathrm{~mL}$ de puré se colocaron en un recipiente de vidrio especial (cristalizador) de $100 \mathrm{~mL}$ de capacidad $(7 \mathrm{~cm}$ de profundidad $\times 6,5 \mathrm{~cm}$ de diámetro). Antes de la medida de cada lote de muestras, el equipo se calibró con un blanco y negro standard. A partir de las coordenadas $L^{*} a^{*} b^{*}$ se calculó el tono 
$\left(h^{\star}\right)$, croma $\left(C^{*}\right)$ y diferencia de color $\left(\Delta E^{*}\right)$ entre muestras, según las ecuaciones III.1, III.2 y III.3, respectivamente.

$$
\begin{aligned}
& \mathrm{h}^{*}=\operatorname{arctg}\left(\mathrm{b}^{*} / \mathrm{a}^{*}\right) \\
& \mathrm{C}^{*}=\left(\left(\mathrm{a}^{*}\right)^{2}+\left(\mathrm{b}^{*}\right)^{2}\right)^{1 / 2} \\
& \Delta \mathrm{E}^{*}=\left(\left(\Delta \mathrm{L}^{*}\right)^{2}+\left(\Delta \mathrm{a}^{*}\right)^{2}+\left(\Delta \mathrm{b}^{*}\right)^{2}\right)^{1 / 2}
\end{aligned}
$$

\section{III.2.9. Reología.}

Se estudió el comportamiento reológico de los purés de fresa a través de las curvas de flujo obtenidas con un reómetro rotacional (HAAKE RheoStress 1, Thermo Electron Corporation), rotor Z34 DIN 53019. Se realizaron, por triplicado, barridos ascendentes y descendentes de gradiente de velocidad de 0 a $300 \mathrm{~s}^{-1}$ en 180 s. A las curvas se ajustó la ley de Potencia o modelo de Ostwald-de Waele (Ecuación III.4). De esta forma se obtuvo el índice de consistencia K (Pa s$\left.{ }^{n}\right)$ y el índice de comportamiento al flujo $\mathrm{n}$ (adimensional). También se caracterizó el área de histéresis relativa (Ecuación III.5).

$$
\sigma=K \dot{\gamma}^{n}
$$




$$
\Delta H_{r}(\%)=\frac{A_{a}-A_{d}}{A_{a}} \cdot 100
$$

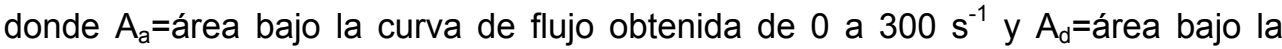

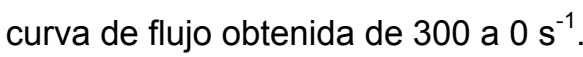

\section{III.2.10. Analisis sensorial.}

Las pruebas se realizaron mediante un test de ordenación simple de muestras. Cada panelista recibió tres o más muestras codificadas y se le pidió ordenarlas de acuerdo con la intensidad de una característica específica, en este caso la intensidad de sabor a fresco y ausencia de sabores extraños.

El mismo día de la obtención de los purés se hizo un test de ordenación de las 4 muestras obtenidas (fresca, pasteurizada a $75^{\circ} \mathrm{C}-5 \mathrm{~s}$, pasteurizada a $90^{\circ} \mathrm{C}$ 20s y envasada en caliente). Un segundo test se llevó a cabo para evaluar el sabor a fresco de las muestras pasteurizadas y almacenadas hasta 60 días en refrigeración. Por último, se realizó un tercer test de ordenación de muestras para evaluar el efecto de la temperatura $\left(3^{\circ} \mathrm{C}\right.$ ó $\left.22^{\circ} \mathrm{C}\right)$ y tiempo de almacenamiento en el sabor del puré de fresa envasado en caliente. En el ensayo de cata participaron 27-48 catadores. Los datos de la cata fueron recogidos y procesados por el sistema Compusense Five 3.6 y evaluados por test no paramétricos para detectar diferencias significativas. 


\section{III.2.11. Actividades enzimaticas.}

III.2.11.1. Actividad polifenoloxidasa.

La actividad polifenoloxidasa (PPO) se midió usando el procedimiento descrito por Pizzocaro et al. (1993) con algunas modificaciones. El extracto del enzima se obtuvo por mezcla de $10 \mathrm{~g}$ de pulpa de fresa con $10 \mathrm{~mL}$ del reactivo buffer Mcllvaine: tampón fosfato sódico 0,2M a pH 6,6, con 2\% (peso/volumen) de polivinilpolipirrolidona y $1 \%$ (volumen/volumen) de Triton $\mathrm{X}-100$, todo ello mantenido a baja temperatura $\left(4^{\circ} \mathrm{C}\right)$. La mezcla se agitó durante 3 minutos en baño a $4^{\circ} \mathrm{C}$, después se centrifugó a $5000 \mathrm{rpm}$ durante 30 minutos (también a $4^{\circ} \mathrm{C}$ ) y finalmente el sobrenadante se recogió y se filtró a través de papel Whatman $\mathrm{N}^{\circ}$ 1. A continuación se tomaron $0,3 \mathrm{~mL}$ del extracto enzimático y se mezclaron con $0,5 \mathrm{~mL}$ de catecol $(0,175 \mathrm{M})$ y $1 \mathrm{~mL}$ de tampón fosfato sódico $0,05 \mathrm{M}(\mathrm{pH} 6,6)$, agitando bien el contenido. El blanco se preparó de la misma forma pero utilizando 0,3 mL de agua destilada en lugar del extracto enzimático. La muestra y el blanco se colocan en sus respectivas cubetas y éstas se introdujeron en un espectrofotómetro Ultrospec 3100 pro de doble haz. Se midió al mismo tiempo el blanco y la muestra. Se registró la absorbancia a $420 \mathrm{~nm}$ tomando lecturas cada 15 segundos durante un total de 10 minutos. La actividad enzimática se determinó a partir de la pendiente en el origen de la curva de ajuste y los resultados se expresaron como \% del valor del puré fresco. Cada determinación fue realizada por triplicado. 
III.2.11.2. Actividad peroxidasa.

Se preparó un extracto del enzima por mezcla de $10 \mathrm{~g}$ de pulpa de fresa con $20 \mathrm{~mL}$ del reactivo buffer Mcllvaine: tampón fosfato sódico $0,2 \mathrm{M}$ a pH 6,6, con $2 \%$ (peso/volumen) de polivinilpolipirrolidona y $1 \%$ (volumen/volumen) de Triton X100 , todo ello mantenido a baja temperatura $\left(4^{\circ} \mathrm{C}\right)$. La mezcla se agitó durante 3 minutos en baño a $4^{\circ} \mathrm{C}$, después se centrifugó a $5000 \mathrm{rpm}$ durante 30 minutos (también a $4^{\circ} \mathrm{C}$ ) y finalmente el sobrenadante se recogió y se filtró a través de papel Whatman $\mathrm{N}^{\circ}$ 1. A continuación se tomaron $0,1 \mathrm{~mL}$ del extracto enzimático y se mezclaron con $2,7 \mathrm{~mL}$ de tampón fosfato sódico $0,05 \mathrm{M}(\mathrm{pH} \mathrm{6,6)}$ y $0,2 \mathrm{~mL}$ de una disolución de p-fenilendiamina al $1 \%$ (peso/volumen) y $0,1 \mathrm{~mL}$ de agua oxigenada al $1.5 \%$. Se usó como blanco un extracto paralelo obtenido con puré de fresa esterilizado en autoclave a $121^{\circ} \mathrm{C}$ durante 15 minutos. La muestra y el blanco se agitaron y se colocaron en las respectivas cubetas del espectrofotómetro. Se tomaron lecturas de la absorbancia a $485 \mathrm{~nm}$ cada 30 segundos y durante un total de 30 minutos. La actividad enzimática se determinó a partir de la pendiente en el origen de la curva de ajuste y los resultados se expresaron como \% de la actividad residual con respecto al puré fresco. Cada determinación fue realizada por triplicado. 
III.2.11.3. Actividad pectinmetilesterasa.

La actividad pectinmetilesterasa (PME) fue determinada usando el método propuesto por Carbonell et al. (2006), una modificación del método tradicional desarrollado por Rouse et al. (1962). Esta modificación consiste en medir directamente el descenso del $\mathrm{pH}$ que tiene lugar cuando el enzima presente en el puré hidroliza una disolución de pectina y genera grupos carboxílicos libres. Una muestra de $5 \mathrm{~mL}$ de puré y $5 \mathrm{~mL}$ de agua se llevó a pH 7,8 con $\mathrm{NaOH} 0,1 \mathrm{~N}$ y se mezcló con $20 \mathrm{~mL}$ de una disolución de pectina comercial al 0,5\% (Grinsted pectin MRS 351, Danisco, Dinamarca). Se registró el descenso del pH con el tiempo y se obtuvo la pendiente del tramo lineal inicial de la curva. La actividad PME fue medida por triplicado en cada muestra analizada.

\section{III.2.12. Antocianinas, vitamina C y actividad antirradical.}

III.2.12.1. Antocianidinas.

Se utilizó el método descrito por Lopes da Silva et al., (2007) con ligeras modificaciones. Se tomaron $5 \mathrm{~g}$ de puré de fresa y se homogenizaron en un Politrón (DI 25 basic Yellow Line); se lavó bien el vástago del Politrón empleando 25-30 mL de $\mathrm{MeOH}$ acidificado con $\mathrm{HCl}$ 4M. La muestra homogeneizada se sonicó durante 10 min y se centrifugó a $5000 \mathrm{rpm}$ durante 20 minutos, manteniendo la 
temperatura a $4^{\circ} \mathrm{C}$. Se procedió inmediatamente a filtrar a vacío empleando lana de vidrio, debido a que en papel de filtro utilizado en los primeros ensayos quedaban retenidas parte de las antocianinas de la muestra. Una vez filtrada la muestra, la lana de vidrio se lavó bien usando $5 \mathrm{~mL}$ de la disolución metanólica ácida de forma que no quedaran restos de color. Sobre el residuo sólido se volvieron a añadir $5 \mathrm{~mL}$ de la disolución metanólica ácida y se repitió todo el proceso de agitación, sonicación, centrifugación y filtración. El proceso completo de extracción se repitió de tres a cuatro veces hasta que el residuo quedó incoloro.

Se juntaron todos los extractos y las aguas de lavado (disolución con las antocianinas de la muestra) y se calentó en un baño de agua a $90^{\circ} \mathrm{C}$ durante 45 minutos, con el fin de eliminar el resto azucarado de las antocianinas. Después de enfriar, se eliminó el metanol, empleando un rotavapor (Rotavapor RII, Buchi) provisto de un ultratermostato de circulación (Frigiterm -10, Selecta), trabajando a $38-40^{\circ} \mathrm{C}$. Cuando se consiguió eliminar totalmente el metanol la muestra se redisolvió en 25-30 mL de agua ácida a pH 2,0, se pasó a un tubo y se centrifugó durante 10 minutos a $5000 \mathrm{rpm}$. El sobrenadante se separó del residuo sólido. Con el fin de separar las antocianinas del resto de componentes se utilizó un cartucho Sep-Pak (C18, Waters), llevando a cabo en todos los casos el mismo procedimiento de activación, consistente en pasar en primer lugar $5 \mathrm{~mL}$ de $\mathrm{MeOH}$ ácido $(\mathrm{pH} 2-2,5$ con $\mathrm{HCl}$ ), en segundo lugar $5 \mathrm{~mL}$ de agua y finalmente $5 \mathrm{~mL}$ de agua ácida $(\mathrm{pH} \mathrm{2,0} \mathrm{con} \mathrm{HCl})$. Una vez activado el cartucho, se pasó el volumen total de la disolución. Cuando fue necesario se empleó presión para pasar el volumen total de muestra. Para eluir las antocianinas retenidas en el cartucho, se pasaron $5 \mathrm{~mL}$ de $\mathrm{MeOH}$ acido $(\mathrm{pH} 2-2,5$ con $\mathrm{HCl})$ y se recogieron en un matraz 
aforado de $5 \mathrm{~mL}$. La disolución se filtró empleando un filtro de membrana de nylon de $0,45 \mu \mathrm{m}$ de tamaño de poro (PK/100, Teknokroma) y se pasó a un vial ámbar de $2 \mathrm{~mL}$ para ser determinadas por HPLC.

Se comprobaron los porcentajes de recuperación de las antocianinas al pasarlas por el cartucho Sep-pack C-18. Para ello, después de eluir del cartucho las antocianinas de la muestra, se volvieron a pasar otros $5 \mathrm{~mL}$ de metanol ácido y la disolución recogida se volvió a inyectar en el cromatógrafo, observando que no se detectó ningún pico cromatográfico correspondiente a las antocianinas. Se comprobó pues que $5 \mathrm{~mL}$ de metanol ácido son suficientes para eluir completamente todas las antocianinas del cartucho.

Para el análisis por HPLC se utilizó un cromatógrafo (1100 Series, Agilent Technologies), equipado con desgasificador a vacío, bomba binaria, inyector automático con carro de muestras termostatizado y detector de hilera de fotodiodos. El control del instrumento y el análisis de los datos se llevó a cabo en un ordenador personal, empleando el software HP Chemstation. Como fase estacionaria se usó una columna de fase reversa C-18, de dimensiones 250 × 4,6 mm y $5 \mu \mathrm{m}$ de diámetro de particula (Luna II, Phenomenex, Torrance, USA). Para la elución se utilizó el siguiente gradiente: $10 \%$ B a t=0 min, 10\% B a $t=10 \mathrm{~min}$, $70 \%$ B a $t=35$ min y $100 \%$ B a $t=36$ min, siendo la fase B acetonitrilo (ACN) y la fase $\mathrm{A} 0.01 \mathrm{M} \mathrm{NH}_{4} \mathrm{Cl}$ en agua $\mathrm{pH} 2,5$ con acido acético. El flujo utilizado fue $1 \mathrm{~mL} / \mathrm{min}$, el volumen de inyección $5 \mu \mathrm{l}$ y la detección se llevó a cabo empleando una longitud de onda de $520 \mathrm{~nm}$.

Para la cuantificación del contenido total de pelargonidina y cianidina se construyeron curvas de calibrado, después de pasar los patrones por un cartucho 
Sep-Pak (activado por el procedimiento explicado anteriormente). Se usaron concentraciones desde 0 hasta 500 ppm de pelargonidina $\left(n=6\right.$ y $\left.R^{2}=0,99\right)$ y desde 0 hasta 50 ppm de cianidina $\left(n=6\right.$ y $\left.R^{2}=0,99\right)$.

III.2.12.2. Ácido ascórbico y vitamina C.

Para la extracción del ácido ascórbico contenido en la muestra de fresa se utilizó la metodología publicada por Gil-Izquierdo et al. (2002) y Sanchez-Mata et al. (2000) con algunas modificaciones. Se empleó como disolución extractora agua ácida ( $\mathrm{pH} 3,5$ con $\mathrm{H}_{3} \mathrm{PO}_{4}$ al 85\%). Se utilizaron $5 \mathrm{~g}$ de muestra (puré de fresa) y se adicionó $10 \mathrm{~mL}$ de la disolución extractora. Se homogenizó y centrifugó a 5000 rpm durante 20 minutos. Posteriormente, se filtró empleando papel de filtro Whatman $\mathrm{n}^{\circ} 1$, se lavó el residuo sólido restante con $5 \mathrm{~mL}$ de agua ácida y se recogieron las aguas de lavado. Se juntó el líquido filtrado con las aguas de lavado y se llevaron hasta un volumen total de $20 \mathrm{~mL}$ empleando un matraz aforado. Esta disolución obtenida se pasó a través de un cartucho Sep Pack, con el fin de retener en el cartucho posibles interferencias hidrofóbicas (la activación fue la misma que se describió en el anterior apartado). Una parte de la disolución obtenida se filtró empleando un filtro de nylon de 0,45 $\mu \mathrm{m}$ y se pasó a un vial para su inyección por HPLC. También se tomó una alícuota de $2,5 \mathrm{~mL}$ de esta disolución, se le añadieron 0,5 mL de ditiotreitol (DTT, $20 \mathrm{~g} / \mathrm{L}$ en agua) y se dejó durante 2 horas en oscuridad, para asegurar la conversión de todo el ácido dehidroascórbico en ácido ascórbico. La medida del ácido ascórbico obtenido después de completar la reacción nos dio el valor del contenido en vitamina $\mathrm{C}$ de 
la muestra, que corresponde a la suma de ácido ascórbico y ácido dehidroascórbico.

Para la determinación cromatográfica se utilizó la misma columna que en la determinación de antocianinas. En este caso se empleó eluyente isocrático utilizando como fase móvil una mezcla $\mathrm{MeOH}: \mathrm{H}_{2} \mathrm{O}$ 5:95 ajustada a $\mathrm{pH}=3,5$ con $\mathrm{H}_{3} \mathrm{PO}_{4}$. El flujo de la fase móvil fue de $1 \mathrm{~mL} / \mathrm{min}$; el volumen de inyección $10 \mu \mathrm{L}$ y se midió la señal a una longitud de onda de $245 \mathrm{~nm}(\Delta \lambda=10 \mathrm{~nm})$.

Para la cuantificación del contenido en ácido ascórbico se realizó previamente un calibrado. Para ello se empleó una disolución de 1000 ppm de ácido ascórbico como disolución stock. Con esta disolución se prepararon los patrones para el calibrado (entre 0 y 100 ppm), los cuales se pincharon en el cromatógrafo antes y después de pasarlos por el cartucho Sep-Pak. En ambos casos la linealidad fue adecuada $\left(n=6, R^{2}=0,999\right)$ y se obtuvo la misma pendiente.

\section{III.2.12.3. Actividad antirradical.}

En el zumo de fresa encontramos compuestos con actividad antirradical como son el ácido ascórbico y los polifenoles (entre ellos, las antocianinas). La actividad antirradical del puré de fresa se determinó mediante el ensayo de 2,2 difenil-1-picrilhidracil (DPPH), es decir, se midió la capacidad para reducir el radical libre estable $\mathrm{DPPH}^{\circ}$ (que absorbe intensamente a $515 \mathrm{~nm}$ ) a la correspondiente hidracina (que no presenta prácticamente absorción a esta longitud de onda). La variable a medir fue la reducción de la absorbancia del DPPH con el tiempo (Sentandreu, 2006). 
Para la preparación de la muestra se tomaron $5 \mathrm{~g}$ del puré de fresa, se diluyeron con $10 \mathrm{~mL}$ de agua, se homogeneizó y se centrifugó a 5000 rpm durante 15 minutos, se filtró sobre lana de vidrio y la disolución obtenida se volvió a diluir con otros $10 \mathrm{~mL}$ de agua. Se centrifugó de nuevo durante 5 minutos para depositar las partículas sólidas y del sobrenadante se tomaron diferentes volúmenes entre 20 y $50 \mu \mathrm{l}$. Para las medidas en el espectrofotómetro se utilizó una cubeta de cuarzo de $3 \mathrm{~mL}$ de capacidad y $1 \mathrm{~cm}$ de recorrido óptico. A la cubeta se añadieron $1,9 \mathrm{~mL}$ de una disolución de $\mathrm{DPPH} 100 \mu \mathrm{m}$ en $\mathrm{MeOH}$ y el volumen correspondiente de muestra. El volumen se completó hasta $2 \mathrm{~mL}$ con $\mathrm{MeOH}$. La cubeta se agitó y se colocó en el espectrofotómetro para la medida de la absorbancia, teniendo en cuenta el tiempo en que se añadió la muestra y comenzó la reacción y el tiempo en que comenzó la medida. En todos los casos se añadió una cubeta con $\mathrm{MeOH}$, que se tomó como blanco.

Previo a la realización de los ensayos de actividad antirradical, se realizó un calibrado para determinar el coeficiente de extinción molar $(\varepsilon)$ del DPPH. Teniendo en cuenta la ecuación III.6, a partir del ajuste lineal de los datos experimentales absorbancia frente a concentración de DPPH, se obtuvo la pendiente correspondiente al coeficiente, que resultó ser $\varepsilon=1,03 \cdot 10^{4} \mathrm{~L} \cdot \mathrm{mol}^{-1} \cdot \mathrm{cm}^{-1}$.

$$
A=\varepsilon \cdot l \cdot C
$$


III.2.13. Microbiología.

Se realizó una determinación de la flora natural procedente del puré de fresa por siembra del producto en medios de cultivo. Se realizaron análisis para recuento de aerobios mesófilos y de mohos y levaduras. De acuerdo a las recomendaciones de ICMSF (1988) se utilizaron placas petri con agar para recuento en placa (Plate Count Agar - PCA) para aerobios mesófilos y agarpatata-dextrosa (Potato Dextrosa Agar - PDA) para mohos y levaduras.

Cada uno de los medios de cultivo se preparó de acuerdo a lo especificado por el fabricante (Scharlau Chemie S.A., Barcelona, España) y se esterilizó en autoclave a $121^{\circ} \mathrm{C}$ durante 15 minutos. Posteriormente se dejaron enfriar hasta $40^{\circ} \mathrm{C}$ aproximadamente, antes de repartirlo en los tubos de siembra. De la misma manera se preparó una solución de agua peptonada (Scharlau Chemie S.A., Barcelona, España) en la proporciones establecidas ( $5 \mathrm{~g} / 200 \mathrm{~mL})$.

Se procedió a preparar las diluciones con su respectiva repetición desde $10^{-1}$ hasta $10^{-7}$ en tubos Eppendorf, utilizando una cámara de flujo laminar. Finalmente se hizo la siembra en profundidad en placas petri, que se llevaron a una estufa de incubación a $37^{\circ} \mathrm{C}$ durante 48 horas para bacterias y levaduras y $32^{\circ} \mathrm{C}$ durante 120 horas para mohos.

Para prever el comportamiento de muestras de puré de fresa con una mayor contaminación microbiana se inoculó al puré un microorganismo modelo (Lactobacillus plantarum) muy utilizado en este tipo de estudios y se hicieron recuentos microbianos tras la aplicación de los correspondientes tratamientos 
térmicos. En el caso de purés con alto contenido en pulpa (caso de la fresa), donde es difícil el manejo del producto en tubos capilares, lo habitual es centrifugar la muestra y utilizar el sobrenadante como sustrato a inocular. En este caso concreto, el puré de fresa se centrifugó a $400 \mathrm{~g}$ durante 10 minutos y se tomó el sobrenadante clarificado para su inoculación con L. plantarum. Se Ilenaron viales con $9 \mathrm{~mL}$ de zumo clarificado y se esterilizaron a $100^{\circ} \mathrm{C}$ durante 10 minutos.

Se utilizaron cepas liofilizadas de L. plantarum proporcionadas por la Colección Española de Cultivos Tipo (CECT). El vial con el microorganismo liofilizado se disolvió en $15 \mathrm{~mL}$ de medio MRS previamente esterilizado y se incubó a $37^{\circ} \mathrm{C}$, manteniéndose esta temperatura durante 30 minutos. A continuación el contenido se vertió sobre $500 \mathrm{~mL}$ del caldo de cultivo MRS (también previamente esterilizado) y se incubó a $37^{\circ} \mathrm{C}$ durante 20 horas para que el microorganismo alcanzase la fase estacionaria de crecimiento. $500 \mathrm{~mL}$ del cultivo se centrifugaron $\left(3220 \mathrm{~g}, 5\right.$ minutos, $\left.4^{\circ} \mathrm{C}\right)$ y el precipitado se disolvió en 100 y $50 \mathrm{~mL}$, respectivamente, de caldo de cultivo MRS. El contenido fue transferido a viales de $2 \mathrm{~mL}$ con $1 \mathrm{~mL}$ de suspensión y $1 \mathrm{~mL}$ de glicerol diluido al $20 \%$ con medio MRS que se almacenadron, a $-80^{\circ} \mathrm{C} 9 \mathrm{~mL}$ de la muestra a analizar de zumo clarificado de fresa fue inoculada con $1 \mathrm{~mL}$ de esta solución del microorganismo, obteniéndose una concentración final de $9 \times 10^{8}$ ufc/mL.

Los viales inoculados fueron tratados térmicamente en un baño termostatado de silicona liquida a las diferentes temperaturas de estudio $(50,55$, $60,65,70$ y $\left.75^{\circ} \mathrm{C}\right)$ y los tiempos establecidos de $10,20,30,40,60$ y $120 \mathrm{~s}$. Los capilares así tratados se enfriaron rápidamente en un baño de agua y hielo. 
Posteriormente se llevó todo a una cámara de flujo laminar y se pasaron las muestras de los capilares a tubos Eppendorf y se obtuvieron diluciones seriadas (entre $10^{-1}$ y $10^{-8}$ ) en tubos que contenían $900 \mu \mathrm{L}$ de agua peptonada, se homogenizaron y se sembraron $100 \mu \mathrm{L}$ de cada dilución por cuadruplicado en placas petri. Se les agregó el medio de cultivo y las placas petri se llevaron a una cámara de incubación a $37^{\circ} \mathrm{C}$ durante 48 h y a continuación se procedió al recuento de las colonias. 

IV. RESULTADOS Y
DISCUSIÓN 



\section{IV.1. CARACTERIZACIÓN DEL PURÉ DE FRESA FRESCO.}

IV.1.1. Macrocomponentes y propiedades fisicoquímicas del puré de fresa fresco.

La tabla IV.1.1 muestra las características iniciales promedio del puré de fresa fresca empleado en el estudio.

Tabla IV.1.1. Características iniciales del puré de fresa.

\begin{tabular}{|c|c|}
\hline Características & Valor $^{a}$ \\
\hline Sólidos solubles ( ${ }^{\circ}$ Brix) & $6,5 \pm 0,2$ \\
\hline Glucosa $(g / 100 \mathrm{~g})$ & $2,9 \pm 3$ \\
\hline Xilosa (g/100 g) & $0,14 \pm 0,04$ \\
\hline Fructosa (g/100 g) & $1,9 \pm 0,4$ \\
\hline Sacarosa (g/100 g) & $0,50 \pm 0,01$ \\
\hline Acidez (expresada como acido cítrico anhidro, \%) & $1,02 \pm 0,07$ \\
\hline${ }^{\circ}$ Brix/acidez & $6,4 \pm 0,7$ \\
\hline $\mathrm{pH}$ & $3,42 \pm 0,08$ \\
\hline$a_{w}$ & $0,997 \pm 0,001$ \\
\hline Contenido en agua (g agua/100g muestra) & $90,2 \pm 0,8$ \\
\hline
\end{tabular}


Estos valores se asemejan a los publicados por Moraga et al. (2006) en fresa de la variedad Camarosa cultivada en España (Huelva), así como a los obtenidos por otros autores como Kafkas et al. (2007) en frutas maduras de la misma variedad cultivadas en Turquía (acidez 0,83\%, pH 3,29 azucares totales $57,90 \mathrm{~g} / \mathrm{L}$ ) y similares a los publicados por Sturm et al. (2003) en fresas producidas en Slovenia.

Su contenido en azúcares y la relación azúcar/acidez nos indica que la materia prima de partida se encontraba en el punto óptimo para la elaboración de los purés. Según Wozniak et al. (1997), que estudio cómo afecta la relación azúcar/ acidez en las características organolépticas de las fresas, un valor igual a 7 está relacionado con un sabor definido como dulce mientras que un valor igual a 6 se corresponde con un gusto a ácido. En nuestro caso, el valor promedio de la relación azúcar/acidez que presentaron los lotes de fresa empleados en este estudio fue de 6,34 lo que corresponde a un gusto bien equilibrado entre dulce y ácido.

\section{IV.1.2. Comportamiento reológico del puré de fresa fresco.}

La figura IV.1.1 muestra, como ejemplo, el reograma o curva de flujo obtenido en una muestra de puré de fresa fresca tras la realización de los barridos ascendente y descendente de gradiente de velocidad que se describen en el apartado III.2.9 de materiales y métodos. 


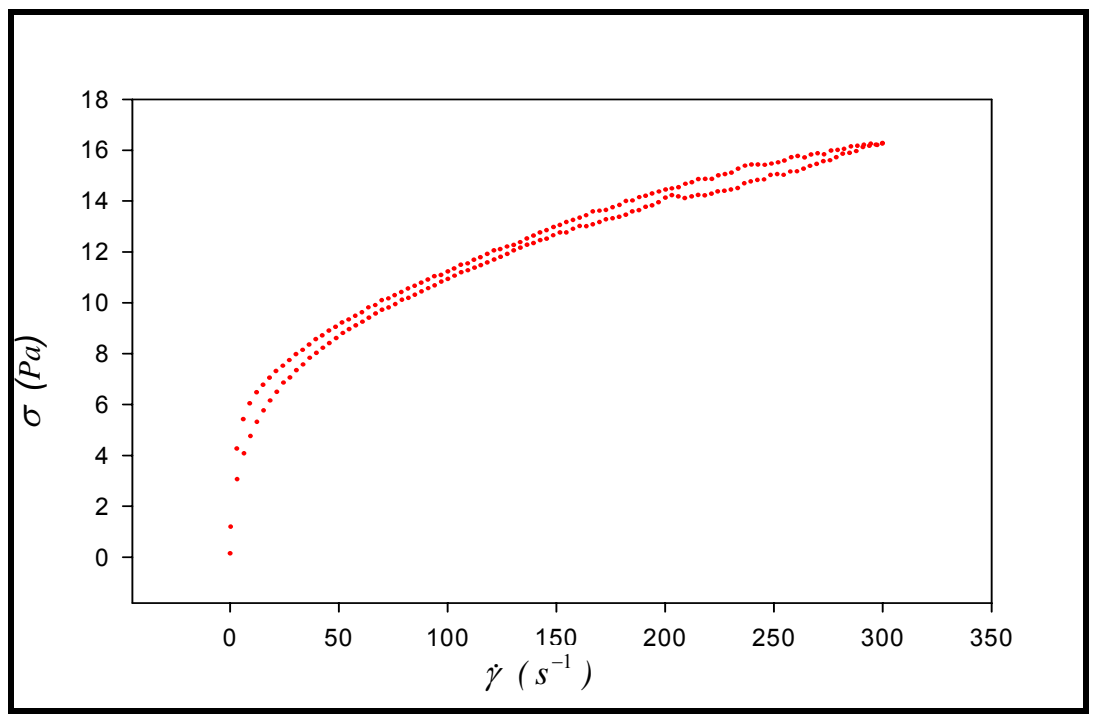

Figura IV.1.1. Reograma del puré de fresa fresca inicial.

Con los puntos experimentales de esfuerzo $(\sigma)$ y gradiente de velocidad $(\dot{\gamma})$ de la curva de flujo ascendente se ajustó, en cada repetición, el modelo de Ostwal de Waele (ec. III.4) a través de una regresión no lineal realizada con el programa SigmaPlot. Los valores promedio de los parámetros del modelo, $\mathrm{K}$ (índice de consistencia) y $\mathrm{n}$ (índice de comportamiento al flujo), obtenidos aparecen en la tabla IV.I.2. El valor del coeficiente $\left(R^{2}\right)$ fue superior a 0.993 en todos los casos estudiados. 
Tabla IV.1.2. Valores medios del índice de consistencia (K), índice de comportamiento al flujo $(n)$ y área relativa de histéresis de las muestras de puré de fresa fresca.

\begin{tabular}{cccc}
\hline Muestra & \multicolumn{2}{c}{ Parámetros reológicos } & Área histéresis relativa \\
& $\mathbf{K}\left(\mathbf{P a}^{\mathrm{n}} \mathbf{s}^{\mathrm{n}}\right)$ & $\mathbf{n}$ & $\mathbf{( \% )}$ \\
\hline Puré de fresa fresco & $2,53 \pm 0,11$ & $0,328 \pm 0,007$ & $3,28 \pm 0,51$ \\
\hline
\end{tabular}

El valor de $\mathrm{n}$ entre 0 y 1 , indicaría en principio, un comportamiento pseudoplástico del puré de fresa, cuya viscosidad decrece al aumentar el gradiente de velocidad. Sin embargo, como la curva ascendente y descendente no coinciden sino que la ascendente va por encima de la descendente, quedando entre ambas un área de histéresis, podemos decir que, para un determinado gradiente de velocidad, la viscosidad disminuye con el tiempo de cizalla y, por lo tanto, se trata de un fluido tixotrópico. A partir de la ecuación III.5 se calculó el área de histéresis relativa $\left(\Delta H_{r}\right)$ en cada una de las repeticiones realizadas. El valor promedio aparece en la tabla IV.I.2 cuya magnitud está relacionada con el pequeño carácter tixotrópico de la muestra.

Desde el punto de vista molecular, la interpretación del comportamiento de este tipo de fluidos corresponde a productos con partículas dispersas (fibras, pectinas, etc.) en una fase continua líquida que como consecuencia del gradiente de velocidad generado, se orientan, desenrollan, deforman o desagregan con el flujo, produciéndose así una disminución de la resistencia al flujo o de la 
viscosidad aparente (Windhab, 1995). Este efecto es tanto mayor cuanto mayor es el gradiente impuesto. A un gradiente dado, con el tiempo se establece un equilibrio entre la desorganización estructural impuesta por el flujo y la reestructuración del sistema provocada por el movimiento Browniano y las interacciones interpartícula. El cambio estructural del sistema por efecto del gradiente hasta la situación de equilibrio puede ocurrir en un tiempo medible dentro de la escala habitual de tiempos u ocurrir muy rápidamente de forma que no se observe la cinética de cambio estructural. En el primer caso se habla de tixotropía y en el segundo caso de pseudoplasticidad.

\section{IV.1.3. Color del puré de fresa fresco.}

En el proceso de obtención del puré de fresa, la presencia de aire ocluido en el producto es inevitable pudiendo afectar en la medida del color de las muestras. En las industrias de zumos, generalmente se incluye una etapa de desaireado para proteger al producto de reacciones oxidativas. En este sentido, la la tabla IV.1.3 muestra cómo afecta la desaireación a vacío, en las condiciones que aparecen en el apartado III.1 de materiales y métodos, en los valores de las coordenadas $\mathrm{CIE} L^{*} \mathrm{a}^{*} \mathrm{~b}^{*}$ y los atributos tono $\left(\mathrm{h}^{*}\right)$ y croma $\left(\mathrm{C}^{*}\right)$ del puré de fresa, calculados a partir de las ecuaciones III.1 y III.2, respectivamente.

La desaireación da lugar a purés más oscuros, ya que el valor de L* (luminosidad) es significativamente menor, y con un valor de la coordenada a* significativamente menor. Sin embargo, la desaireación no supone diferencias 
significativas en el tono y pureza de color de las muestras de estas muestras. La ausencia de aire implica un índice de refracción más homogéneo en la muestra y una mayor absorción de luz, con la correspondiente disminución de la reflectancia y por lo tanto de $L^{*}$. La diferencia de color calculado entre ambas muestras es de \pm 4,5 unidades, lo que ya es perceptible al ojo humano. En cualquier caso, para evitar oxidaciones, parece recomendable la desaireación previa del puré.

Tabla IV.I.3. Efecto de la desaireación en el color del puré de fresa.

\begin{tabular}{|c|c|c|c|c|c|}
\hline Desaireación & $\mathbf{L}^{*}$ & $a^{*}$ & $\mathbf{b}^{*}$ & $C^{*}$ & $\mathbf{h}^{*}$ \\
\hline No & $28,0 \pm 0,4^{a}$ & $35,1 \pm 0,6^{a}$ & $23 \pm 3^{a}$ & $42 \pm 2^{a}$ & $33 \pm 3^{a}$ \\
\hline Sí & $24,1 \pm 0,5^{b}$ & $33,1 \pm 1,1^{b}$ & $22 \pm 4^{a}$ & $40 \pm 2^{a}$ & $34 \pm 5^{a}$ \\
\hline
\end{tabular}

\section{IV.1.4. Actividad enzimática.}

IV.1.4.1. Pectinmetilesterasa.

La figura IV.1.2 muestra la curva obtenida para la evaluación de la actividad PME del puré de fresa fresco. Los puntos experimentales se ajustaron a una función exponencial doble y de la pendiente en el origen se obtuvo el valor máximo: $\Delta \mathrm{pH} / \Delta \mathrm{t}=0,00176$. Utilizando la conversión descrita por Carbonell et al 
(2006) se obtuvo una actividad, expresada en unidades internacionales, de 0,385 nKat.

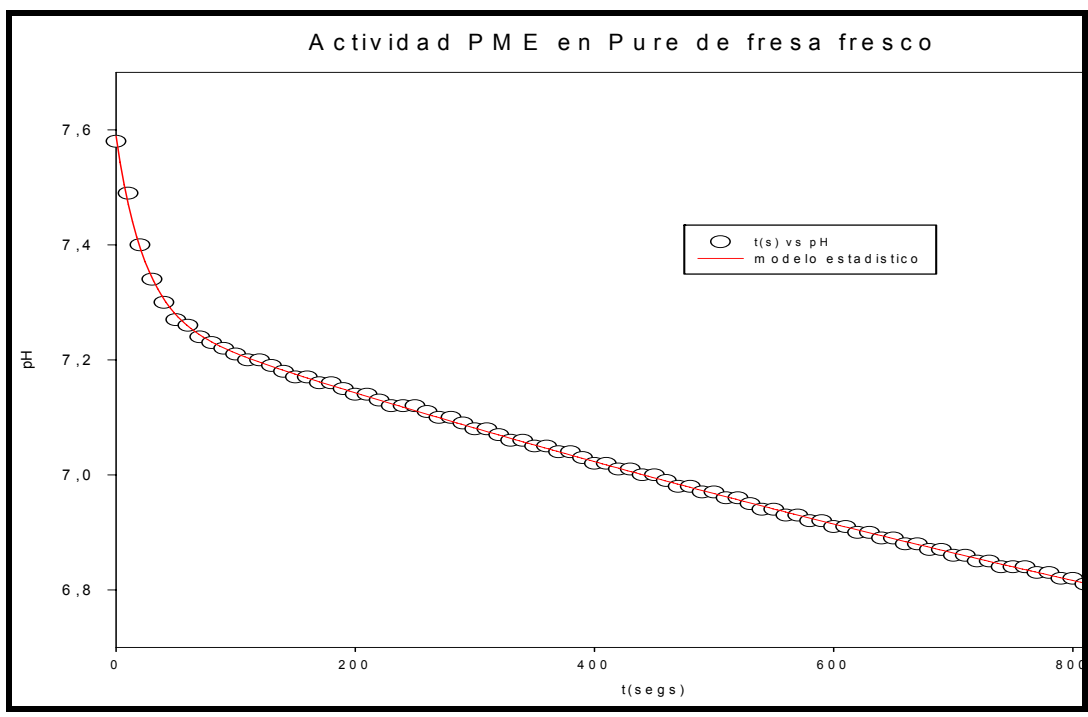

Figura IV.1.2. Descenso del pH con el tiempo de incubación enzimàtica.

IV.1.4.2. Peroxidasa.

La figura IV.1.3 muestra la evolución de la densidad óptica (absorbancia) de la muestra y el blanco con el tiempo de incubación. Los puntos experimentales se ajustan perfectamente a una recta, con una pendiente de $\Delta \mathrm{Abs} / \Delta \mathrm{t}=0,0100$. 


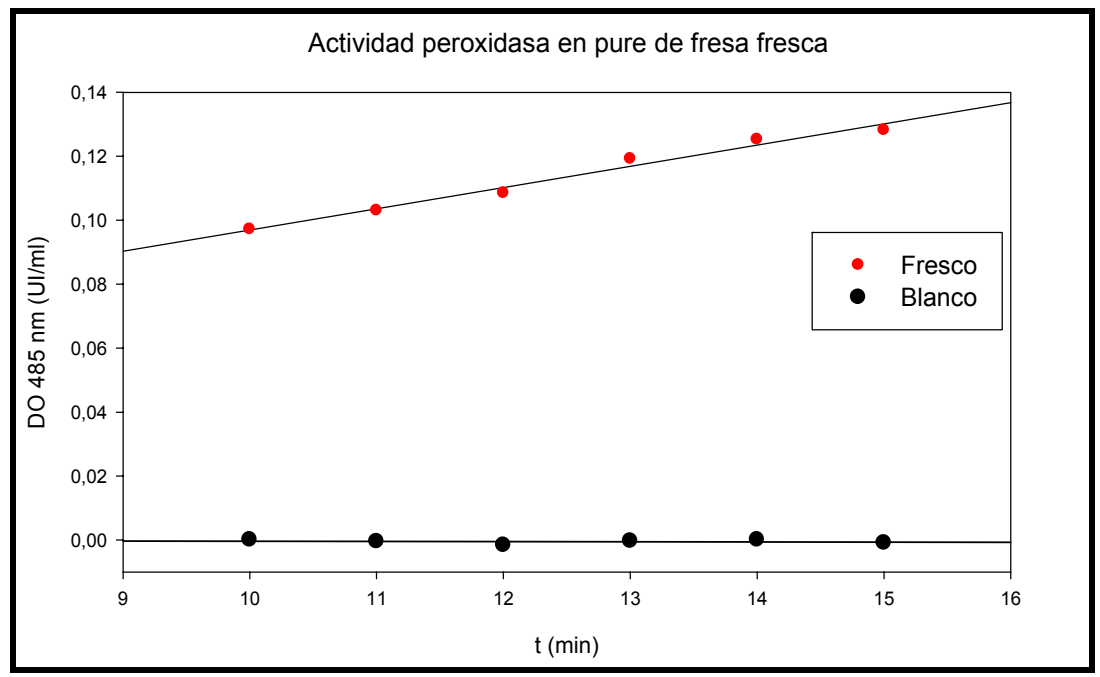

Figura IV.1.3. Evolución de la actividad enzimàtica $\mathrm{POD}(\Delta \mathrm{Abs} / \Delta \mathrm{t})$.

\section{IV.1.4.3. Polifenoloxidasa.}

La figura IV.1.4 nos muestra los puntos experimentales y el ajuste mediante el modelo matemático de la regresión polinomial cúbica. El valor de la máxima pendiente correspondió a $\Delta \mathrm{Abs} / \Delta \mathrm{t}=0,0008$. 


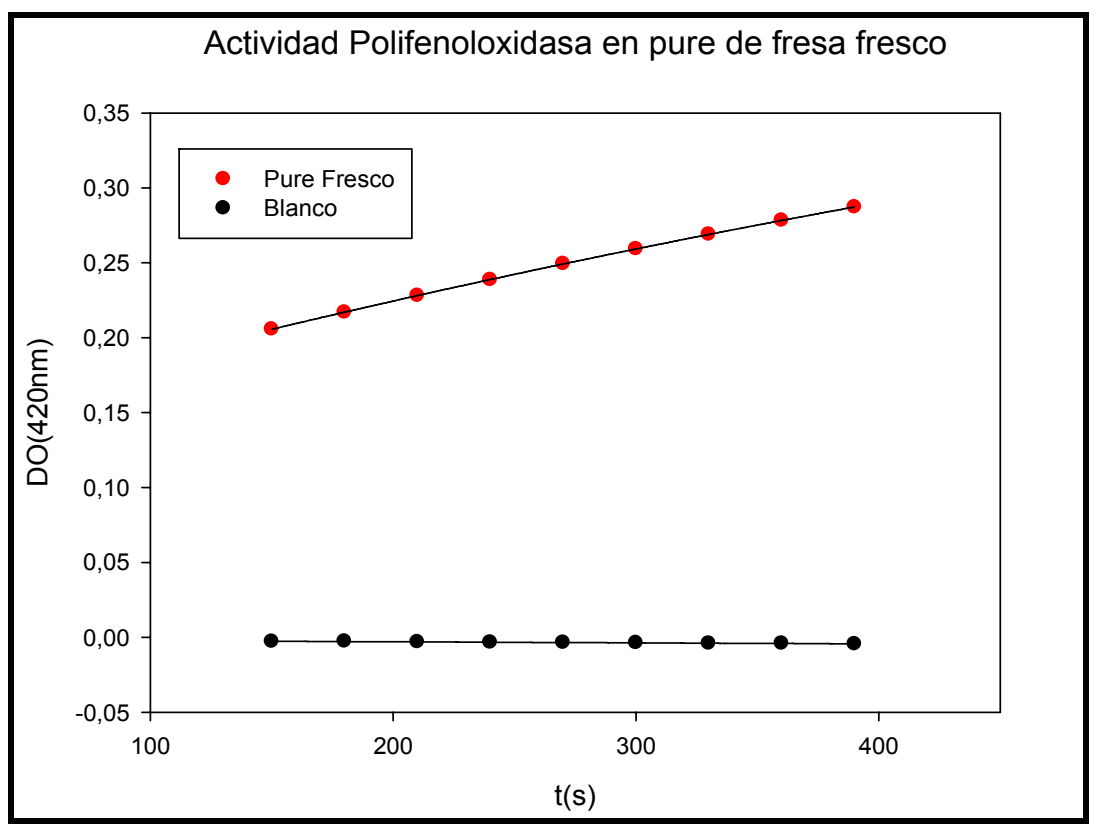

Figura IV.1.4. Evolución de la actividad enzimàtica PPO ( $\Delta \mathrm{Abs} / \Delta \mathrm{t})$.

Tabla IV.1.4. Resumen de las actividades enzimáticas encontradas en el puré de fresa fresco.

\section{$\mathrm{PME}^{*}$ (nKat) $\quad \mathrm{PPO}^{*}(\Delta \mathrm{Abs} / \Delta \mathrm{t}) \quad \mathrm{POD}^{*}(\Delta \mathrm{Abs} / \Delta \mathrm{t})$}

$\begin{array}{llll}\text { Actividad (pure fresco) } & 0,385 \pm 0,036 & 0,010 \pm 0,002 & 0,008 \pm 0,001\end{array}$

\footnotetext{
* Media de tres determinaciones analíticas.
} 


\section{IV.1.5. Contenido en antocianidinas.}

La figura IV.1.5 muestra el cromatograma obtenido a una longitud de onda de $520 \mathrm{~nm}$ del extracto de fresa. Los picos se han identificado por su espectro de absorción en el ultravioleta visible y están desplazados ligeramente para facilitar su observación. Las concentraciones de cianidina y pelargonidina son mayores en el puré de fresa sometido durante su procesamiento a una intensa desaireación a vacío, lo que podría estar relacionado con una cierta oxidación de estos compuestos en presencia de aire. La tabla IV.1.5 muestra las concentraciones correspondientes de cada antocianidina.

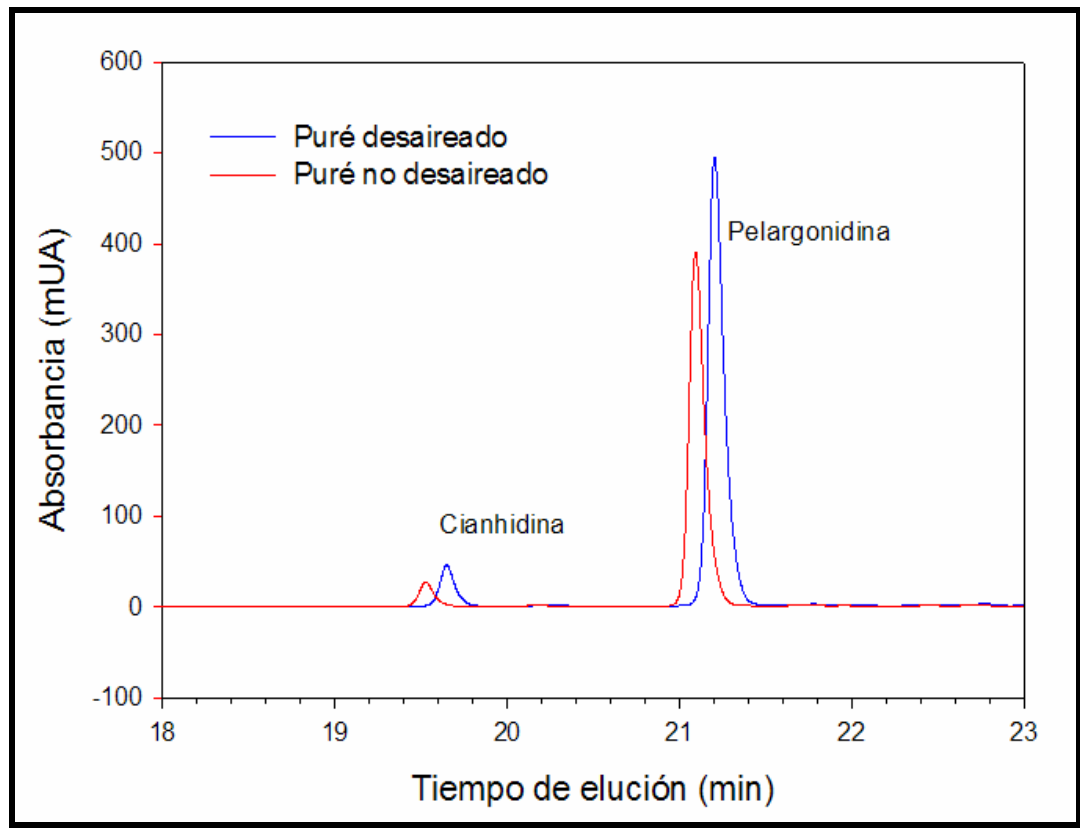

Figura IV.1.5. Cromatograma de antocianinas en puré de fresa. 
Tabla IV.1.5. Concentraciones de los picos mostrados en la figura IV.1.6.

\begin{tabular}{lcc}
\hline & Cianidina* $\left.^{*} \mathbf{m g} / \mathbf{g}\right)$ & Pelargonidina* $\left.^{*} \mathbf{m g} / \mathbf{g}\right)$ \\
\hline Puré desaireado & $0,0292 \pm 0,001$ & $0,343 \pm 0,01$ \\
Puré no desaireado & $0,0163 \pm 0,001$ & $0,270 \pm 0,02$ \\
\hline
\end{tabular}

* Media de dos determinaciones analíticas.

\section{IV.1.6. Contenido en vitamina C.}

La figura IV.1.6 nos muestra los cromatógramas obtenidos en el análisis de vitamina $\mathrm{C}$ y ácido ascórbico del puré de fresa. Se observa una mayor concentración de ambos en la muestra obtenida según el proceso de fabricación en el que se somete el puré a desaireación a vacío, lo que indicaría la oxidación de la vitamina C La tabla IV.1.6 muestra las concentraciones respectivas de los compuestos en las dos muestras.

Tabla IV.1.6. Concentraciones de los picos mostrados en la figura IV.1.7.

\begin{tabular}{lcc}
\hline & Acido ascórbico * $(\mathbf{m g} / \mathbf{g})$ & Vitamina $\mathbf{C}^{*}(\mathbf{m g} / \mathbf{g})$ \\
\hline Puré desaireado & $0,093 \pm 0,02$ & $0,340 \pm 0,02$ \\
Puré no desaireado & $0,031 \pm 0.03$ & $0,295 \pm 0,03$ \\
\hline & \\
\hline
\end{tabular}


Como puede observarse, el efecto de la presencia de oxígeno es mucho más intenso sobre el ácido ascórbico que sobre la vitamina C.
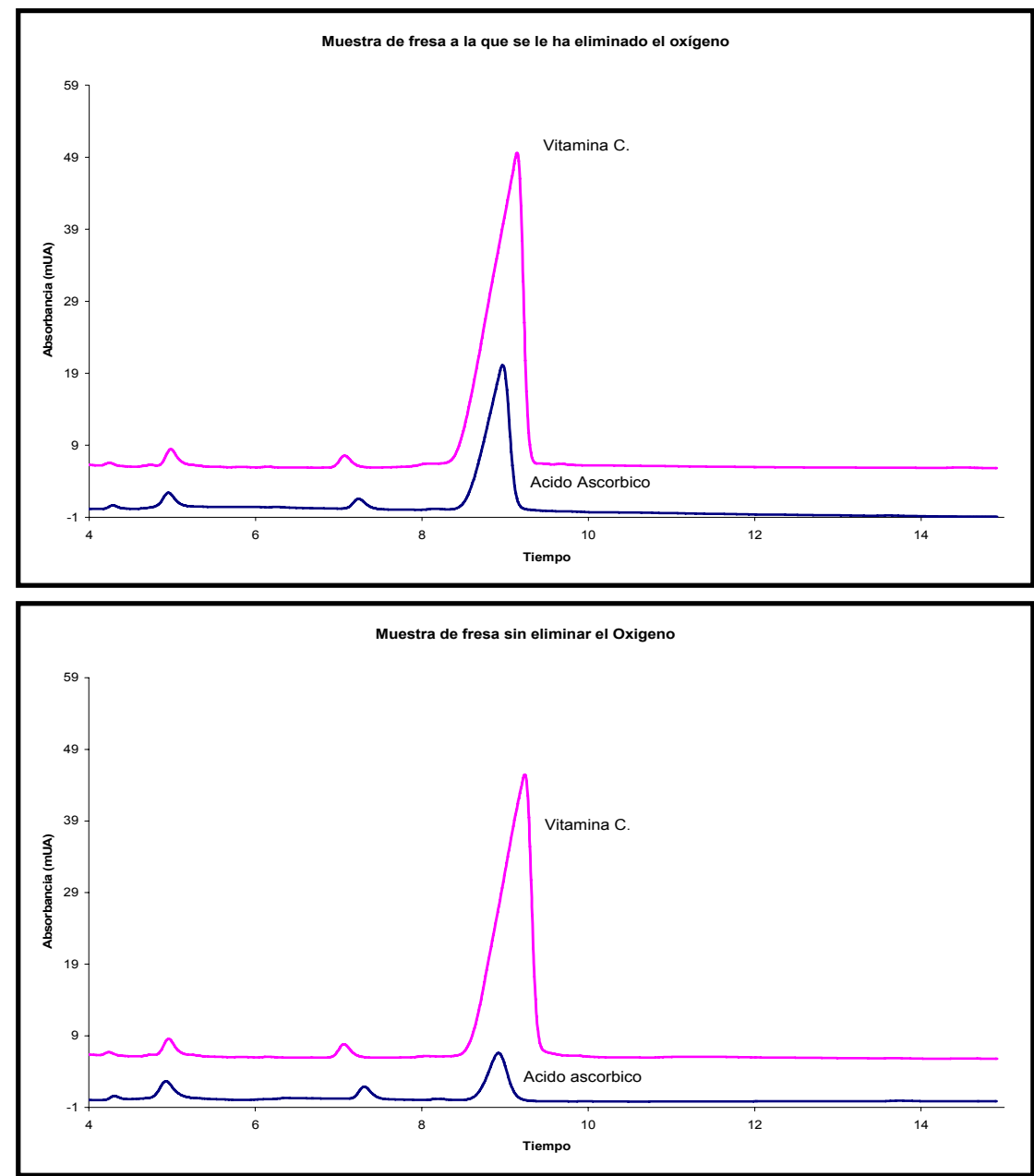

Figura IV.1.6. Cromatógramas de purés de fresa mostrando el pico del ácido ascórbico antes y después de la conversión de ácido dehidroscórbico a ascórbico. 


\section{IV.1.7. Actividad antirradical.}

Los zumos de frutas son ricos en compuestos, tales como los antocianos y la vitamina C, con capacidad para inactivar radicales libres. En el caso del puré de fresa se espera un comportamiento similar al que presentan los zumos cítricos (Sentandreu, 2006) donde los componentes que presentan actividad antirradical se pueden dividir en tres grupos generales en función de la cinética de reacción con el DPPH. Los compuestos de cinética rápida sólo son capaces de transferir átomos de hidrógeno al DPPH de forma rápida y normalmente contienen un grupo alcohol vinílico (como el ácido ascórbico). Los de cinética rápida-lenta transfieren hidrógenos al DPPH tanto de forma rápida como de forma lenta. Normalmente son compuestos que contienen al menos un grupo $p$-catecol (como el ácido clorogénico o la cianidina). Los componentes de cinética lenta sólo son capaces de la transferencia lenta de átomos de hidrógeno al DPPH y son compuestos que contienen fenoles aislados (como la pelargonidina).

Para la determinación de la actividad antirradical de la fresa fresca se emplearon volúmenes de muestra de $20,30,40$ y 50 microlitros. Las curvas en las que se representa la disminución de la concentración de DPPH con el tiempo se muestran en la figura IV.1.7. 


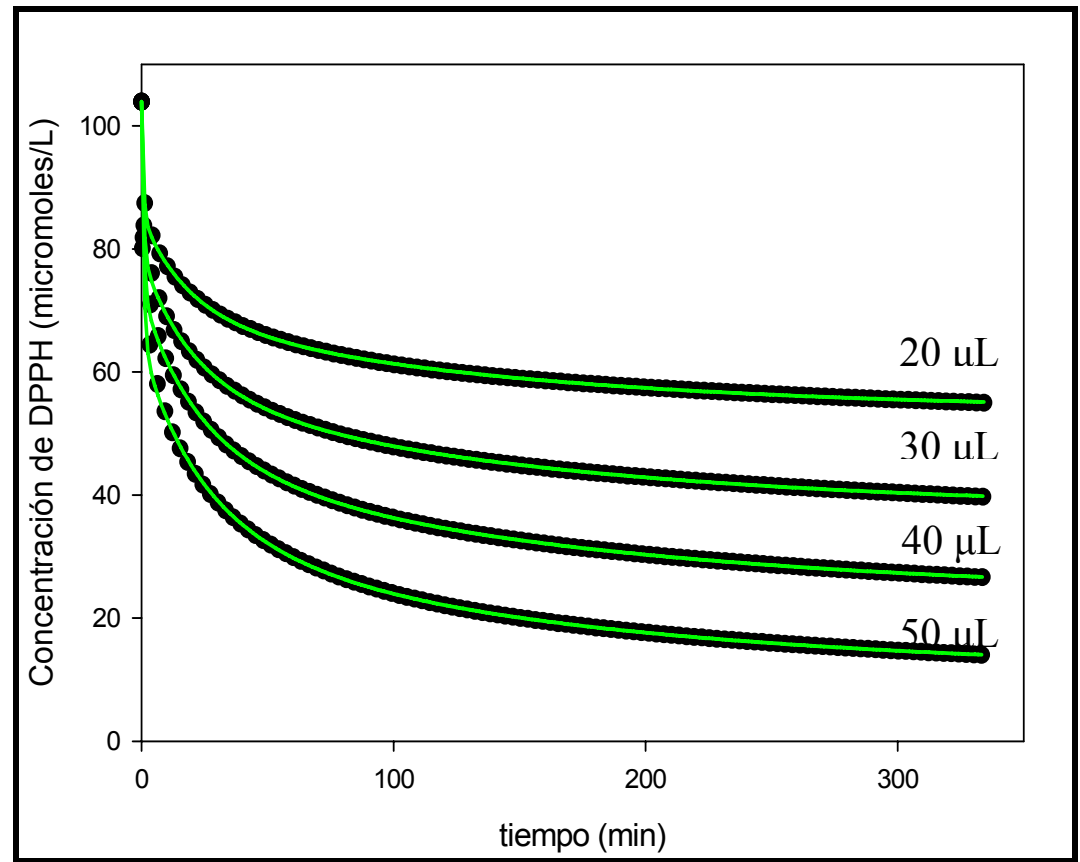

Figura IV.1.7. Representación de la disminución de la concentración de DPPH en función del tiempo de reacción de los diferentes volúmenes de muestra que se indican en la gráfica. Las líneas verdes corresponden a las respectivas curvas ajustadas.

El modelo cinético para explicar la forma de las curvas experimentales corresponde al publicado por Sendra et al. (2007) para compuestos con grupos $p$ catecol. Según este modelo, la reacción de reducción del DPPH está dividida en varios pasos sucesivos: 
1․ Transferencia rápida de dos hidrógenos del grupo $p$-catecol al DPPH, formándose la correspondiente o-quinona. Si la reacción se llevara a cabo en acetonitrilo se detendría aquí, pero en disolventes alcohólicos (en nuestro caso, metanol) la reacción continua.

$2^{\circ}$. Adición de una molécula de alcohol en el intermedio o-quinona y regeneración del grupo $p$-catecol. Este segundo paso es lento y depende de la estructura de la molécula antirradical y del impedimento estérico que proporcione para el ataque nucleófilo de la molécula de alcohol.

$3^{\circ}$. El grupo p-catecol regenerado vuelve a transferir dos átomos de hidrógeno al DPPH, transformándose de nuevo en o-quinona. Aunque esta transferencia de hidrógenos es rápida, la velocidad de este paso viene limitada por la del paso anterior que es lento.

$4^{\circ}$. Regeneración del grupo p-catecol por adición de una nueva molécula de alcohol. De esta forma, el grupo $p$-catecol se puede regenerar hasta tres veces, transfiriendo dos átomos de hidrógeno al DPPH cada vez (transferencia de hasta ocho átomos de hidrógeno).

En resumen, la reducción del DPPH con moléculas que tienen un grupo $p$ catecol se puede dividir en hasta 4 etapas de transferencia de dos hidrógenos al DPPH en cada una, y la constante estequiométrica global de la reacción debe ser un número entre 4 y 8.

Las curvas experimentales se ajustaron a una ecuación de 3 términos (Ecuación IV.1), correspondientes a las tres etapas de reacción con tres constantes de velocidad $\left(k_{1}, \rho_{2}\right.$ y $\left.\rho_{3}\right)$ y tres constantes estequimétricas $\left(\sigma_{1}, \sigma_{2}, \sigma_{3}\right)$ (Sentandreu et al., 2008). 


$$
y-y_{s}=\frac{y_{1}\left(y_{o}-y_{1}\right)}{y_{1}-y_{o}\left(1-e^{k_{1} y_{1} t / \sigma_{1}}\right)}+\frac{y_{2}\left(y_{o}-y_{2}\right)}{y_{2}-y_{o}\left(1-e^{\rho_{2} y_{2} t / \sigma_{2}}\right)}+\frac{y_{3}\left(y_{o}-y_{3}\right)}{y_{3}-y_{o}\left(1-e^{\rho_{3} y_{3} t / \sigma_{3}}\right)}
$$

El subíndice 1 corresponde al primer paso de transferencia rápida de dos hidrógenos al DPPH y el 2 y 3 a los siguientes pasos en los que en cada uno se regenera el $p$-catecol y se transfieren otros dos átomos de hidrógeno al DPPH. Como se explica en el citado trabajo de Sentandreu et al. (2008) los valores de los coeficientes estequiométricos son $\sigma_{1}=\sigma_{2}=2$, las etapas 1 y 2 son irreversibles y la etapa 3 es reversible (por lo tanto, $\sigma_{3}<2$ ), aunque a dilución infinita del compuesto antirradical se puede considerar $\sigma_{3} \approx 2$.

Además, en la anterior ecuación, $y_{0}$ es la concentración inicial de DPPH, $y_{1}$ es el valor acumulado de la concentración de DPPH que se alcanzaría debido a la actividad antirradical de los componentes de cinética rápida y a la primera etapa de la reacción de transferencia de hidrógenos de los componentes con grupo $p$ catecol, $y_{2}$ sería el valor que alcanzaría la concentración de DPPH debido a la actividad antiradical de la segunda etapa de la reacción de los componentes con grupo $p$-catecol, $y_{3}$ sería el valor acumulado que alcanzaría la concentración de DPPH debido a la actividad de los componentes de cinética lenta y a la tercera etapa de la reacción de los componentes con grupo $p$-catecol y $y_{s}$ sería la concentración final alcanzada por el DPPH.

Del ajuste de los valores experimentales, se obtienen los parámetros $y_{1}$, $y_{2}, y_{s}, k_{1} / \sigma_{1}, \rho_{2} / \sigma_{2}$ y $\rho_{3} / \sigma_{3}$. El valor de $y_{3}$ se calculó como $2 y_{0}+y_{s}-y_{1}-y_{2}$. Por otro lado, se representaron los valores de $y_{o}-y_{i}$ frente al volumen de muestra añadido obteniéndose la grafica mostrada en la figura IV.1.8. Los valores de $y_{0}-y_{1}$ y de $y_{0}$ 
- $y_{2}$ se ajustaron a una recta, mientras que los de $y_{0}-y_{3}$ se ajustaron a una hipérbola. La representación de $y_{0}-y_{s}$ corresponde a la suma de las tres anteriores representaciones y, por lo tanto, también corresponde a una hipérbola.

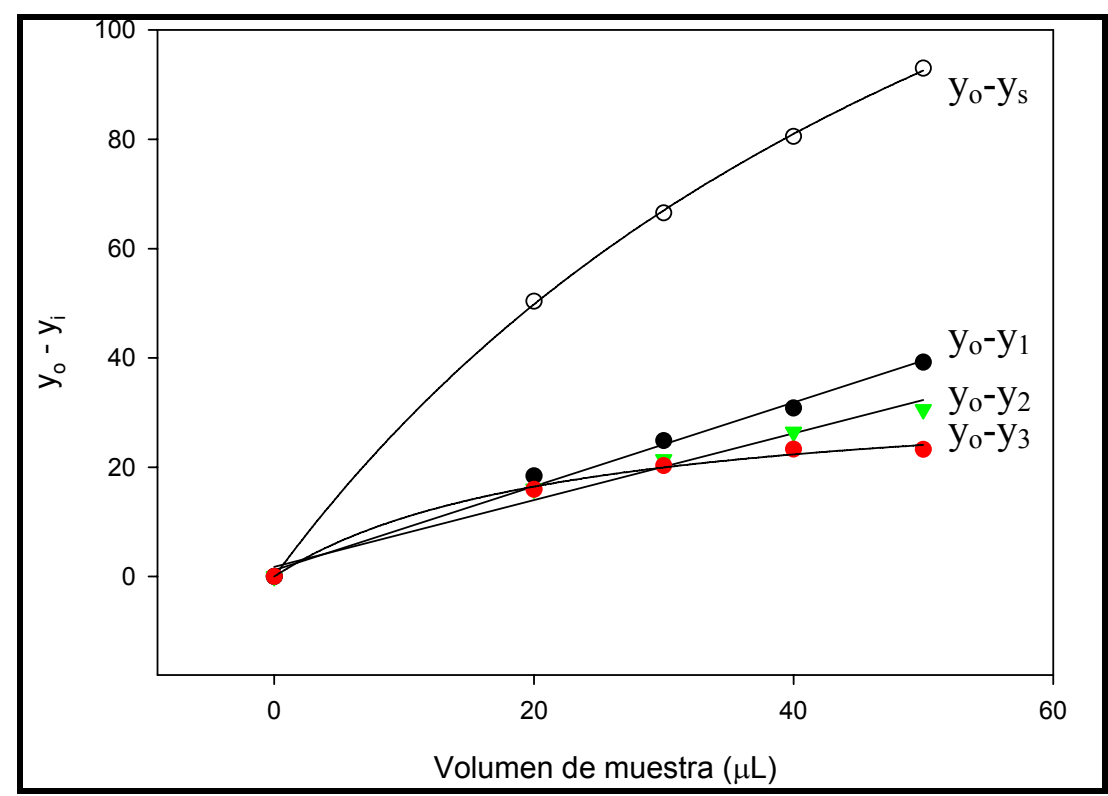

Figura IV.1.8. Representación de las diferencias $y_{o}-y_{i}$ para diferentes volúmenes de muestra, en los trazos se muestra cada una de las contribuciones correspondientes a los tres componentes de la muestra, así como la contribución total.

La máxima pendiente de la hipérbola $m_{s}=\left(y_{0}-y_{s}\right) / V_{0}$ cuantifica la cantidad de DPPH que ha sido reducida por microlitro de muestra añadida. La pendiente de la recta $m_{1}=\left(y_{0}-y_{1}\right) / V_{o}$ cuantifica la cantidad de DPPH que ha sido reducida por microlitro de muestra, pero debida únicamente a la actividad 
acumulada de cinética rápida; la pendiente de la recta $m_{2}=\left(y_{0}-y_{2}\right) / V_{o}$ cuantifica la cantidad de DPPH que ha sido reducida por microlitro de muestra, pero debida a la actividad de la segunda etapa de reacción de los componentes con p-catecol ; la pendiente de la hipérbola $m_{3}=\left(y_{0}-y_{3}\right) / V_{0}$ en el origen cuantifica la cantidad de DPPH que ha sido reducida por microlitro de muestra, pero debida únicamente a la actividad acumulada de cinética lenta.

La actividad antirradical total $\left(A_{t}\right)$ de la muestra de puré de fresa corresponde a $V \cdot m_{s} / \sigma(\mathrm{mmol} / \mathrm{L})$, donde $V$ es el volumen total $(2 \mathrm{~mL})$ y $\sigma$ el coeficiente estequiométrico de la reacción. Si se tiene en cuenta que la constante estequiométrica del ácido ascórbico es $\sigma=2$ (Sentandreu, 2006), la actividad total se puede expresar como equivalentes molares de ácido ascórbico. Para la muestra de fresa sin tratar térmicamente se obtuvo un valor de actividad total 3,22 $\mathrm{mmol} / \mathrm{L}$. La actividad correspondiente a los componentes de cinética rápida $A_{1}$ fue de 0,77 mmol ascórbico/L, lo que equivale a 0,67 mg ascórbico/g muestra. Si se compara este valor con el valor obtenido por HPLC (0,2 mg ascórbico/g muestra) se puede deducir que hay otros componentes en la fresa que exhiben una cinética rápida para la reducción del $\mathrm{DPPH}$, como la cianidina o otros componentes con grupo $p$-catecol. 


\section{IV.2. EFECTO DEL TRATAMIENTO TÉRMICO Y DEL ALMACENAMIENTO EN}

\section{LA ACTIVIDAD ENZIMÁTICA DEL PURÉ DE FRESA.}

El objetivo del presente apartado fue analizar el efecto de tratamientos térmicos moderados y el posterior almacenamiento refrigerado sobre la actividad pectinmetilesterasa (PME), peroxidasa (POD), y polifenoloxidasa (PPO).

IV.2.1. Pectinmetilesterasa.

La figura IV.2.1 muestra la caída del pH con el tiempo de incubación del puré con la solución de pectina.

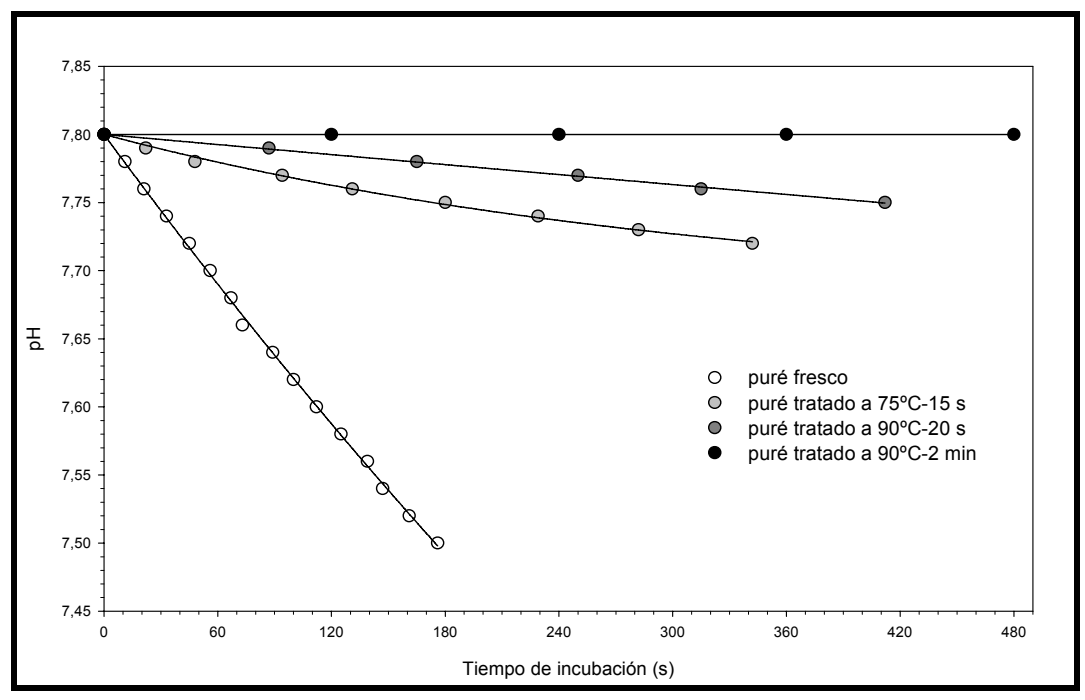

Figura IV.2.1. Actividad PME del puré de fresa fresco y de los tratados térmicamente. 
De las pendientes en el origen de las correspondientes curvas de ajuste se obtiene la actividad enzimàtica PME, cuyos valores se dan en la tabla IV.2.1.

Tabla IV.2.1. Actividad PME del puré de fresa.

\begin{tabular}{lcc}
\hline \multicolumn{1}{c}{ Tratamiento térmico } & \multicolumn{2}{c}{ Actividad PME } \\
& nkat & $\begin{array}{c}{ }^{*} \\
\text { Actividad relativa } \\
\text { Ninguno (pure fresco) }\end{array}$ \\
Pasteurizado $75^{\circ} \mathrm{C}-15 \mathrm{sec}$ & $0,39 \pm 0.04$ & 100 \\
Pasteurizado $90^{\circ} \mathrm{C}-20 \mathrm{sec}$ & $0,10 \pm 0.07$ & 25,5 \\
Envasado en caliente $90^{\circ} \mathrm{C}-2 \mathrm{~min}$ & $0,02 \pm 0.01$ & 0 \\
\hline
\end{tabular}

*Valor promedio (calculado sobre 3 repeticiones) \pm desviación típica.

La actividad PME del puré de fresa fresco, como ya se había comentado en el apartado IV.1.4.1 fue de 0,39 Nkat/mL, aproximadamente un tercio de la actividad en jugos de naranja variedad valencia late o mandarinas clementinas (Carbonell et al., 2006), pero encontramos que su resistencia térmica es levemente mas alta.

El tratamiento térmico a $75^{\circ} \mathrm{C}$ por 15 segundos no es lo bastante eficaz para reducir la actividad de la PME por debajo del nivel del $10 \%$ del inicial, que es el valor máximo que recomiendan Irwe y Olson (1994) para los zumos pasteurizados refrigerados. Una pasterización más severa $\left(90^{\circ} \mathrm{C}\right.$ durante 20 segundos), produjo en el puré de fresa solo una actividad residual del 5,4\% y en el 
puré de fresa sometido a envasado en caliente $\left(90^{\circ} \mathrm{C}\right.$ durante 2 minutos) ya no se detectó ninguna actividad PME.

No se detectaron cambios significativos en la actividad PME por efecto del almacenamiento durante 30 y 60 días, por lo que se ha decidido no incluir las correspondientes tablas o gráficas.

\section{IV.2.2. Peroxidasa.}

La figura IV.2.2 muestra, como ejemplo, una curva de evolución de la absorbancia del puré fresco y de los tratados térmicamente tomadas para la medida de la actividad POD (no se han incluido todas por claridad de la imagen). El valor de la pendiente en el origen de las correspondientes curvas de ajuste permite obtener la actividad POD de las muestras. Los resultados obtenidos se muestran en la figura IV.2.3. Como puede observarse, sólo los tratamientos térmicos más enérgicos $\left(90^{\circ} \mathrm{C}-2\right.$ minutos) permiten reducir la actividad $\mathrm{POD}$ por debajo del $10 \%$ de la inicial.

Al cabo de 30 días de almacenamiento en refrigeración, la actividad POD de las muestras tratadas térmicamente se redujo a menos de la mitad de la que presentaba la muestra recién tratada y a los 60 días ninguna muestra tratada presentó actividad POD. La actividad POD también desapareció en las dos muestras que sufrieron mayor tratamiento térmico cuando se almacenaron a temperatura ambiente durante 30 días. En la tabla IV.2.2 se incluyen los valores de la actividad POD de estas muestras. 


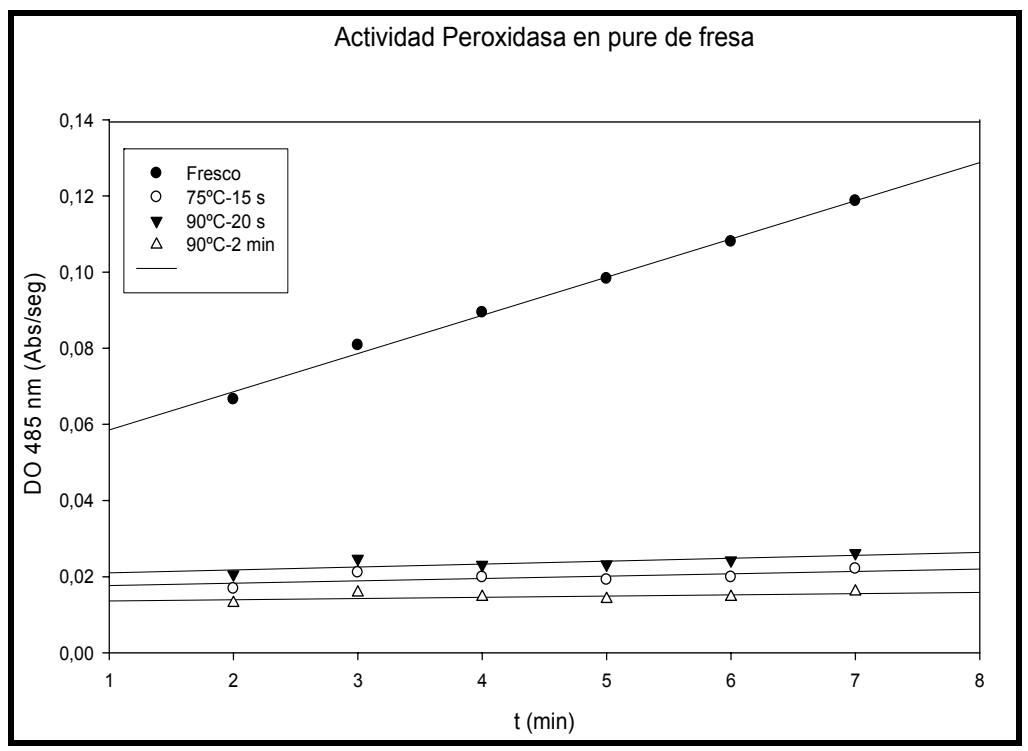

Figura IV.2.2. Medida espectrofotometrica de la actividad POD en fresa

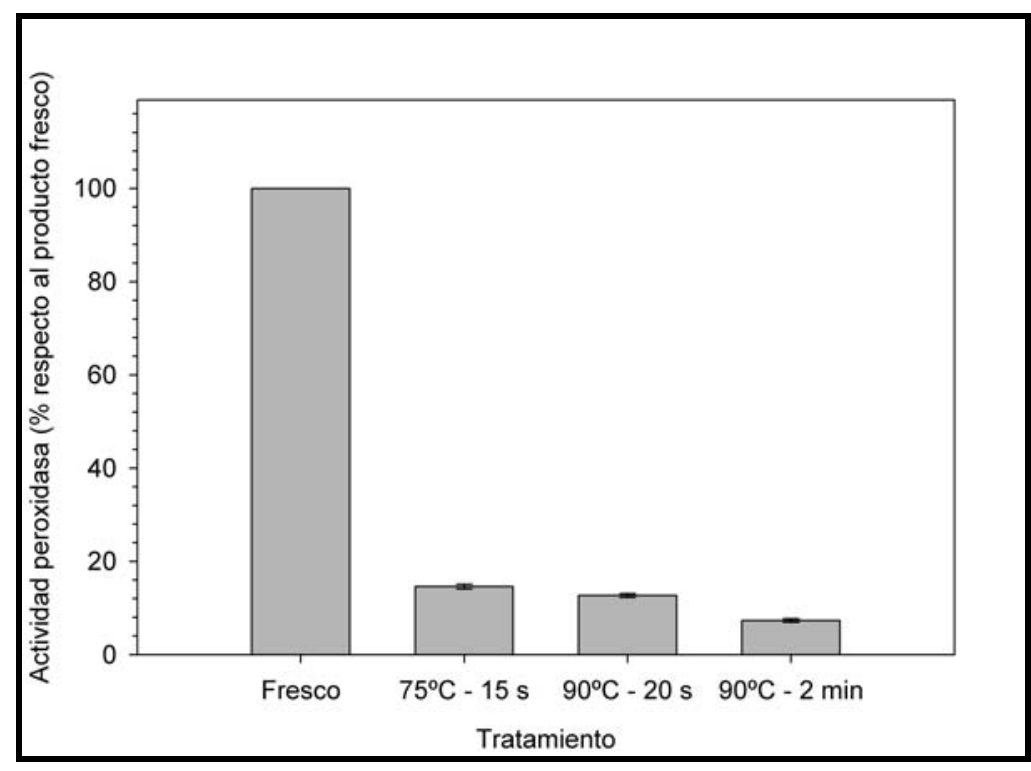

Figura IV.2.3. Efectos del tratamiento térmico en la POD. 
Tabla IV.2.2. Valores de actividad POD del puré de fresa almacenado a $3^{\circ} \mathrm{C}$.

\begin{tabular}{lccccc}
\hline & \multicolumn{5}{c}{ Actividad POD del puré de fresa (\% del puré fresco) } \\
Tratamiento & \multicolumn{2}{c}{ 0 días } & \multicolumn{2}{c}{$\mathbf{3 0}$ días } & $\mathbf{6 0}$ días \\
& Media & Desv.típica & Media & Desv. típica & Media \\
\hline Puré fresco & 100 & - & - & - & - \\
$75^{\circ} \mathrm{C}-15 \mathrm{~s}$ & 14,6 & 0,5 & 4,1 & 0,9 & 0,0 \\
$90^{\circ} \mathrm{C}-20 \mathrm{~s}$ & 12,7 & 0,4 & 4,2 & 0,2 & 0,0 \\
$90^{\circ} \mathrm{C}-2 \mathrm{~min}$ & 7,3 & 0,3 & 2,4 & 0,13 & 0,0 \\
\hline
\end{tabular}

IV.2.3. Polifenoloxidasa.

La figura IV.2.4 muestra los resultados de la actividad PPO residual de las muestras de puré de fresa fresco y sometidas a los diversos tratamientos térmicos. Como puede observarse las PPO de la fresa presenta un alto nivel de termorresistencia, pues incluso con el tratamiento de envasado en caliente $\left(90^{\circ} \mathrm{C}-2\right.$ minutos) queda una actividad residual del $16 \%$.

Ensayos adicionales, que se muestran en la tabla IV.2.3 señalan que esta actividad se mantiene tanto en el almacenamiento refrigerado como a temperatura ambiente $\left(21^{\circ} \mathrm{C}\right)$. 


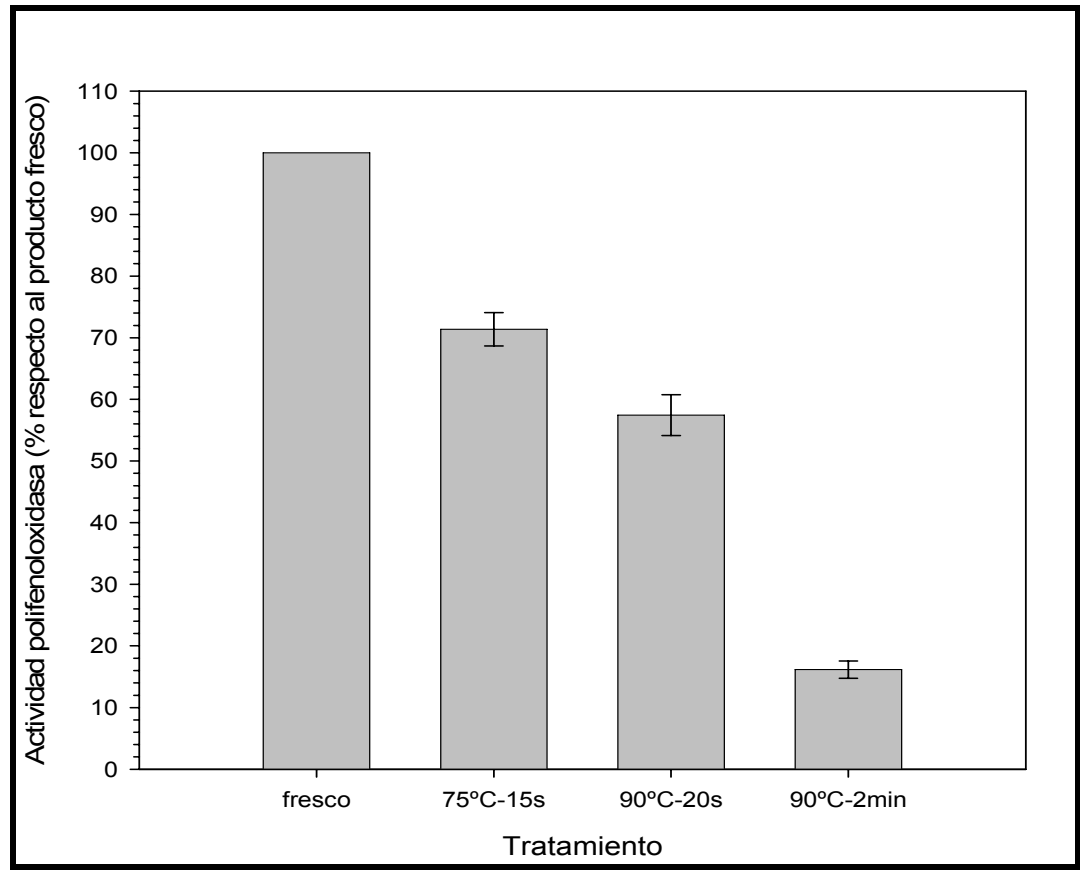

Figura IV.2.4. Actividad PPO a tiempo cero. Las barras indican el valor promedio de 3 determinaciones referidos al producto fresco y las líneas de error muestran la desviación típica.

Cabe concluir que los purés de fresa tratados térmicamente pueden mantener una actividad residual PPO nada despreciable y que debe comprobarse si esta actividad afecta a algunos de los parámetros de calidad del producto (sabor, color, etc.) durante su vida útil. 
Tabla IV.2.3. Valores de actividad PPO del puré de fresa almacenado a 3 y $21^{\circ} \mathrm{C}$.

\begin{tabular}{lcccc}
\hline & & \multicolumn{4}{c}{$\begin{array}{c}\text { Actividad PPO del puré de fresa } \\
\text { (\% respecto del al puré fresco })^{*}\end{array}$} \\
Tratamiento & $\begin{array}{c}\text { Temperatura } \\
\text { almacenamiento }\end{array}$ & $\mathbf{0}$ días & $\mathbf{3 0}$ días & $\mathbf{6 0}$ días \\
\hline Puré fresco & & 100 & - & - \\
$75^{\circ} \mathrm{C}-15 \mathrm{~s}$ & $3^{\circ} \mathrm{C}$ & $71,39 \pm 6,61$ & $75,37 \pm 6,38$ & $67,53 \pm 0,79$ \\
$90^{\circ} \mathrm{C}-20 \mathrm{~s}$ & $3^{\circ} \mathrm{C}$ & $57,46 \pm 8,10$ & $66,07 \pm 8,22$ & $59,91 \pm 0,81$ \\
$90^{\circ} \mathrm{C} 2 \mathrm{~min}$ & $3^{\circ} \mathrm{C}$ & $16,16 \pm 3,44$ & $13,47 \pm 0,63$ & $20,44 \pm 1,25$ \\
$90^{\circ} \mathrm{C}-20 \mathrm{~s}$ & $21^{\circ} \mathrm{C}$ & - & $59,84 \pm 4,58$ & $57,47 \pm 1,83$ \\
$90^{\circ} \mathrm{C} 2 \mathrm{~min}$ & $21^{\circ} \mathrm{C}$ & - & $15,07 \pm 1,30$ & $18,87 \pm 1,15$ \\
\hline
\end{tabular}

${ }^{*}$ Media de 3 repeticiones \pm desviación típica. 


\section{IV.3. EFECTO DEL TRATAMIENTO TÉRMICO Y DEL ALMACENAMIENTO EN EL CONTENIDO DE ANTOCIANIDINAS, VITAMINA C Y ACTIVIDAD ANTIRRADICAL.}

\section{IV.3.1. Efecto del tratamiento térmico y del almacenamiento en el contenido de antocianidinas.}

En la figura IV.3.1 se muestra el contenido total de pelargonidina y cianidina en el puré de fresa en función del tratamiento térmico a que ha sido sometida la muestra. Tanto la pelargonidina como la cianidina soportan perfectamente el tratamiento térmico, puesto que no se han detectado diferencias significativas entre muestras.

La figura IV.3.2 muestra, para cada uno de los tratamientos térmicos a los que ha sido sometido el puré de fresa, la variación en el contenido de pelargonidina y cianidina con el tiempo y temperatura de almacenamiento. En las muestras almacenadas a $3^{\circ} \mathrm{C}$ los cambios no fueron significativos. Las muestras sometidas a un mayor tratamiento térmico $\left(90^{\circ} \mathrm{C}-20\right.$ s y $90^{\circ} \mathrm{C}-2 \mathrm{~min}$, figuras IV.3.1 B y IV.3.1.C) cuando se conservan a temperatura ambiente $\left(21^{\circ} \mathrm{C}\right)$, sufren un significativo descenso en la concentración de pelargonidina y cianidina. Al cabo de 1 mes a temperatura ambiente, las concentraciones de pelargonidina y cianidina son del orden del $50 \%$ de las iniciales y continúan experimentando un descenso, significativo aunque más moderado, entre el $1^{\mathrm{er}}$ y el $2^{\circ}$ mes. 


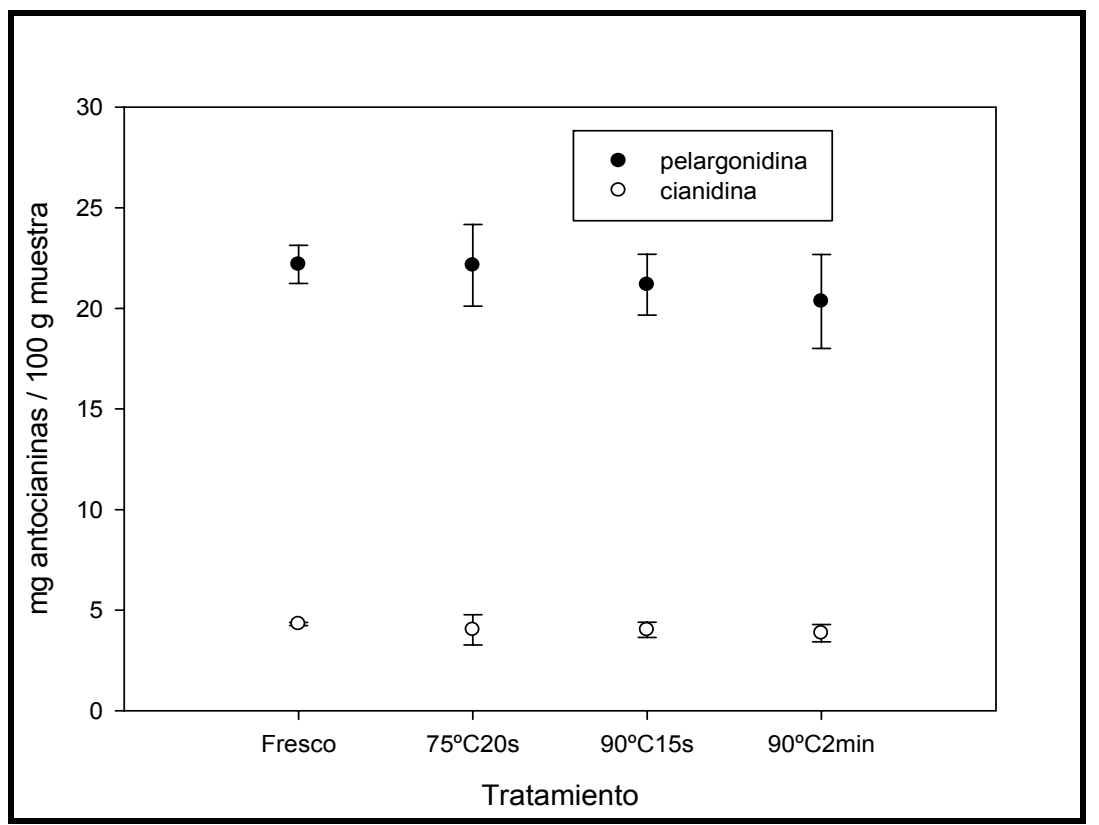

Figura IV.3.1. Variación del contenido total en pelargonidina y cianidina (en $\mathrm{mg} / 100 \mathrm{~g}$ ) según el tratamiento a que ha sido sometida la muestra.

Se puede concluir que la temperatura del almacenamiento afecta al contenido de antocianinas del puré de fresa más que el tratamiento térmico recibido por cada muestra. Si las muestras se almacenan en refrigeración $\left(3^{\circ} \mathrm{C}\right)$, al cabo de 2 meses de almacenamiento su contenido en antocianinas no difiere significativamente del que se da en el producto fresco. 


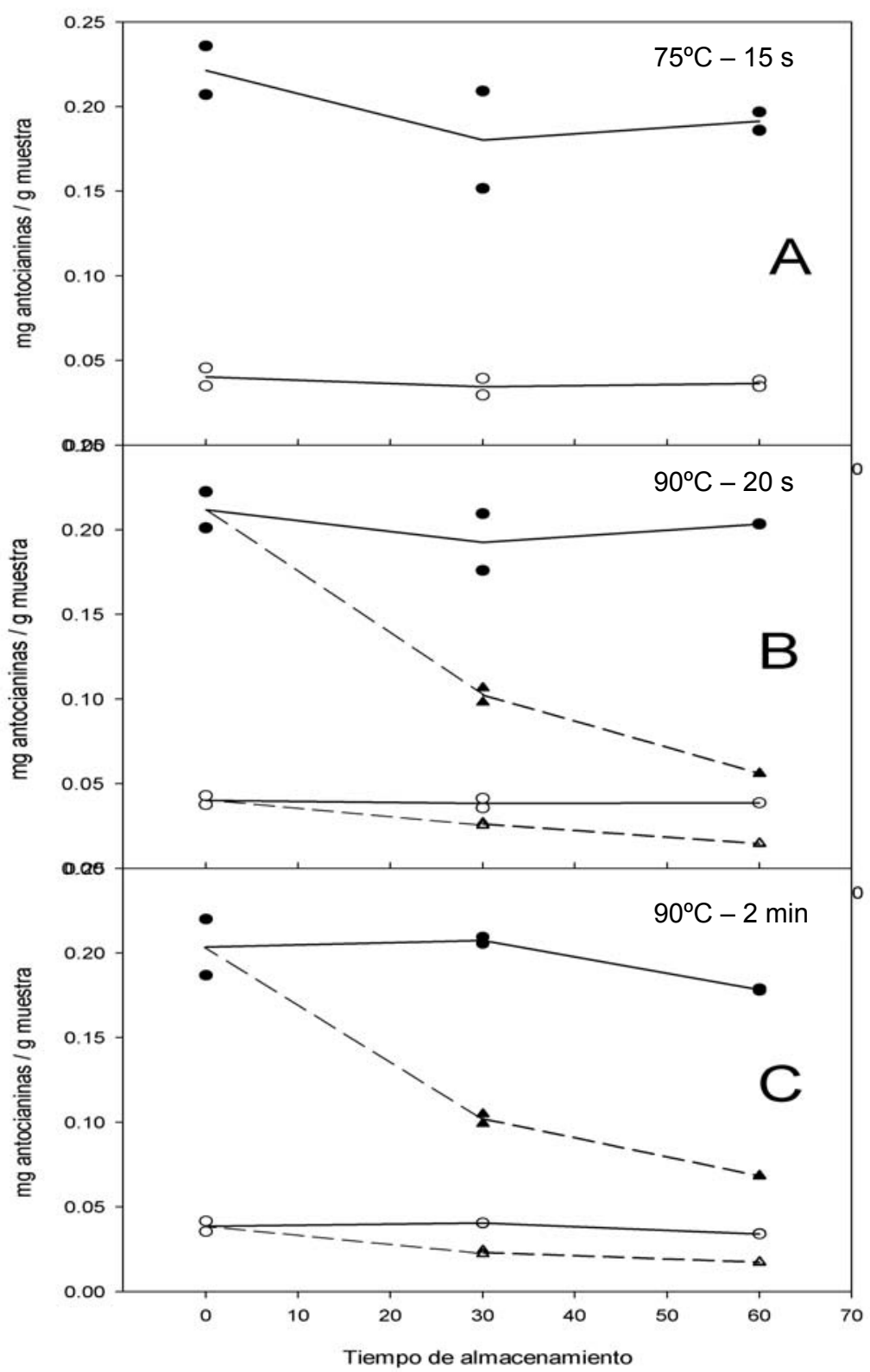

Figura IV.3.2. Variación del contenido total de pelargonidina $(\bullet)$ y de cianidina (०) en función del tiempo de almacenamiento a $3^{\circ} \mathrm{C}$ (líneas contínuas). En las figuras B y $C$ también se representa el contenido en pelargonidina $(\boldsymbol{\Delta})$ y cianidina $(\Delta)$ en almacenamiento a temperatura ambiente $\left(21^{\circ} \mathrm{C}\right.$, líneas discontínuas). 
IV.3.2. Efecto del tratamiento térmico y del almacenamiento en el contenido de vitamina $\mathrm{C}$.

La figura IV.3.3 muestra la influencia del tratamiento térmico en el contenido de vitamina $\mathrm{C}$ y acido ascórbico del puré de fresa. Se puede considerar que el contenido de ácido ascórbico y de vitamina $\mathrm{C}$ se mantiene inalterado con el tratamiento térmico.

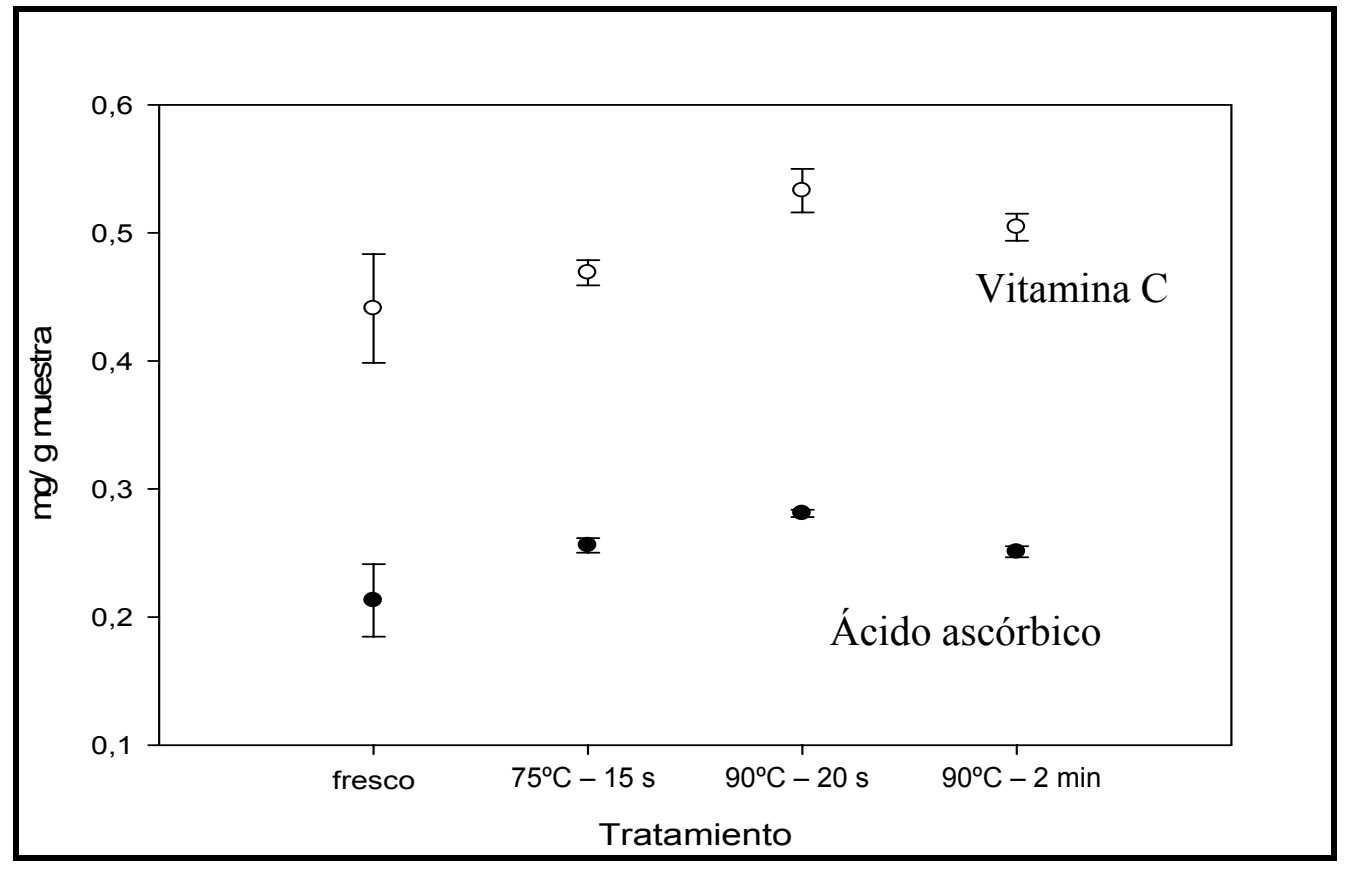

Figura IV.3.3. Variación del contenido en ácido ascórbico y vitamina C (en mg/g) en función del tratamiento térmico a que ha sido sometido el puré de fresa. 
Con el fin de conocer la sensibilidad de la vitamina $\mathrm{C}$ y del ácido ascórbico al tratamiento térmico, se aplicaron tratamientos más intensos, también a $90^{\circ} \mathrm{C}$, pero durante prolongados períodos de tiempo. Los resultados se muestran en la figura IV.3.4. Como se puede observar existe un progresivo y significativo descenso de la vitamina $\mathrm{C}$ y el ácido ascórbico cuando el tratamiento se prolonga bastantes minutos. Sin embargo, según los resultados comentados anteriormente, las diferencias son mínimas cuando el tratamiento se limita a un par de minutos, el más intenso de los que se ha decidido aplicar en esta tesis al puré de fresa.

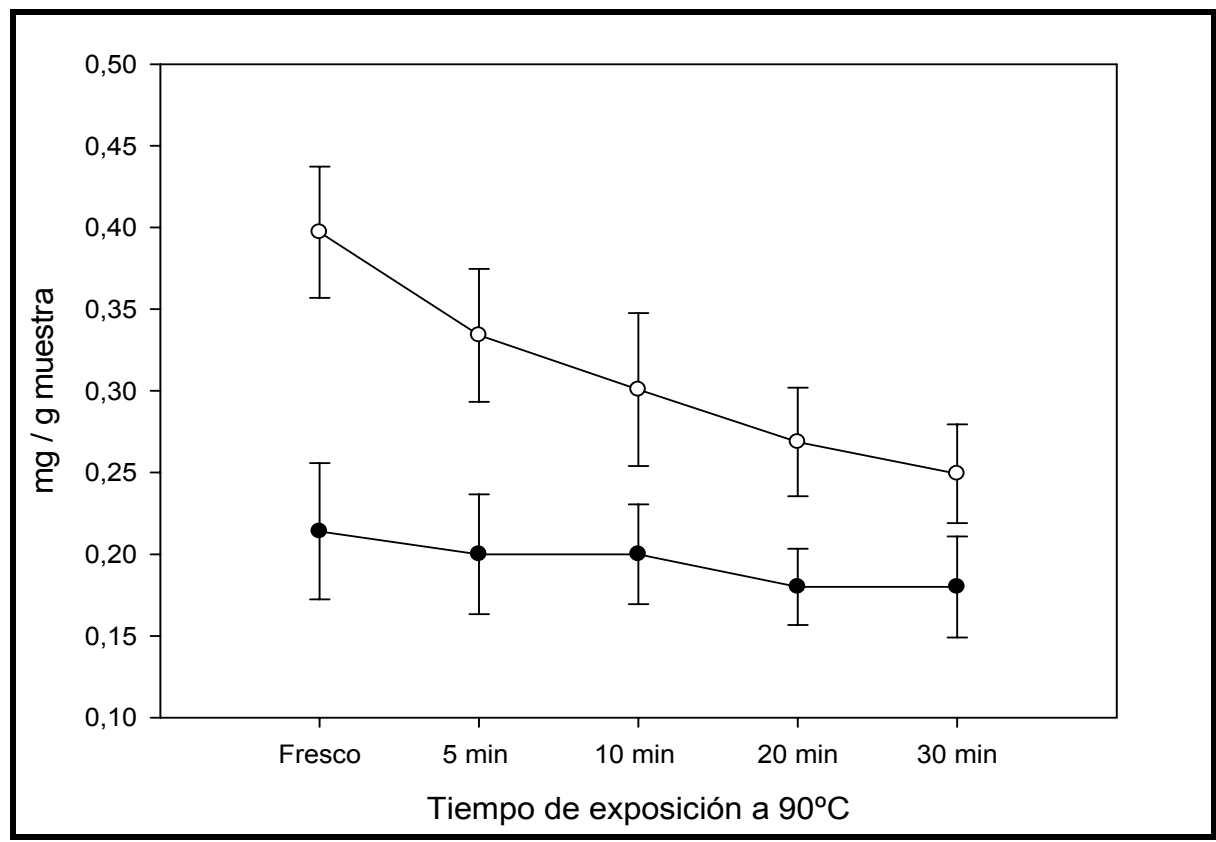

Figura IV.3.4. Variación del contenido en vitamina C ( ○ ) y ácido ascórbico (• ) en función del tiempo de exposición de la muestra a una temperatura de $90^{\circ} \mathrm{C}$. 
En la figura IV.3.5 se muestra la variación de vitamina C y ácido ascórbico en función del tiempo de almacenamiento para cada una de las muestras sometidas a los diversos tratamientos térmicos ensayados con el puré de fresa.

En todos los tratamientos se observa que el contenido en vitamina $\mathrm{C}$ disminuyó considerablemente después de 30 días de almacenamiento, pero entre los 30 y 60 días de almacenamiento prácticamente se mantiene constante. Esta disminución es, en parte, consecuencia de la disminución del contenido en ácido ascórbico que también se observa en ese periodo. Los ensayos de almacenamiento a $21^{\circ} \mathrm{C}$, con los purés tratados a $90^{\circ} \mathrm{C}-20 \mathrm{~s}$ y $90^{\circ} \mathrm{C}-2 \mathrm{~min}$, muestran una tendencia similar, con un descenso algo más acusado. 


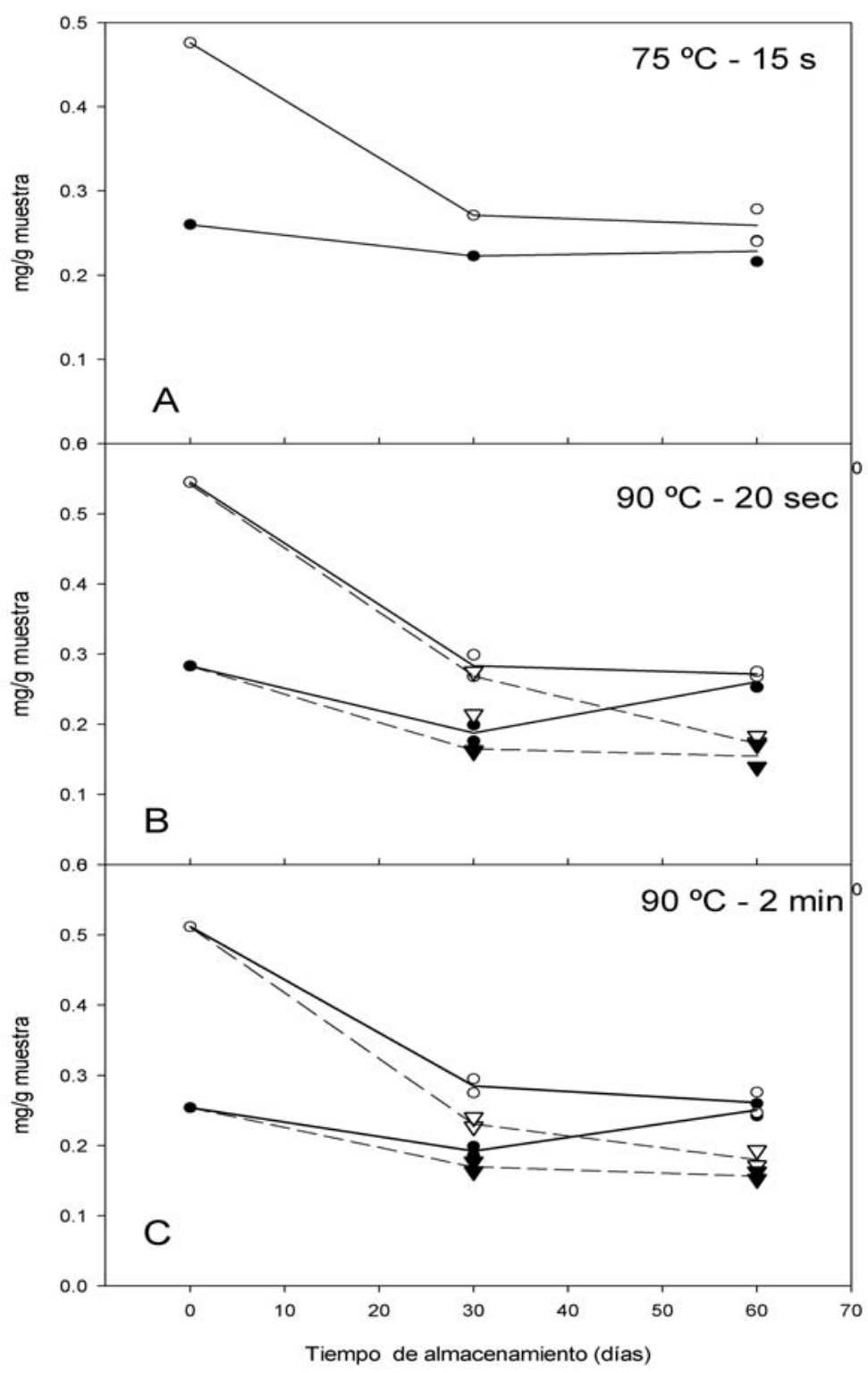

Figura IV.3.5. Variación del contenido en vitamina C (০) y ácido ascórbico (•) en función del tiempo de almacenamiento a $3{ }^{\circ} \mathrm{C}$ (líneas contínuas). En las figuras $\mathrm{B}$ y $C$ también se representa el contenido en vitamina $C(\nabla)$ y ácido ascórbico $(\boldsymbol{\nabla})$ en almacenamiento a temperatura ambiente $\left(21^{\circ} \mathrm{C}\right.$, líneas discontínuas). 


\section{IV.3.3. Efecto del tratamiento térmico y del almacenamiento en la actividad} antirradical.

La tabla IV.3.1 muestra los distintos componentes cinéticos de la actividad antirradical de los purés de fresa frescos y sometidos a diversos tratamientos térmicos, tiempos de conservación y temperaturas de almacenamiento.

Como se indicó anteriormente, la actividad antirradical es consecuencia de la presencia de tres grupos de componentes: los responsables de una cinética rápida $\left(A_{1}\right)$ los de cinética rápida lenta $\left(A_{2}\right)$ y los de cinética lenta $\left(A_{3}\right)$ Como puede observarse, en el puré de fresa existe una participación ponderada de las tres actividades, con un ligero dominio de la cinética lenta, seguido de la cinética rápida y, por último, la cinética rápida-lenta, que también tiene una participación importante.

Los resultados parecen indicar una tendencia a la reducción de la actividad antirradical con la intensidad del tratamiento térmico, con el tiempo de almacenamiento y con la temperatura de almacenamiento, pero las diferencias carecen de significación estadística. Estos resultados contrastan con los que cabría esperar de acuerdo con los descensos observados de la vitamina C y del ácido ascórbico por el tiempo de almacenamiento y por los de las antocianinas de los purés almacenados a temperatura ambiente. Posiblemente la estabilidad de otros componentes presentes en el puré de fresa hayan podido atenuar o enmascarar estos cambios. 
Tabla IV.3.1. Actividad antirradical (milimoles equivalentes de ácido ascórbico /L) del puré de fresa con distintos tratamientos térmicos y condiciones de almacenamiento.

\begin{tabular}{|c|c|c|c|c|c|c|}
\hline \multirow[t]{2}{*}{ Tratamiento } & \multicolumn{2}{|c|}{ Almacenamiento } & \multirow[b]{2}{*}{$A_{t}$} & \multirow[b]{2}{*}{$A_{1}$} & \multirow[b]{2}{*}{$A_{2}$} & \multirow[b]{2}{*}{$A_{3}$} \\
\hline & Días & Temperatura & & & & \\
\hline Fresco & - & - & $3,05 \pm 0,25$ & $0,84 \pm 0,06$ & $0,60 \pm 0,08$ & $1,43 \pm 0,18$ \\
\hline \multirow[t]{3}{*}{$75^{\circ} \mathrm{C}-15 \mathrm{~s}$} & 0 & - & $2,67 \pm 0,30$ & $0,92 \pm 0,08$ & $0,64 \pm 0,11$ & $0,92 \pm 0,03$ \\
\hline & 30 & $3^{\circ} \mathrm{C}$ & $2,89 \pm 0,33$ & $0,80 \pm 0,07$ & $0,67 \pm 0,01$ & $0,80 \pm 0,11$ \\
\hline & 60 & $3^{\circ} \mathrm{C}$ & $2,39 \pm 0,47$ & $0,78 \pm 0,03$ & $0,60 \pm 0,08$ & $0,77 \pm 0,04$ \\
\hline \multirow[t]{5}{*}{$90^{\circ} \mathrm{C}-20 \mathrm{~s}$} & 0 & - & $3,10 \pm 0,13$ & $0,95 \pm 0,15$ & $0,63 \pm 0,05$ & $1,30 \pm 0,37$ \\
\hline & 30 & $3^{\circ} \mathrm{C}$ & $3,07 \pm 0,18$ & $0,88 \pm 0,06$ & $0,60 \pm 0,02$ & $1,41 \pm 0,18$ \\
\hline & 60 & $3^{\circ} \mathrm{C}$ & $2,77 \pm 0,06$ & $0,92 \pm 0,11$ & $0,62 \pm 0,01$ & $1,07 \pm 0,69$ \\
\hline & 30 & $21^{\circ} \mathrm{C}$ & $2,84 \pm 0,17$ & $0,80 \pm 0,10$ & $0,53 \pm 0,05$ & $1,40 \pm 0,15$ \\
\hline & 60 & $21^{\circ} \mathrm{C}$ & $2,69 \pm 0,15$ & $0,95 \pm 0,10$ & $0,50 \pm 0,08$ & $0,94 \pm 0,20$ \\
\hline \multirow[t]{5}{*}{$90^{\circ} \mathrm{C}-2 \min$} & 0 & - & $2,77 \pm 0,47$ & $0,89 \pm 0,11$ & $0,59 \pm 0,07$ & $1,42 \pm 0,27$ \\
\hline & 30 & $3^{\circ} \mathrm{C}$ & $2,95 \pm 0,30$ & $0,89 \pm 0,08$ & $0,66 \pm 0,06$ & $1,38 \pm 0,49$ \\
\hline & 60 & $3^{\circ} \mathrm{C}$ & $2,82 \pm 0,19$ & $0,90 \pm 0,06$ & $0,62 \pm 0,03$ & $1,28 \pm 0,06$ \\
\hline & 30 & $21^{\circ} \mathrm{C}$ & $2,58 \pm 0,16$ & $0,92 \pm 0,10$ & $0,59 \pm 0,05$ & $0,96 \pm 0,10$ \\
\hline & 60 & $21^{\circ} \mathrm{C}$ & $2,46 \pm 0,20$ & $0,87 \pm 0,09$ & $0,51 \pm 0,03$ & $1,24 \pm 0,15$ \\
\hline
\end{tabular}

*Valor medio de dos determinaciones \pm desviación típica 


\section{IV.4. EFECTO DEL TRATAMIENTO TÉRMICO Y DEL ALMACENAMIENTO EN ASPECTOS DE CALIDAD SENSORIAL, COLOR Y REOLOGÍA DEL PURÉ DE FRESA.}

IV.4.1. Efecto del tratamiento térmico y almacenamiento en el comportamiento reológico.

La figura IV.4.1 muestra, como ejemplo, la curva de flujo media obtenida en el barrido ascendente de gradiente de velocidad para cada una de las muestras consideradas antes del almacenamiento. El índice de consistencia, $\mathrm{K}$, y el índice de comportamiento al flujo, $\mathrm{n}$, fueron obtenidos por una regresión no lineal ajustando individualmente cada curva de flujo experimental al modelo de Ostwaldde-Waele. El coeficiente de determinación $\left(R^{2}\right)$ obtenido fue mayor que 0.993 en todos los casos estudiados.

Los parámetros del modelo obtenidos para el puré fresco y tratado térmicamente en función del almacenamiento se muestran en la tabla IV.4.1. Al igual que el puré fresco, en todos estos casos el valor $n$ fue positivo (comportamiento pseudoplástico) aunque también se observó un comportamiento tixotrópico al evaluar la evolución de la curva de flujo con el tiempo de experimentación.. El ANOVA realizado no mostró diferencias significativas $(p>0,05)$ en el valor de este parámetro en las diferentes muestras consideradas recién procesadas. Si que se observó, excepto para el puré envasado en caliente y almacenado a $21^{\circ} \mathrm{C}$, un efecto significativo $(p<0,05)$ del tiempo de 
almacenamiento, de manera que $\mathrm{n}$ aumentó con el tiempo, en relación con una evolución del producto hacia un comportamiento más newtoniano.

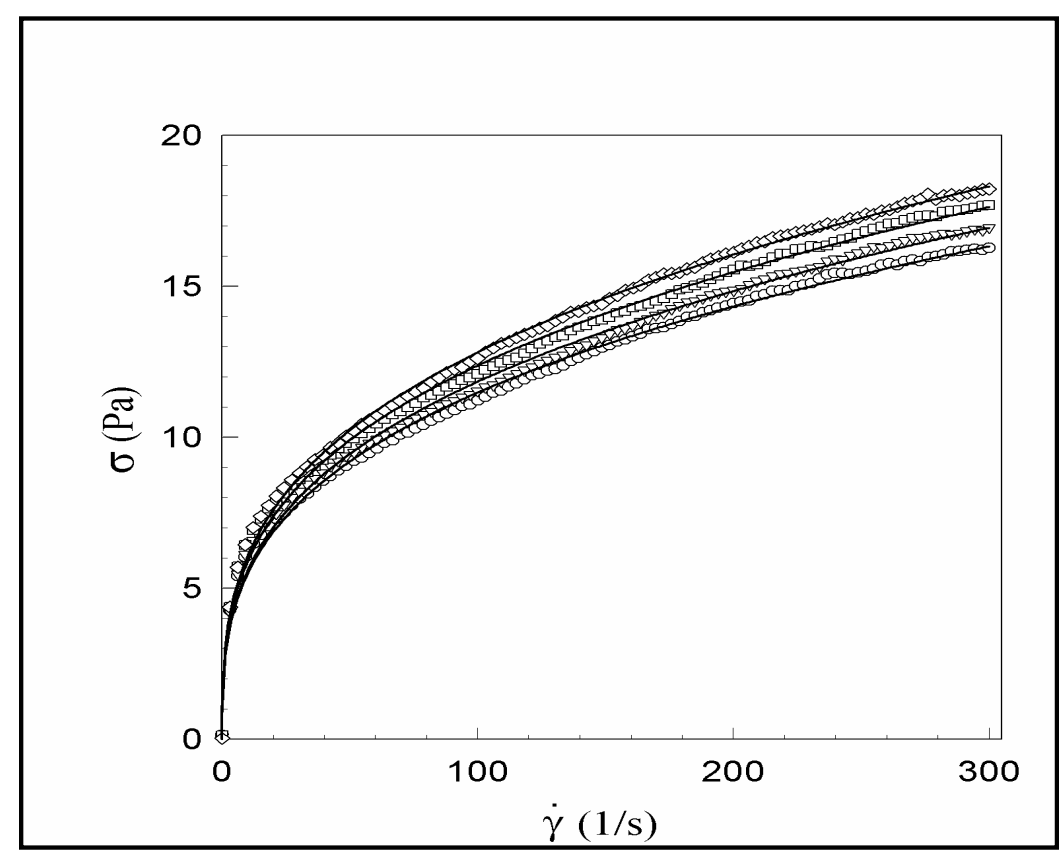

Figura IV.4.1. Comportamiento reológico del puré de fresa fresco y tratado térmicamente. Valor medio de los puntos experimentales $\left(O\right.$ puré fresco, $\nabla 75^{\circ} \mathrm{C}$ $\left.15 \mathrm{~s}, \square 90^{\circ} \mathrm{C}-20 \mathrm{~s} ; \diamond 90^{\circ} \mathrm{C}-2 \mathrm{~min}\right)$ y modelo de Ostwald-de-Waele ajustado (líneas continuas). 
Tabla IV.4.1. Índice de consistencia (K), índice de comportamiento al flujo (n) y área relativa de histéresis de las muestras de puré de fresa tratadas térmicamente.

\begin{tabular}{|c|c|c|c|c|c|}
\hline \multirow[t]{2}{*}{ Tratamiento } & \multicolumn{2}{|c|}{$\begin{array}{c}\text { Temperatura Tiempo } \\
\text { almacenamiento }\end{array}$} & \multicolumn{2}{|c|}{$\begin{array}{l}\text { Parámetros } \\
\text { reológicos }\end{array}$} & \multirow{2}{*}{$\begin{array}{c}\text { Área } \\
\text { relativa de } \\
\text { histéresis } \\
(\%)\end{array}$} \\
\hline & $\left({ }^{\circ} \mathrm{C}\right)$ & (dias) & $K\left(P a . s^{n}\right)$ & $\mathrm{n}$ & \\
\hline Fresco & & & $2,53 \pm 0,11^{b c}$ & $0,328 \pm 0,007^{f g}$ & $3,3 \pm 0,5^{a}$ \\
\hline \multirow[t]{3}{*}{$75^{\circ} \mathrm{C}-15 \mathrm{~s}$} & - & 0 & $2,67 \pm 0,05^{b}$ & $0,324 \pm 0,001^{g h}$ & $3,8 \pm 0,5^{a}$ \\
\hline & 3 & 30 & $1,55 \pm 0,11^{f}$ & $0,375 \pm 0,013^{c}$ & $12,7 \pm 0,7^{d}$ \\
\hline & 3 & 60 & $1,25 \pm 0,01^{g}$ & $0,387 \pm 0,001^{b}$ & $13,9 \pm 1,6^{d}$ \\
\hline \multirow[t]{3}{*}{$90^{\circ} \mathrm{C}-20 \mathrm{~s}$} & - & 0 & $3,02 \pm 0,19^{a}$ & $0,315 \pm 0,008^{h}$ & $3,2 \pm 0,8^{a}$ \\
\hline & 3 & 30 & $1,73 \pm 0,03^{e}$ & $0,364 \pm 0,003^{d}$ & $16,1 \pm 1,8^{\mathrm{e}}$ \\
\hline & 3 & 60 & $1,12 \pm 0,05^{\mathrm{g}}$ & $0,415 \pm 0,006^{a}$ & $14 \pm 2^{d}$ \\
\hline \multirow[t]{5}{*}{$90^{\circ} \mathrm{C}-2 \mathrm{~min}$} & - & 0 & $2,98 \pm 0,12^{a}$ & $0,320 \pm 0,005^{g h}$ & $5,5 \pm 0,8^{b}$ \\
\hline & 3 & 30 & $2,27 \pm 0,02^{d}$ & $0,346 \pm 0,003^{e}$ & $5,7 \pm 0,6^{b}$ \\
\hline & 3 & 60 & $1,87 \pm 0,01^{\mathrm{e}}$ & $0,370 \pm 0,001^{c d}$ & $9,94 \pm 0,02^{c}$ \\
\hline & 21 & 30 & $2,52 \pm 0,05^{b c}$ & $0,337 \pm 0,003^{\text {ef }}$ & $9,3 \pm 0,4^{c}$ \\
\hline & 21 & 60 & $2,39 \pm 0,11^{\mathrm{cd}}$ & $0,339 \pm 0,005^{e f}$ & $9,8 \pm 0,4^{c}$ \\
\hline
\end{tabular}

Valor medio (calculado a partir de tres repeticiones) \pm desviación estándar.

a, b, c, d, e, f, g, h Grupos homogéneos (á<0.05) establecidos por el ANOVA.

En el caso del índice de consistencia, relacionado con la viscosidad aparente, el puré pasteurizado a $90^{\circ} \mathrm{C}$ durante $20 \mathrm{~s}$ y el envasado en caliente mostraron valores significativamente $(p<0,05)$ mayores que el fresco y el sometido al tratamiento térmico más suave. Esto puede ser debido al efecto de la 103 
temperatura más alta de los tratamientos intensos que, según lo descrito por Contreras et al. (2007), hace aumentar la fracción de pectina soluble en agua y disminuir la soluble en oxalato, lo cual puede incidir en el aumento de la viscosidad en la fase liquida del puré de fresa.

Por su parte, durante el almacenamiento del puré de fresa tratado térmicamente se observó una disminución significativa $(p<0,05)$ en los valores de K. En algunos estudios realizados con puré de tomate, la disminución de la viscosidad del producto térmicamente tratado se ha relacionado con una actividad enzimática residual (Vercet et al., 2002; Krebbers et al., 2003; Plaza et al., 2003). En este caso, la actividad residual de la PME puede no ser la única responsable de estos cambios, puesto que la enzima parece haberse inactivado totalmente en las muestras envasadas en caliente. En este sentido, otros cambios químicos o estructurales ocurridos durante el almacenamiento de las muestras deben ser los responsables de la disminución de la viscosidad observada.

Para analizar el efecto del almacenamiento en el índice de consistencia, se calculó su disminución relativa considerando su valor a los 0 y 60 días de almacenamiento a $3^{\circ} \mathrm{C}\left(K_{t=0}\right.$ y $K_{t=60}$, respectivamente), según la ecuación IV.2. Ésta fue del $53 \%$ para las muestras tratadas a $75^{\circ} \mathrm{C}-15 \mathrm{~s}$, del $63 \%$ para las muestras a $90^{\circ} \mathrm{C}-20$ s y del $37 \%$ para las muestras a $90^{\circ} \mathrm{C}-2$ min. Si se considera el efecto comentado de los tratamientos térmicos intensos de promover la solubilización de la pectina, es posible que la mayor cantidad de fracción de pectina soluble en agua sea más accesible a la actividad residual de la PME, a pesar de la existencia de otra clase de reacciones. 


$$
\frac{K_{t=0}-K_{t=60}}{K_{t=0}}
$$

Si se compara el comportamiento reológico del puré envasado en caliente almacenado en refrigeración con el almacenado a $21^{\circ} \mathrm{C}$ (tabla IV.4.1), se observan valores de $\mathrm{K}$ significativamente $(p<0.05)$ mayores en los almacenados a temperatura ambiente. Esto podría justificarse en base a la mayor movilidad de las partículas a temperatura ambiente, que puede causar un aumento de las interacciones de la pectina induciendo un aumento de la consistencia del producto (Vercet et al., 2002).

Cuando se estudió el efecto del tiempo de cizalla en el comportamiento reológico de las muestras se observó, al igual que en el puré fresco, un área de histéresis entre las curvas de flujo obtenidas en el barrido ascendente y descendente de gradientes de velocidad que mostró un comportamiento tixotrópico en todos los casos. Dado que las curvas ascendentes de todas las muestras no son iguales, para poder comparar el efecto del tiempo de cizalla en las distintas muestras se calculó el área relativa de histéresis (tabla IV.4.1). No se encontraron diferencias significativas en el comportamiento tixotrópico de las muestras frescas y tratadas térmicamente, a excepción de las envasadas en caliente que mostraron valores mayores. Esto de nuevo puede estar relacionado con una mayor cantidad de pectina soluble en agua presente en estas muestras, que formaría un entramado macromolecular más orientable con el flujo responsable de la mayor área de histéresis detectada. 
En todos los casos se observó un aumento significativo del área relativa de histéresis con el tiempo de almacenamiento, asociada a la disminución observada de la viscosidad que aumentaría la movilidad de las partículas. Durante el almacenamiento a $3^{\circ} \mathrm{C}$, las muestras envasadas en caliente parecen ser las más estables, dado el valor más bajo de su área relativa de histéresis. Las muestras envasadas en caliente almacenadas a $21^{\circ} \mathrm{C}$ mostraron mayor carácter tixotrópico después de 30 días de almacenamiento que las envasadas en caliente y almacenadas a $3^{\circ} \mathrm{C}$. Esto podría explicarse si la progresión de las interacciones de la pectina que ocurren durante el almacenamiento a temperatura ambiente, comentadas anteriormente, alcanzan un máximo a los 30 días. Estos resultados y su relación con la actividad PME han sido aceptados para su publicación (Osorio et al., 2008).

\section{IV.4.2. Efecto del tratamiento térmico y almacenamiento en la calidad} sensorial.

En referencia al aspecto sensorial, el sabor a fresco de las muestras se vio afectado por los tratamientos térmicos, tal como se muestra en la tabla IV.4.2. Se encontraron grandes y significativas diferencias, según la prueba de ordenación realizada entre el puré fresco y las tres muestras tratadas térmicamente. No obstante, no se detectaron diferencias entre las muestras tratadas, con diferencias en la suma de las puntuaciones mucho menores de 32 (diferencia mínima significativa). De acuerdo a los comentarios de los jueces, las diferencias entre las 
muestras frescas y las procesadas eran debidas a la pérdida de la intensidad del sabor a fresco, pero no al desarrollo de sabor a cocido u olores extraños. Así pues los purés de fresa resistieron satisfactoriamente los tratamientos de calor intensos, aunque a costa de perder una parte importante de su delicado sabor a fresco.

Tabla IV.4.2. Resultados del test de ordenación comparando la aceptabilidad del puré fresco y el tratado térmicamente.

\begin{tabular}{|c|c|c|}
\hline & Tratamiento & $\begin{array}{l}\text { Suma de puntuaciones } \\
\text { (48 jueces) }\end{array}$ \\
\hline \multirow{4}{*}{ 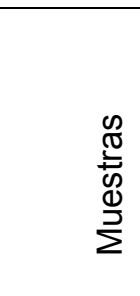 } & Fresco & 81 \\
\hline & Pasteurizado $75^{\circ} \mathrm{C}-15 \mathrm{~s}$ & 140 \\
\hline & Pasteurizado $90^{\circ} \mathrm{C}-20 \mathrm{~s}$ & 132 \\
\hline & Envasado caliente $\left(90^{\circ} \mathrm{C}->2 \mathrm{~min}\right)$ & 127 \\
\hline \multicolumn{2}{|c|}{$\begin{array}{l}\text { Diferencia mínima significativa en la suma de } \\
\text { puntuaciones ( } p 0.05 \text {, test de Tukey) }\end{array}$} & 32 \\
\hline
\end{tabular}

Los análisis de almacenamiento refrigerado $\left(3^{\circ} \mathrm{C}\right)$ mostraron como ambos purés pasteurizados de fresa mantuvieron su aceptabilidad inicial durante dos meses, tiempo de vida comercial habitual de este tipo de productos de fruta. Como puede observarse en la tabla IV.4.3, la diferencia de la suma de puntuaciones entre muestras no excedieron en ningún caso la diferencia mínima significativa de 50. La alta actividad residual de la PME del puré de fresas pasteurizado a $75^{\circ} \mathrm{C}$ 15s y de la PPO en todas las muestras no afectó significativamente a las 
características sensoriales del producto al final de los 2 meses de almacenamiento refrigerado.

Tabla IV.4.3. Resultados del test de ordenación comparando la aceptabilidad del puré de fresa pasteurizado y almacenado a $3^{\circ} \mathrm{C}$

\begin{tabular}{|c|c|c|c|}
\hline & Tratamiento & $\begin{array}{l}\text { Almacenamiento } \\
\text { (días) }\end{array}$ & $\begin{array}{c}\text { Suma de } \\
\text { puntuaciones } \\
\text { (44 jueces) }\end{array}$ \\
\hline \multirow{6}{*}{ 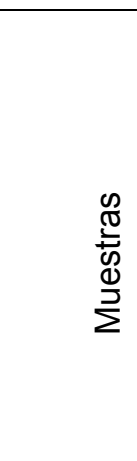 } & \multirow{3}{*}{ Pasteurizado $75^{\circ} \mathrm{C}-15 \mathrm{~s}$} & 0 & 180 \\
\hline & & 30 & 142 \\
\hline & & 60 & 171 \\
\hline & \multirow{3}{*}{ Pasteurizado $90^{\circ} \mathrm{C}-20 \mathrm{~s}$} & 0 & 149 \\
\hline & & 30 & 135 \\
\hline & & 60 & 147 \\
\hline \multicolumn{3}{|c|}{$\begin{array}{l}\text { Diferencia mínima significativa en la suma de puntuaciones } \\
\text { (p 0.05, test de Tukey) }\end{array}$} & 50 \\
\hline
\end{tabular}

Las muestras pasteurizadas necesitan el almacenamiento refrigerado, pero los purés de frutas ácidas envasados en caliente son alimentos esterilizados que habitualmente se almacenan a temperatura ambiente. En el caso de puré de fresa recién procesado, para el que no se detectó diferencia en la aceptabilidad entre los productos pasteurizados y los envasados en caliente, es interesante saber la evolución del sabor de este último durante el almacenamiento en refrigeración y a temperatura ambiente. La tabla IV.4.4 muestra los resultados 108 
obtenidos de este análisis. Según puede observarse, la suma de puntuaciones de los purés almacenados a temperatura ambiente excede a los de las respectivas muestras refrigeradas en valores superiores a la diferencia mínima significativa. Por lo tanto, el puré envasado en caliente mantuvo su aceptabilidad inicial durante dos meses de almacenamiento refrigerado pero no cuando se almacena a temperatura ambiente. Estos resultados han sido aceptados para su publicaciòn (Osorio et al., 2008).

Tabla IV.4.4. Resultados del test de ordenación comparando la aceptabilidad del puré de fresa envasado en caliente y almacenado a $3^{\circ} \mathrm{C}$ y a $21^{\circ} \mathrm{C}$.

\begin{tabular}{|c|c|c|c|}
\hline & $\begin{array}{c}\text { Temperatura } \\
\text { almacenamiento }\end{array}$ & $\begin{array}{l}\text { Tiempo de } \\
\text { almacenamiento } \\
\text { (días) }\end{array}$ & $\begin{array}{l}\text { Suma de } \\
\text { puntuaciones } \\
\text { (27 jueces) }\end{array}$ \\
\hline & Muestra inicial & 0 & 72 \\
\hline \multirow{5}{*}{ 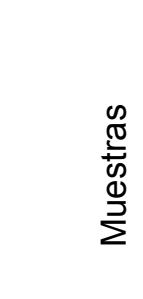 } & \multirow{3}{*}{$3^{\circ} \mathrm{C}$} & 30 & 61 \\
\hline & & 60 & 57 \\
\hline & & 60 & $5 /$ \\
\hline & \multirow{2}{*}{$21^{\circ} \mathrm{C}$} & 30 & 94 \\
\hline & & 60 & 121 \\
\hline \multicolumn{3}{|c|}{$\begin{array}{l}\text { Diferencia mínima significativa en la suma de puntuaciones } \\
\text { (p 0.05, test de Tukey) }\end{array}$} & 31.7 \\
\hline
\end{tabular}


IV.4.3. Efecto del tratamiento térmico y del almacenamiento en el color.

La tabla IV.4.5 muestra los resultados de las coordenadas y atributos de color medidos en los purés de fresa sometidos a los diferentes tratamientos térmicos y la correspondiente muestra de puré fresco desaireado.

Tabla IV.4.5. Efecto del tratamiento térmico en las coordenadas de color CIEL*a* $b^{*}$ y en los atributos de color croma $\left(C^{*}\right)$ y tono $\left(h^{*}\right)$ del puré de fresa. Valor medio \pm desviación estándar de 5 repeticiones.

\begin{tabular}{lcccccc}
\hline $\begin{array}{l}\text { Tratamiento } \\
\text { térmico }\end{array}$ & $\mathbf{L}^{*}$ & $\mathbf{a}^{*}$ & $\mathbf{b}^{*}$ & $\mathbf{C}^{*}$ & $\mathbf{h}^{*}$ & $\Delta \mathbf{E}^{(1)}$ \\
\hline No tratado & $24,1 \pm 0,5^{\mathrm{a}}$ & $33,1 \pm 1,1^{\mathrm{a}}$ & $22 \pm 4^{\mathrm{a}}$ & $40 \pm 2^{\mathrm{a}}$ & $34 \pm 5^{\mathrm{a}}$ & \\
$75^{\circ} \mathrm{C}-15 \mathrm{~s}$ & $27,4 \pm 0,3^{\mathrm{b}}$ & $36,5 \pm 0,7^{\mathrm{b}}$ & $26 \pm 3^{\mathrm{b}}$ & $44,6 \pm 1,7^{\mathrm{b}}$ & $35 \pm 4^{\mathrm{a}}$ & 7,7 \\
$90^{\circ} \mathrm{C}-20 \mathrm{~s}$ & $26,1 \pm 0,3^{\mathrm{c}}$ & $36,1 \pm 0,8^{\mathrm{bc}}$ & $26 \pm 2^{\mathrm{b}}$ & $44,6 \pm 0,8^{\mathrm{b}}$ & $36 \pm 3^{\mathrm{a}}$ & 7,0 \\
90 으-2 min & $23,7 \pm 0,4^{\mathrm{a}}$ & $34,7 \pm 1,4^{\text {ac }}$ & $25 \pm 3^{\mathrm{b}}$ & $43 \pm 2^{\mathrm{b}}$ & $36 \pm 3^{\mathrm{a}}$ & 5,1 \\
\hline $\begin{array}{l}\text { Letras iguales en cada columna implica ausencia de diferencias estadísticamente significativas } \\
\text { (p<0.05). } \\
\text { (1) Diferencia de color entre las muestras tratadas térmicamente y la no tratada. }\end{array}$
\end{tabular}

La mayoría de las muestras tratadas térmicamente mostraron un incremento en todos los parámetros $\mathrm{CIEL}^{*} \mathrm{a}^{*} \mathrm{~b}^{*}$ con respecto al puré sin tratar. La coordenada $b^{*}$ el tono y el croma no cambiaron significativamente por la intensidad del tratamiento. La luminosidad y la coordenada $a^{*}$ fueron los 
parámetros $\mathrm{CIEL}^{*} \mathrm{a}^{*} \mathrm{~b}^{*}$ más sensibles al mismo, con un comportamiento similar a la desaireación. El tratamiento suave a $75^{\circ} \mathrm{C}$ durante $15 \mathrm{~s}$ causó un incremento significativo en los valores $L^{*}$ y $a^{*}$, que fueron menos acusados en los tratamientos más fuertes. El cambio de color global por efecto del tratamiento térmico (Tabla IV.4.5) resultó ser independiente de la intensidad del mismo.

La conservación en refrigeración de los purés de fresa tratados térmicamente indujo pequeños cambios, aunque significativos, en las muestras almacenadas durante dos meses (Tabla IV.4.6).

El comportamiento de los tres tipos de purés tratados térmicamente fue similar, con un pequeño aumento de la luminosidad y una pequeña disminución de la coordenada $a^{*}$. Estos cambios fueron más pronunciados en las dos muestras almacenadas a $21^{\circ} \mathrm{C}$, donde se observa una clara pérdida de color.

En todos los grupos de muestras tratadas por el mismo proceso térmico, los cambios en los parámetros de color no fueron significativos en los primeros 30 días, pero cambiaron drásticamente entre 30 y 60 días de almacenamiento. Estos cambios afectaron principalmente al parámetro $b^{*}$, poniendo de manifiesto una variación de las tonalidades amarillentas hacia tonalidades azuladas, que se refleja tanto en el cambio del tono como en las diferencias de color calculadas (Tabla IV.4.6). Los cambios entre 30 y 60 días fueron obviamente mucho más altos cuando los purés de fresa fueron almacenados a $21^{\circ} \mathrm{C}$. 
Tabla IV.4.6. Efecto del almacenamiento en las coordenadas de color $\mathrm{CIEL}^{*} \mathrm{a}^{*} \mathrm{~b}^{*} \mathrm{y}$ en los atributos de color croma $\left(\mathrm{C}^{*}\right)$ y tono $\left(\mathrm{h}^{*}\right)$ del puré de fresa. Valor medio \pm desviación estándar de 5 repeticiones.

\begin{tabular}{|c|c|c|c|c|c|c|c|c|}
\hline \multirow{2}{*}{$\begin{array}{l}\text { Tratamiento } \\
\text { térmico }\end{array}$} & \multicolumn{2}{|c|}{ Almacenamiento } & \multirow[t]{2}{*}{$L^{*}$} & \multirow[t]{2}{*}{$a^{*}$} & \multirow[t]{2}{*}{$\mathbf{b}^{*}$} & \multirow[t]{2}{*}{$\mathrm{C}^{*}$} & \multirow[t]{2}{*}{$\mathbf{h}^{*}$} & \multirow[t]{2}{*}{$\Delta \mathrm{E}^{(1)}$} \\
\hline & $\begin{array}{c}\text { t } \\
\text { (días) }\end{array}$ & $\begin{array}{c}\mathrm{T} \\
\left({ }^{\circ} \mathrm{C}\right)\end{array}$ & & & & & & \\
\hline \multirow[t]{3}{*}{$75 \div C-15 s$} & 0 & - & $27.4 \pm 03^{a}$ & $36.5 \pm 0.6^{a}$ & $26 \pm 3^{a}$ & $44.6 \pm 1.5^{a}$ & $35 \pm 3^{a}$ & - \\
\hline & 30 & $3 \circ \mathrm{C}$ & $27.7 \pm 0.7^{a}$ & $35.7 \pm 1.0^{a}$ & $26 \pm 2^{a}$ & $44.0 \pm 1.1^{\mathrm{a}}$ & $36 \pm 3^{a}$ & 0.86 \\
\hline & 60 & $3 \circ \mathrm{C}$ & $32.0 \pm 0.6^{b}$ & $32.5 \pm 0.7^{b}$ & $9.6 \pm 0.7^{b}$ & $33.9 \pm 0.8^{b}$ & $16 \pm 1^{\mathrm{b}}$ & 17.08 \\
\hline \multirow[t]{5}{*}{$90 \div \mathrm{C}-20 \mathrm{~s}$} & 0 & - & $26.0 \pm 0.3^{a}$ & $36.1 \pm 0.8^{\mathrm{a}}$ & $26 \pm 2^{a}$ & $44.6 \pm 0.7^{a}$ & $36 \pm 3^{a}$ & - \\
\hline & 30 & $3 \circ \mathrm{C}$ & $26.4 \pm 0.2^{\mathrm{a}}$ & $36.2 \pm 0.5^{a}$ & $27 \pm 3^{a}$ & $45.1 \pm 1.1^{\mathrm{a}}$ & $37 \pm 3^{a}$ & 0.96 \\
\hline & 60 & $3 \circ \mathrm{C}$ & $30.1 \pm 0.2^{b}$ & $32.3 \pm 0.8^{b}$ & $13 \pm 1$ & $34.7 \pm 0.9^{b}$ & $21 \pm 2^{b}$ & 14.59 \\
\hline & 30 & $21 \stackrel{\circ}{C}$ & $27.4 \pm 0.2^{c}$ & $31.5 \pm 0.4^{b}$ & $23 \pm 2^{c}$ & $39.3 \pm 1.0^{c}$ & $37 \pm 2^{a}$ & 5.50 \\
\hline & 60 & $21^{\circ} \mathrm{C}$ & $35.0 \pm 0.4^{d}$ & $22.6 \pm 0.6^{c}$ & $0.7 \pm 0.5^{d}$ & $22.6 \pm 0.6^{d}$ & $2 \pm 1^{c}$ & 30.14 \\
\hline \multirow[t]{5}{*}{$90 \div \mathrm{C}-2 \mathrm{~min}$} & 0 & - & $23.7 \pm 0.4^{\mathrm{a}}$ & $34.7 \pm 1.3^{\mathrm{a}}$ & $25 \pm 3^{a}$ & $43 \pm 2^{a}$ & $36 \pm 3^{a}$ & - \\
\hline & 30 & $3 \circ \mathrm{C}$ & $24.9 \pm 0.3^{b}$ & $34.2 \pm 0.9^{a}$ & $26 \pm 2^{a}$ & $43.2 \pm 1.3^{\mathrm{a}}$ & $38 \pm 2^{a}$ & 1.65 \\
\hline & 60 & $3 \circ \mathrm{C}$ & $29.2 \pm 0.4^{c}$ & $31.8 \pm 0.8^{b}$ & $12 \pm 1^{b}$ & $34 \pm 1^{b}$ & $20 \pm 2^{b}$ & 15.01 \\
\hline & 30 & $21^{\circ} \mathrm{C}$ & $27.3 \pm 0.4^{d}$ & $31.3 \pm 0.7^{b}$ & $27 \pm 3^{a}$ & $41 \pm 2^{a}$ & $41 \pm 3^{a}$ & 5.23 \\
\hline & 60 & $21^{\circ} \mathrm{C}$ & $35.8 \pm 0.3^{e}$ & $22.1 \pm 0.8^{c}$ & $1.7 \pm 0.5^{c}$ & $22.2 \pm 0.8^{c}$ & $4 \pm 1^{c}$ & 32.19 \\
\hline
\end{tabular}

Letras iguales en cada columna implica ausencia de diferencias estadísticamente significativas $(p<0.05)$.

(1) Diferencia de color calculada a partir de los valores medios entre cada muestra almacenada y la correspondiente al mismo tratamiento térmico recién procesada. 
La diferencia de color calculada durante el almacenamiento a $3^{\circ} \mathrm{C}$ de las muestras tratadas a $75^{\circ} \mathrm{C}-15 \mathrm{~s}$ y $90^{\circ} \mathrm{C}-20 \mathrm{~s}$, calculada tomando como referencia la correspondiente muestra no almacenada, fue menor de 1,0 unidad después de 30 días. Esto puede considerarse como un cambio de color no apreciable, de acuerdo a valores de $\Delta \mathrm{E}$ publicados para otros jugos similares (Soon-Mi y Gun-Hee, 2002). El cambio de color registrado para el puré de fresa tratado a $90^{\circ} \mathrm{C}-2$ minutos fue un poco más alto $(1,65)$, lo que estaría cerca de 2 , valor considerado umbral para la detección visual de diferencias de color (Francis y Clydesdale, 1975, citado por Hongmei et al., 2007). A los 60 días el cambio de color resultó superior, aunque del mismo orden en todas las muestras. Estos cambios de color sólo pueden relacionarse con la actividad residual de las enzimas oxidativas (Tabla IV.2.2) si se considera que un $16 \%$ dicha actividad residual es suficiente como para inducir los cambios de color observados. Como es lógico, esta actividad enzimàtica es mucho mayor a temperatura ambiente. 


\section{IV.5. ASPECTOS MICROBIÓLOGICOS DEL PURÉ DE FRESA}

Este estudio incluye dos partes. En la primera se estudia la flora contaminante del puré de fresa obtenido en la planta piloto y la que queda tras los tratamientos térmicos aplicados. Estos análisis permiten evaluar la calidad sanitaria de las fresas adquiridas y las condiciones higiénicas de la planta piloto donde se elaboraron los distintos purés. Obviamente también sirvieron para evaluar la seguridad microbiológica de las muestras obtenidas y almacenadas utilizadas en los ensayos de cata. Pero los resultados obtenidos son insuficientes para permitir su extrapolación a escala industrial, dado que los productos fabricados industrialmente suelen tener una contaminación microbiana inicial mucho más elevada. El menor control de la materia prima, cuando se adquiere en grandes cantidades, la mayor permanencia de los productos en curso de elaboración en depósitos, pasadoras, tuberías..., la mayor temperatura habitual en las naves de procesado, la existencia de una flora microbiana adaptada a las condiciones del local y del producto, etc., son las principales causas de esta mayor contaminación microbiana.

Para obtener resultados que permitan predecir el comportamiento de las muestras con alta contaminación frente a los tratamientos térmicos (u otros procesos de conservación), se recurre a la inoculación de los productos a tratar con algún microorganismo modelo que pueda estar en el ambiente y crecer en el producto. En zumos de frutas ácidos, con un pH alrededor de 3,5 (como es el caso del puré de fresa), es frecuente simular la mayor contaminación de la muestra 
inoculando Lactobacillus plantarum (Torres et al., 2008). El producto, con un recuento conocido, se introduce en tubos capilares que se someten a tratamientos térmicos controlados y se obtienen curvas de supervivencia a las distintas temperaturas. La segunda parte del estudio microbiológico aborda la cinética de destrucción por calor de este microorganismo inoculado en puré de fresa previamente clarificado por centrifugación.

IV.5.1. Determinación de la flora mesófila, hongos y levaduras en puré de fresa.

Para el estudio de la flora presente en la pulpa de fresa fresca obtenida a nivel de planta piloto, se tomó una muestra del producto fresco y se realizó recuento de mesófilos, hongos y levaduras. Para evaluar la eficacia de los diferentes tratamientos de pasteurización se tomaron 10 muestras de puré pasteurizado a diferentes combinaciones t- $\mathrm{T}^{\mathrm{a}}\left(70^{\circ} \mathrm{C}-15 \mathrm{~s}, 90^{\circ} \mathrm{C}-20 \mathrm{~s}\right.$ y $\left.90^{\circ} \mathrm{C} 2 \mathrm{~min}\right)$ y almacenados a 3 y $21^{\circ} \mathrm{C}$ durante la vida comercial del producto (dos meses).

La tabla IV.5.1 nos muestra los resultados de los análisis microbiológicos del puré de fresa procesado en planta piloto y almacenado durante 60 días. 
Tabla IV.5.1. Recuento de mohos, levaduras y mesófilos durante el almacenamiento del puré de fresa a 3 y $21^{\circ} \mathrm{C}$ durante 60 días.

\begin{tabular}{|c|c|c|c|}
\hline Tratamiento & $\begin{array}{l}\text { Almacenamiento } \\
\text { (dias/temperatura) }\end{array}$ & $\begin{array}{l}\text { Recuento } \\
\text { total de } \\
\text { mesófilos } \\
\text { aerobios } \\
\text { (UFC/g) }\end{array}$ & $\begin{array}{c}\text { Recuento } \\
\text { total de } \\
\text { mohos y } \\
\text { levaduras } \\
\text { (UFC/g) }\end{array}$ \\
\hline Fresco & 0 & $20-30$ & $<10$ \\
\hline $75^{\circ} \mathrm{C}-15 \mathrm{~s}$ & 0 & $<10$ & $<10$ \\
\hline $90^{\circ} \mathrm{C}-20 \mathrm{~s}$ & 0 & $<10$ & $<10$ \\
\hline $90^{\circ} \mathrm{C}-2 \min$ & 0 & 0 & 0 \\
\hline $75^{\circ} \mathrm{C}-15 \mathrm{~s}$ & $30-3^{\circ} \mathrm{C}$ & $<10$ & $<10$ \\
\hline $90^{\circ} \mathrm{C}-20 \mathrm{~s}$ & $30-3^{\circ} \mathrm{C}$ & 0 & $<10$ \\
\hline $90^{\circ} \mathrm{C}-2 \min$ & $30-3^{\circ} \mathrm{C}$ & 0 & 0 \\
\hline $75^{\circ} \mathrm{C}-15 \mathrm{~s}$ & $60-3^{\circ} \mathrm{C}$ & 0 & $<10$ \\
\hline $90^{\circ} \mathrm{C}-20 \mathrm{~s}$ & $60-3^{\circ} \mathrm{C}$ & 0 & $<10$ \\
\hline $90^{\circ} \mathrm{C}-2 \min$ & $60-3^{\circ} \mathrm{C}$ & 0 & 0 \\
\hline $90^{\circ} \mathrm{C}-20 \mathrm{~s}$ & $30-21^{\circ} \mathrm{C}$ & 0 & $<10$ \\
\hline $90^{\circ} \mathrm{C}-2 \min$ & $30-21^{\circ} \mathrm{C}$ & 0 & $<10$ \\
\hline $90^{\circ} \mathrm{C}-20 \mathrm{~s}$ & $60-21^{\circ} \mathrm{C}$ & 0 & $<10$ \\
\hline $90^{\circ} \mathrm{C}-2 \min$ & $60-21^{\circ} \mathrm{C}$ & 0 & $<10$ \\
\hline
\end{tabular}


Estos recuentos microbiológicos son muy bajos y se corresponden con una materia prima de excelente estado sanitario, un buen lavado, y buenas condiciones higiénicas del equipo piloto utilizado para la extracción del puré de fresa. Por otra parte el $\mathrm{pH}$ del producto, cercano a 3,5, influye positivamente en el bajo desarrollo bacteriano (Parish et al., 1990; Torres et al., 2008).

A su vez, el recuento microbiológico de las muestras pasteurizadas también fue relativamente bajo por lo que los tratamientos térmicos utilizados en las experiencias son suficientes para garantizar la seguridad microbiológica de este producto y evitar el desarrollo bacteriano durante su almacenamiento. Los zumos de frutas están regulados en España por el R.D. 1650/91 en el BOE de 8/11/91, pero la legislación no recoge normas microbiológicas, con lo que los resultados obtenidos en la presente tesis doctoral no pueden ser comparados con la normativa vigente.

\section{IV.5.2. Cinéticas de inactivación por calor de Lactobacillus plantarum en} suero de puré de fresa.

En el presente apartado se procedió a evaluar el tratamiento térmico adecuado para estabilizar microbiológicamente la fracción suero del puré de fresa. Para ello se estudiaron las cinéticas de inactivación por calor de un microorganismo alterador susceptible de crecer en el producto. Como ya se ha comentado, Lactobacillus plantarum es un microorganismo frecuentemente 
utilizado en ensayos microbiológicos en productos ácidos debido a su ácidotolerancia y termoresistencia (Torres et al., 2008; Jordan y Cogan, 1999).

Los datos experimentales se obtuvieron a temperaturas de 50, 55, 58, 60, $65^{\circ} \mathrm{C}, 70^{\circ} \mathrm{C}$ y $75^{\circ} \mathrm{C}$ manteniendo cada una de ellas durante $10,20,30,40,60$ y 120 segundos. Las curvas se ajustaron a los modelos matemáticos de Bigelow (1921) y de Weibull (1951) (Ecuaciones IV.3 y IV.4, respectivamente), estudiados previamente por Mafart y Leguerinell (1998) y por Nolasco y de Massaguer (2006).

$$
\log (S)=-\frac{t}{D}
$$

donde $S$ es la fracción de microorganismos supervivientes, $t$ el tiempo de tratamiento y $D$ el tiempo de reducción decimal.

$$
\operatorname{Ln}(S)=-\left(\frac{t}{a}\right)^{b}
$$

donde $S$ y $t$ tienen el mismo significado anterior, a es un parámetro cinético y $b$ es el parámetro de forma.

La figura IV.5.1 muestra las curvas de supervivencia de L. plantarum en la fase suero tras el tratamiento térmico y el ajuste al modelo de Weibull, que ha resultado ser el que mejor se ajusta a los datos experimentales (véase la tabla IV.5.2). 


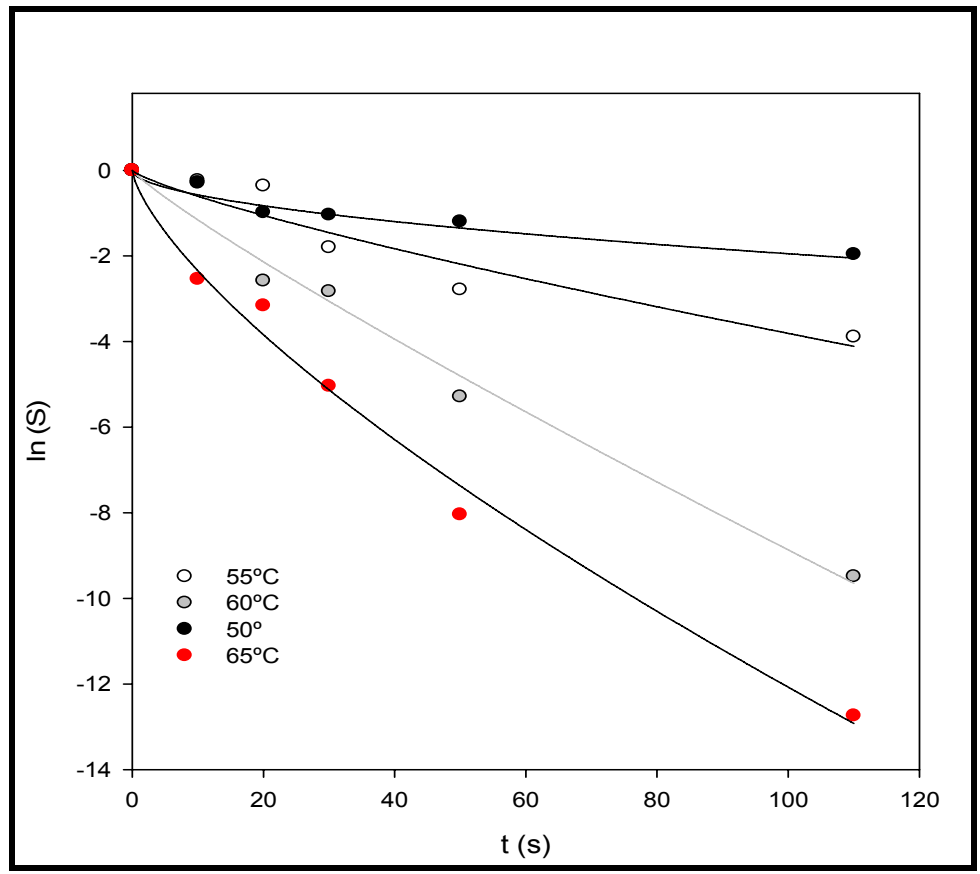

Figura IV.5.1. Ajuste de las curvas de supervivencia de L. plantarum en suero de fresa al modelo de Weibull.

Se pudo observar que los valores de $b$ (modelo de Weibull) fueron menores a 1, lo cual nos indica presencia de colas en las curvas de supervivencia. No se detectaron microorganismos supervivientes en los tratamientos realizados a 70 y $75^{\circ} \mathrm{C}$, lo que demuestra la viabilidad industrial de aplicar el tratamiento de pasteurización a $75^{\circ} \mathrm{C}$ durante 15 segundos ensayado en este trabajo. 
Tabla IV.5.2. Valor de los parámetros del modelo de Weibull y Bigelow en las curvas de supervivencia de L. plantarum en el suero de fresa.

\begin{tabular}{cccccc}
\hline $\mathbf{T}^{\circ} \mathbf{C}$ & Bigelow & & \multicolumn{3}{c}{ Weibull } \\
& $\boldsymbol{D}(\mathbf{s})$ & $\mathbf{R}^{2}$ & $\boldsymbol{a}(\mathbf{s})$ & $\boldsymbol{b}$ & $\mathbf{R}^{\mathbf{2}}$ \\
\hline $\mathbf{5 0}$ & $202 \pm 7$ & 0,700 & $33 \pm 5$ & $0,54 \pm 0,09$ & 0,952 \\
$\mathbf{5 5}$ & $102 \pm 11$ & 0,752 & $19 \pm 6$ & $0,80 \pm 0,18$ & 0,911 \\
$\mathbf{6 0}$ & $48 \pm 3$ & 0,970 & $8 \pm 2$ & $0,88 \pm 0,09$ & 0,978 \\
$\mathbf{6 5}$ & $41 \pm 4$ & 0,922 & $3,0 \pm 0,7$ & $0,71 \pm 0,05$ & 0,990 \\
\hline
\end{tabular}




\section{CONCLUSIONES}





\section{CONCLUSIONES.}

1. El puré de fresa obtenido por lavado y escurrido del fruto, prensado-tamizado del mismo, desaireación a vacío, pasteurización y envasado, tiene una calidad microbiológica y sensorial muy aceptable, con ausencia se sabores extraños o a cocido, pero con menor intensidad de sabor a fresco que el puré no pasteurizado.

2. No se han detectado diferencias significativas en el sabor de los purés sometidos a diversos tratamientos térmicos $\left(75^{\circ} \mathrm{C}-15 \mathrm{~s}, 90^{\circ} \mathrm{C}-20 \mathrm{~s}\right.$ y $90^{\circ} \mathrm{C}-2$ minutos). Tampoco se han detectado diferencias significativas entre el sabor de las muestras recién obtenidas y las almacenadas a $3^{\circ} \mathrm{C}$ durante 2 meses. Por el contrario, el sabor se deteriora significativamente cuando el producto se ha almacenado dos meses a temperatura ambiente $\left(21-22^{\circ} \mathrm{C}\right)$. Todos los tratamientos térmicos aplicados han evitado la alteración microbiana en las muestras almacenadas.

3. La actividad polifenoloxidasa (PPO) del puré de fresa es más resistente a los tratamientos térmicos que la peroxidasa (POD) y la pectinmetilesterasa (PME). El tratamiento de pasteurización a $90^{\circ} \mathrm{C}-20$ segundos, reduce la actividad de la PME a un $5,4 \%$ de la inicial y la POD a un $12,7 \%$, pero todavía permanece un $57,5 \%$ de la actividad PPO. Afortunadamente esta actividad residual no ha tenido efecto desfavorable sobre la aceptación sensorial del puré al término de los dos meses de almacenamiento refrigerado. 
4. La inoculación del puré de fresa con Lactobacillus plantarum, para simular condiciones de alta contaminación microbiana, y la evaluación de la supervivencia tras la aplicación de diversos tratamientos térmicos, ha demostrado que el tratamiento de pasteurización más suave $\left(75^{\circ} \mathrm{C}-15 \mathrm{~s}\right)$ es suficiente para evitar la aparición de unidades formadoras de colonias.

5. La variación del esfuerzo con el gradiante de velocidad, se ajusta con precisión al modelo de Ostwald de Waele. El puré de fresa es un fluido tixotrópico (su viscosidad disminuye con el tiempo a un esfuerzo de cizalla constante) que, a un tiempo dado, se comporta como pseudoplástico (su viscosidad disminuye al aumentar el esfuerzo de cizalla).

6. No se detectan diferencias significativas en el índice de comportamiento al flujo por efecto del tratamiento térmico. Por el contrario la viscosidad aparente es significativamente mayor en las dos muestras sometidas a los tratamientos térmicos más intensos $\left(90^{\circ} \mathrm{C}-20 \mathrm{~s}\right.$ y $\left.90^{\circ} \mathrm{C}-2 \mathrm{~min}\right)$, fenómeno que podría atribuirse a una mayor solubilización de la pectina en la fase líquida de la muestra.

7. Durante el almacenamiento se detecta una significativa evolución del puré hacia un comportamiento más newtoniano. El menor cambio lo registra la muestra que recibe el tratamiento térmico más intenso, por lo que este fenómeno podría atribuirse a una insuficiente inactivación de la actividad pectinmetilesterasa. 
8. Las muestras tratadas térmicamente mostraron un incremento en todos los parámetros de color $C I E L{ }^{*}{ }^{*}{ }^{*}$ con respecto al puré fresco de fresa. La luminosidad $\left(L^{*}\right)$ y la coordenada $a^{*}$ fueron los parámetros más sensibles al tratamiento térmico, aunque el tono no llega a verse significativamente afectado. En el almacenamiento refrigerado los cambios durante los primeros 30 días son muy ligeros y no llegan a tener significación estadística. Entre los 30 y los 60 días se producen cambios estadísticamente significativos en todos los parámetros obtenidos. Estos cambios se aprecian, con mayor intensidad, en las muestras almacenadas a temperatura ambiente. Estos cambios de color podrían utilizarse como indicadores de la pérdida de calidad del puré.

9. El contenido de vitamina $\mathrm{C}$, cianidina $\mathrm{y}$ pelargonidina no resulta afectado significativamente por los distintos tratamientos térmicos. En el almacenamiento refrigerado se mantienen, sin diferencias significativas, los contenidos en cianidina y pelargonidina, pero se reducen los de ácido ascórbico y vitamina C, en especial durante los primeros 30 días. En las muestras almacenadas a temperatura ambiente se registra un acusado y significativo descenso de los contenidos en cianidina, pelargonidina, vitamina C y ácido ascórbico, especialmente durante los primeros 30 días. Sin embargo estos descensos no han repercutido significativamente en la actividad antirradical del puré de fresa, que se ha mantenido en todas las muestras a un nivel muy elevado y comparable con el del puré fresco. 
10. Como resumen puede afirmarse que el puré de fresa soporta mejor el tratamiento térmico que el almacenamiento, por lo que resulta recomendable asegurar y simplificar el proceso recurriendo al sencillo y tradicional envasado en caliente y conservar el producto en refrigeración durante su periodo de vida útil. El producto mantiene así unas propiedades físicas, nutritivas, funcionales y sensoriales muy próximas a las del puré original. 
VI. BIBLIOGRAFÍA 



\section{BIBLIOGRAFIA.}

A.O.A.C. (1980).Association of official analytical chemist. Official methods of analysis, 20.013. Washington, DC.

Abers, J. E., Wrolstad, R. E. (1979). Causative Factors of Color Deterioration in Strawberry Preserves During Processing and Storage. Journal of Food Science 44 (1): 75-78.

Ahmed, J., Shivhare, U. S., Singh, P. (2004). Colour kinetics and rheology of coriander leaf puree and storage characteristics of the paste. Food Chemistry 84 (4): 605-611.

Anese, M., Falcone, P., Fogliano, V., Nicoli, M. C., Massini, R. (2002). Effect of equivalent thermal treatments on the color and the antioxidant activity of tomato purees. Journal of Food Science 67 (9): 3442-3446.

Asozumos (2007). Asociación Española de Fabricantes de Zumos. Noviembre. www.asozumos.org.

Bahceci, K. S., Acar, J. (2007). Modeling the combined effects of $\mathrm{pH}$, temperature and ascorbic acid concentration on the heat resistance of Alicyclobacillus acidoterrestis. International Journal of Food Microbiology 120 (3): 266-273.

Baker, R. A., Cameron, R. G. (1999). Clouds of citrus juices and juice drinks. Food Technology 53 (1): 64-69.

Bakker, J., Bridle, P., Bellworthy, S. J. (1994). Strawberry Juice Color - A Study of the Quantitative and Qualitative Pigment Composition of Juices from 39 Genotypes. Journal of the science of food and agriculture 64 (1): 31-37. 
Bakker, J., Bridle, P., Koopman, A. (1992). Strawberry Juice Color - the Effect of Some Processing Variables on the Stability of Anthocyanins. Journal of the science of food and agriculture 60 (4): 471-476.

Barbosa-Canovas, G. V., Gongora-Nieto, M. M., Swanson, B. G. (1998). Nonthermal electrical methods in food preservation. Food Science and Technology International/Ciencia y Tecnologia de Alimentos Internacional 4 (5): 363-370.

Barbosa-Canovas, G. V., Rodriguez, J. J. (2002). Update on nonthermal food processing technologies: pulsed electric field, high hydrostatic pressure, irradiation and ultrasound. Food Australia 54 (11) : 513-520.

Bello, J. (2005). Calidad de Vida, Alimentos y salud humana: fundamentos cientificos. Diaz de santos, Madrid.

Bendicho, S., Barbosa-Canovas, G. V., Martin, O. (2002). Milk processing by high intensity pulsed electric fields. Trends in Food Science \& Technology 13 (6/7): 195-204.

Bendicho, S., Marselles-Fontanet, A. R., Barbosa-Canovas, G. V., MartínBelloso, O. (2005). High intensity pulsed electric fields and heat treatments applied to a protease from Bacillus subtilis. A comparison study of multiple systems. Journal of Food Engineering 69 (3) : 317-323,

Bigelow, W. D. (1921). The logarithmic nature of thermal death time curves. The Journal of Infectious Diseases. 29 528-536.

Bower, C. K., Daeschel, M. A. (1999). Resistance responses of microorganisms in food environments. International Journal of Food Microbiology 50 (1-2): 33-44.

Brazanti, E. C. (1989). La Fresa. Ed.Mundi Prensa. Madrid. 
Cano, M. P., Hernandez, A., Ancos, B. (1997). High Pressure and Temperature Effects on Enzyme Inactivation in Strawberry and Orange Products. Journal of Food Science 62 (1): 85-88.

Cano, M. P., de Ancos B., Sanchez-Moreno C. (2005). Altas presiones, nueva alternativa para la mejora de la calidad y seguridad en vegetales frescos cortados. 9 Conferencia Internacional sobre Ciencia y Tecnologia .La Habana, Cuba, 8-11 de marzo.

Carbonell, J. V., Contreras, P., Carbonell, L., Navarro, J. L. (2006). Pectin methylesterase activity in juices from mandarins, oranges and hybrids. European Food Research and Technology 222 (1): 83-87.

Castro, I., Goncalves, O., Teixeira, J. A., Vicente, A. A. (2002). Comparative study of Selva and Camarosa strawberries for the commercial market. Journal of Food Science 67 (6): 2132-2137.

Chang, S., Tan, C., Frankel, E. N., Barrett, D. M. (2000). Low-Density Lipoprotein Antioxidant Activity of Phenolic Compounds and Polyphenol Oxidase Activity in Selected Clingstone Peach Cultivars. Journal of Agricultural and Food Chemistry. 48 (2): 147-151.

Chisari, M., Barbagallo, R. N., Spagna, G. (2007). Characterization of polyphenol oxidase and peroxidase and influence on browning of cold stored strawberry fruit. Journal of Agricultural and Food Chemistry 55 (9): 3469-3476.

Chutintrasria, B. y Noomhorm, A. (2006). Thermal inactivation of polyphenoloxidase in pineapple puree. LWT - Food Science and Technology 39 (5): 492-495. 
Chutintrasria, B. and Noomhorm, A. (2007). Color degradation kinetics of pineapple puree during thermal processing. LWT-Food Science and Technology 40 (2): 300-306.

Civello, P. M., Martínez, G. A., Chaves, A. R., Añón, M. C.(1995). Peroxidase from strawberry fruit (Fragaria ananassa Duch.): partial purification and determination of some properties. Journal of Agricultural and Food Chemistry 43 (10): 2596-2601.

Contreras, C., Martín, M. E., Martínez-Navarrete, N., Chiralt, A. (2005). Effect of vacuum impregnation and microwave application on structural changes which occurred during air-drying of apple. Lwt-Food Science and Technology 38471 477.

Contreras, C., Martín-Esparza, M., Martínez-Navarrete, N., Chiralt, A. (2007). Influence of osmotic pre-treatment and microwave application on properties of air dried strawberry related to structural changes. European Food Research and Technology, 224 (4): 499-504 .

Cortes, C., Esteve, M. J., Rodrigo, D., Torregrosa, F., Frigola, A. (2006). Changes of colour and carotenoids contents during high intensity pulsed electric field treatment in orange juices. Food and Chemical Toxicology 44 (11): 19321939.

Curcio, S., Calabro, V., Iorio, G., de Cindio, B. (2001). Fruit juice concentration by membranes: effect of rheological properties on concentration polarization phenomena. Journal of Food Engineering 48 (3): 235-241.

Dalmadi, I., Rapeanu, G., Smout, Ch., Hendrick, M. (2006). Characterization and inactivation by thermal and pressure processing of strawberry (Fragaria ananassa) polyphenol oxidase: a kinetic study. Journal of Food Biochemistry 30: $56-76$. 
De Ancos, B., Cano, M. P., Hernandez, A., Monreal, M. (2007). Effects of microwave heating on pigment composition and colour of fruit purees. Journal of the science of food and agriculture 79 (5): 663-670.

Diels, A. M. J., Callewaert, L., Wuytack, E. Y., Masschalck, B., Michiels, C. W. (2005). Inactivation of Escherichia coli by high-pressure homogenisation is influenced by fluid viscosity but not by water activity and product composition. International Journal of Food Microbiology 101 (3): 281-291.

Divisi, D., Di Tommaso, S., Salvemini, S., Garramone, M., Crisci, R. (2006). Diet and câncer. Acta Biomedica 77: 118-123.

Duhard, V., Garnier, J. C., Megard, D. (1997). Comparison of the stability of selected anthocyanin colorants in drink model systems. Agro Food Industry HiTech 8 (1): 28-34.

Dutta, D., Dutta, A., Raychaudhuri, U., Chakraborty, R. (2006). Rheological characteristics and thermal degradation kinetics of beta-carotene in pumpkin puree. Journal of Food Engineering 76 (4): 538-546.

Estrada-Giron, Y., Swanson, B. G., Barbosa-Canovas, G. V. (2005). Advances in the use of high hydrostatic pressure for processing cereal grains and legumes. Trends in Food Science \& Technology 16 (5): 194-203,

Fernandez-Molina, J. J., Fernandez-Gutierrez, S. A., Altunakar, B., Swanson, B. G., Barbosa-Cánovas, G.V. (2005). The combined effect of pulsed electric fields and conventional heating on the microbial quality and shelf life of skim milk. Journal of Food Processing and Preservation 29 (5-6) : 390-406.

Fernandez-Molina J. J., Barbosa-Canovas G.V., Swanson B. G. (2005). Skim milk processing by combining pulsed electric fields and thermal treatments. Journal of Food Processing and Preservation 29 (5-6) : 291-306. 
Francis, F. J., Clydesdale, F. M. (1975). Food colorimetry: theory and applications. Westport, CT: AVI Publishing.

Gambaro, A., Gimenez, A., Burgueno, J. (2001). Sensory and instrumental evaluation of strawberry yogurt color. Journal of Sensory Studies 16 (1): 11-22.

Ganthavorn, C. y Powers, J. R. (1988). Changes in peroxidase activity, hexanal, oxalic acid, and free sulphydryl in blanched asparagus during frozen storage. Journal of Food Science 53: 1403-1405.

Garcia MA, Martino MN, Zaritzky NE (1998). Plasticized starch-based coatings to improve strawberry (Fragaria $x$ ananassa) quality and stability. Journal of Agricultural and Food Chemistry 46 (9) : 3758-3767.

Garcia-Alonso F.J. (2005). Evaluación in vitro e in vivo de la funcionalidad de un producto rico en antioxidantes. Tesis Doctoral. Universidad de Murcia.

Garcia-Palazon, A., Suthanthangjai, W., Kajda, P., Zabetakis, I. (2004). The effects of high hydrostatic pressure on [beta]-glucosidase, peroxidase and polyphenoloxidase in red raspberry (Rubus idaeus) and strawberry (Fragaria $x$ ananassa). Food Chemistry 88 (1): 7-10.

Garcia-Viguera, C., Zafrilla, P., Romero, F., Abellan, P., Artes, F., TomasBarberan, F. A. (1999). Color stability of strawberry jam as affected by cultivar and storage temperature. Journal of Food Science 64 (2): 243-247.

Gil-Izquierdo, A., Gil, M. I., Ferreres, F. (2002). Effect of Processing Techniques at Industrial Scale on Orange Juice Antioxidant and Beneficial Health Compounds. Journal of Agricultural and Food Chemistry. 50 (18): 5107-5114. 
Golaszewski R, Sims CA, O'Keefe SFO, et al. (1998). Sensory attributes and volatile components of stored strawberry juice. Journal of Food Science 63 (4) : 734-738.

González-Aguilar, G.A., Ayala-Zavala, J.F., Ruiz-Cruz, S., Cruz-Valenzuela, R. y Cuamea-Navarro, F. (2004). Estado actual del mercado de frutos y vegetales cortados. En el simposio "Estado actual del mercado de Frutos y Vegetales cortados en Iberoamérica", dentro del III Congreso Nacional de Ciencia y Tecnología de Alimentos. San José, Costa Rica, Abril del 2004. ISBN 9685862-04-4. p 7-16.

Guerrero-Beltran J. A., Barbosa-Canovas, G. V. (2004). Review: advantages and limitations on processing foods by UV light. Food Science and Technology International $10(3)$ : 137-147

Guerrero-Beltran, J. A., Barbosa-Canovas, G. V. (2005). Reduction of Saccharomyces cerevisiae, Escherichia coli and Listeria innocua in apple juice by ultraviolet light. Journal of Food Process Engineering 28 (5) : 437-452.

Guerrero-Beltran, J. A., Barbosa-Canovas, G. V. (2006). Inactivation of Saccharomyces cerevisiae and polyphenoloxidase in mango nectar treated with UV light. Journal of Food Protection 69 (2) : 362-368.

Guerrero-Beltran, J. A., Barbosa-Canovas, G. V., Swanson, G. (2005). High hydrostatic pressure processing of fruit and vegetable products. Food Reviews International 21 (4) : 411-425, 2005

Guerrero-Beltran, J. A., Barbosa-Canovas, G. V., Moraga, G., Moraga, M. J., Swanson, G. (2006). Effect of pH and ascorbic acid on high hydrostatic pressureprocessed mango puree. Journal of Food Processing and Preservation 30 (5): 582-596. 
Harte, F., Luedecke, L., Swanson, B., Barbosa-Canovas, G. V. (2003). Low-fat set yogurt made from milk subjected to combinations of high hydrostatic pressure and thermal processing. Journal of Dairy Science 86 (4) : 1074-1082.

Hernando, I, Larrea, V., Llorca, E., Lluch, M.A., Pérez-Munuera, I., Puig, A., Quiles, A. (2007). Practicas de Tecnologia Bioquimica. Universidad Politecnica De Valencia. Escuela Tecnica Superior de Ingenieros Industriales. Departamento de Tecnología de Alimentos.

Hongmei Liao, Ying Sun, Yuanying Ni, Xiaojun Liao, Xiaosong Hu, Jihong Wu, Fang Chen, (2007). The effect of enzymatic mash treatment, pressing, centrifugation, homogenization, deaeration, sterilization and storage on carrot juice. Journal of Food Process Engineering 30(4): 421-435

ICMSF (1988). International Commission on Microbiological Specifications for. Microorganisms in foods. Microorganisms in Foods 4: Application of the Hazard Analysis Critical Control Point (HACCP) System to Ensure Microbiological Safety and Quality. Oxford: Blackwell Scientific Publications. ISBN: 0632021810.

Irwe, S., Olson I. (1994). Reduction of pectinesterase activity in orange juice by high-pressure treatment. CRS Press Inc., Boca Raton, Florida.

Jang, M., Cai, L., Udeani, G. O., Slowing, K. V., Thomas, C. F., Fong, H. H. S., Farnsworth, N. R., Kinghorn, A. D., Mehta, R. G., Moon, R. C., Pezzuto, J. M. (1997). Cancer chemopreventive activity of resveratrol, a natural product derived from grapes. Science 10 275: 218-220.

Jordan, K. N., Cogan, T. M. (1999). Heat resistance of Lactobacillus spp. isolated from Cheddar cheese. Letters in Applied Microbiology 29 (2): 136-140. 
Joslyn, M. A., W. Pilnik. (1961). The Orange-Its Biochemistry and Physiology. En: Citrus Processing. A Complete Guide. $2^{\text {nd }}$ Ed. Sinclair (ed.), Kluwer Academic/Plenum Publishers, New York, pp. 373-398.

Juszczak, L., Fortuna, T. (2003). Viscosity of concentrated strawberry juice. Effect of temperature and soluble solids content. Electronic Journal of Polish Agricultural Universities 6 (2).

Kafkas, E., Kosar, M., Paydas, S., Kafkas, S., Baser, K. H. C. (2007). Quality characteristics of strawberry genotypes at different maturation stages. Food Chemistry 100 (3): 1229-1236.

Kimball, D.A. (1999). Citrus processing. A complete Guide. 2nd edn. Kluwer Academic/Plenum Publishers, New York

Klopotek, Y., Otto, K., Bohm, V. (2005). Processing Strawberries to Different Products Alters Contents of Vitamin C, Total Phenolics, Total Anthocyanins, and Antioxidant Capacity. Journal of Agricultural and Food Chemistry. 53 (14): 5640-5646.

Krebbers, B., Matser, A. M., Hoogerwerf, S. W., Moezelaar, R., Tomassen, M. M. M., van den Berg, R. W. (2003). Combined high-pressure and thermal treatments for processing of tomato puree: evaluation of microbial inactivation and quality parameters. Innovative Food Science and Emerging Technologies 4 (4): 377-385.

Krokida, M. K., Maroulis, Z. B., Saravacos, G. D. (2001). Rheological properties of fluid fruit and vegetable puree products: compilation of literature data. International Journal of Food Properties 4 (2): 179-200.

Labuza, T. P. y Simon, I. B. (1969). The surface tension of food juices. Food Technology (Champaign) 23 (5): 694-695. 
Liu RH. (2002). Suplement quick fix fails to deliver. Food Technogy. Inernationalt 1: $71-72$.

Lopes da Silva, F., Escribano-Bailon, M. T., Perez-Alonso, J. J., RibasGonzalo, J. C., Santos-Buelga, C. (2007). Anthocyanin pigments in strawberry. LWT - Food Science and Technology 40 (2): 374-382,

Lopez, P., Sala, F. J., de la Fuente, J. L., Condon, S., Raso, J., Burgos, J. (1994). Inactivation of peroxidase, lipoxygenase, and polyphenol oxidase by manothermosonication. Journal of Agricultural and Food Chemistry. 42 (2): 252-256.

Luh, B. S., Hsu, E. T., Stachowicz, K. (1967). Polyphenolic Compounds in Canned Cling Peaches. Journal of Food Science 32 (3): 251-258.

Maehly, A. C., Chance, B.. (1954). The assay of catalase and peroxide. In: Glick, D, Editor. Methods of Biochemical Analysis. 1, Interscience, pp. 351-425.

Mafart , P., Leguerinell, I. (1998). Modeling Combined Effects of Temperature and $\mathrm{pH}$ on Heat Resistance of Spores by a Linear-Bigelow Equation. Journal of Food Science 63 (1): 6-8.

MAPYA. (2005). Encuesta sobre superficies y rendimientos de cultivos. Ministerio de agricultura pesca y alimentacion.

Martens, M., Scheerlinck, N., De Belie, N., De Baerdemaeker, J. (2001). Numerical model for the combined simulation of heat transfer and enzyme inactivation kinetics in cylindrical vegetables. Journal of Food Engineering 47 (3): 185-193.

Meilgaard, M., Civille, G. (1999). Sensory evaluation techniques. En: CRC press inc., Boca raton, Florida, p. 106-292. 
Michels, K.V., Giovannucci, E., Joshipura, K.J., Rosner, B.A., Stampfer, M.J., Fuchs, C.S., Colditz, G.A., Speizer, F.E., Willett, W.C. (2000). Prospective study of fruit and vegetable comsuption and incidence of colon and rectal cancers. Journal Natural Cancer Institute 92: 1740-1752.

Moraga, G., Martinez-Navarrete, N., Chiralt, A. (2006). Compositional changes of strawberry due to dehydration, cold storage and freezing-thawing processes. Journal of Food Processing and Preservation 30 (4): 458-474.

Moreira, T. (1976). [Relation between freeze-drying characteristics and chemical characteristics of fruit juices.]. Tesis doctoral. Universidad de Dijon, Francia.

Ngaseppam Iboyaima Singh., Eipeson, W. E., (2000). Rheological behaviour of clarified mango juice concentrates. Journal of Texture Studies 31 (3): 287-295.

Nolasco , J. y de Massaguer , P. R. (2006). Thermal degradation kinetics of sucrose, glucose and fructose in sugarcane must for bioethanol production. Journal of Food Process Engineering 29 (5): 462-477.

Osorio, O., Martínez-Navarrete, N., Moraga, G. y Carbonell J. V. 2008. Effect of thermal treatment on enzymatic activity and rheological and sensory properties of strawberry purees. Food Science and Technology International, en prensa.

Otterbacher, A. G. y Skirvin, R. (1978). Derivation of the binomial Fragaria $x$ ananassa for cultivated strawberry. Hortscience, 13: 637-639

Penna, A. L. B., Subbarao, G., Barbosa-Canovas, G. V. (2006). Effect of high hydrostatic pressure processing on rheological and textural properties of probiotic low-fat yogurt fermented by different starter cultures. Journal of Food Process Engineering 29 (5) : 447-461. 
Pace-Asciak, C. R., Hahn, S., Diamandis, E. P., Soleas, G., Goldberg, D. M. (1995). The red wine phenolics trans-resveratrol and quercetin block human platelet aggregation and eicosanoid synthesis: Implications for protection against coronary heart disease. Clinica Chimica Acta 235 (2): 207-219.

Parish, M. E., Sadler, G. D., Wicker, L. (1990). Viability of Lactobacillus Plantarum inorange jiuce under low pH and temperature conditions. Journal of Food Science 55: 1023-1025.

Pilnik, W. y Rombouts, F. (1978). Pectic Enzimes. In: J.M.V. Blanshard and J.R. Mitchell, eds, "Polysaccharides in Food". Butterworths, London,1979, pp.109126.

Pizzocaro, F., Torreggiani, D., Gilardi, G. (1993). Inhibition of apple polyphenoloxidase (PPO) by ascorbic acid, citric acid and sodium chloride. Journal of Food Processing and Preservation 17 (1): 21-30.

Plaza, L., Muñoz, M., de Ancos, B. Cano, M. P. (2003). Effect of combined treatments of high-pressure, citric acid and sodium chloride on quality parameters of tomato puree. European Food Research and Technology 216 (6): 514-519.

Potter, J. D. (1996). Nutrition and colorectal cancer. Cancer Causes and Control 7 (1): 127-146.

Prior, R. L., Cao, G. (2000). Antioxidant phytochemicals in fruits and vegetables: diet and health implications. Hortscience 35: 588-592.

Raso, J., Barbosa-Canovas, G. V. (2003). Nonthermal preservation of foods using combined processing techniques. Critical Reviews in Food Science and Nutrition 43 (3): 265-285. 
Rimm, E. B., Stampfer, M. J., Ascherio, A., Stampfer, M. J., Willet, W. (1996). Relation between intake of flavonoid and risk of $\mathrm{CHD}$ in male health professionals. Annal Inter. Med 125 (348): 389.

Robinson, D. S. (1991). Peroxidases and catalases in foods. In: D.S. Robinson and N.A. Eskin, Editors, Oxidative enzymes in foods, Elsevier, London (1991), p. 1.

Rosa, C., Ibarz, A., Garza, S. (2004). Rheological behaviour of clarified strawberry juice at high concentrations. Alimentaria (350): 91-95.

Rouse, A. H., Atkins, C. D. (1955). Pectinesterase and pectin in commercial citrus juice as determined by methods used at the citrus experiment station. Bull Univ Florida 570: 1-19.

Rouse A.H., Atkins, C. D., Moore, E. L. (1962). Seasonal Changes Occurring in the Pectinesterase Activity and Pectic Constituents of the Component Parts of Citrus Fruits.. I. Valencia Orangesa. Journal of Food Science 27 (5): 419-425.

Sampedro, F., Rodrigo, D., Martinez, A., Barbosa-Canovas, G. V., Rodrigo, M. (2006). Review: Application of pulsed electric fields in egg and egg derivatives. Food Science and Technology International 12 (5): 397-405.

San Martin, M. F., Barbosa-Canovas, G. V., Swanson, B. G. (2002). Food processing by high hydrostatic pressure. Critical Reviews in Food Science and Nutrition 42 (6): 627-645.

Sanchez-Mata, M. C., Cámara-Hurtado, M., Díez-Marqués, C., Torija-Isaza, M. E. (2000). Comparison of hight performance liquid cromatography and spectrofluorimetry for vitamin C analysis of green beans. European Food Research and Technology 210: 220-225. 
Saunders, B. C., Holmes-Siedle, A. G., Stark, B. P. (1964). Peroxidase. En: The properties and uses of a versatile enzime. Butterwoths, London, UK,

Schreier, P. A., Miller E. (1985). Studies on flavonoid degradation by peroxidase: quercetin. Food Chemistry (17): 301-317.

Sendra, J. M., Sentandreu, E., Navarro, J. L. (2007). Kinetic model for the antiradical activity of the isolated p-catechol group in flavanone type structures using the free stable radical 2,2-diphenyl-1-picrylhydrazyl as the antiradical probe. Journal of Agricultural and Food Chemistry 55 (14): 5512-5522.

Sentandreu, E., Carbonell, L., Carbonell, J. V., Izquierdo, L. (2005). Effects of Heat Treatment Conditions on Fresh Taste and on Pectinmethylesterase Activity of Chilled Mandarin and Orange Juices. Food Science and Technology International 11 (3): 217-222.

Sentandreu, E., Carbonell, L., Rodrigo, D., Carbonell, J. V. (2006). Pulsed electric fields versus thermal treatment: equivalent processes to obtain equally acceptable citrus juices. Journal of Food Protection 69 (8): 2016-2018.

Sentandreu, E. (2006). Determinación de la Actividad Antirradical de Zumos Citricos y Caracterización de zumos de Mandarina en Función de su Contenido en Flavoniodes y de su Actividad Antirradical. Tesis Doctoral. Universidad de Valencia-Instituto de Agroquimica y Tecnologia de Alimentos.

Sentandreu, E., Navarro, Jose L., Sendra, José M. (2008). Reduction Kinetics of the Antiradical Probe 2,2-Diphenyl-1-picrylhydrazyl (DPPH•) in Methanol and Acetonitrile by the Antiradical Activity of Protocatechuic Acid and Protocatechuic Acid Methyl Ester. Journal of the Agricultural and Food Chemistry (in press). 
Sepulveda-Ahumada, D. R., Ortega-Rivas, E., Barbosa-Canovas, G.V. (2000). Quality aspects of Cheddar cheese obtained with milk pasteurized by pulsed electric fields. Food and Bioproducts Processing 78 (C2): 65-71.

Silva, F. V. M., Gibbs, P. (2001). Alicyclobacillus acidoterrestris spores in fruit products and design of pasteurization processes. Trends in Food Science \& Technology 12 (2): 68-74.

Silva, F. V. M., Gibbs, P. (2004). Target selection in designing pasteurization processes for shelf-stable high-acid fruit products. Critical Reviews in Food Science and Nutrition 44 (5): 353-360.

Sirisomboon, P., Tanaka, M., Fujita, S., Akinaga, T., Kojima, T. (2001). A Simplified Method for the Determination of Total Oxalate-Soluble Pectin Content in Japanese Pear. Journal of Food Composition and Analysis 14 (1): 83-91.

Song, H. P., Byun, M. W., Jo, C., Lee, C. H., Kim, K. S., Kim, D. H. (2007). Effects of gamma irradiation on the microbiological, nutritional, and sensory properties of fresh vegetable juice. Food Control 18 (1): 5-10.

Soon-Mi Shim, Gun-Hee Kim (2002). Color changes and carotenoid pigment loss in retenate from Star Ruby grapefruit juice under refrigerated conditions. Food Science and Technology Research 8 (3) : 244-246.

Spayd, S. E., Morris, J. R. (1981). Effects of Immature Fruit and Holding on Strawberry Puree Quality and Color Stability. Journal of the American Society for Horticultural Science 106 (2): 211-216.

Sturm, K., Koron, D., Stampar, F. (2003). The composition of fruit of different strawberry varieties depending on maturity stage. Food Chemistry 83 (3): 417422. 
Torres, E. F., Bayarri, S., Sampedro, F., Martinez, A., Carbonell, J. V. (2008). Improvement of the fresh taste intensity of processed clementine juice by separate pateurization of its serum and pulp. Food Science and Technology International In press.

Van Asselt, E. D. y Zwietering, M. H. (2006). A systematic approach to determine global thermal inactivation parameters for various food pathogens. International Journal of Food Microbiology 107 (1): 73-82.

Vercet, A., Sanchez, C., Burgos, J., Montanes, L., Lopez Buesa, P. (2002). The effects of manothermosonication on tomato pectic enzymes and tomato paste rheological properties. Journal of Food Engineering 53 (3): 273-278.

Vidal, J. R. M. B., Gasparetto, C. A. (2000). Rheological behavior of mango pulp (Mangifera indica L) - effect of insoluble solids. Ciencia e Tecnologia de Alimentos 20 (2): 172-175.

Weemaes, C. A., De Cordt, S. V., Ludikhuyze, L. R., Van den Broeck, I., Hendrickx, M. E., Tobback, P. P. (1997). Influence of pH, Benzoic Acid, EDTA, and Glutathione on the Pressure and/or Temperature Inactivation Kinetics of Mushroom Polyphenoloxidase. Biotechnol. Prog. 13 (1): 25-32.

Weemaes, C. A., Ludikhuyze, L. R., Van den Broeck, I., Hendrickx, M. E., Tobback, P. P. (1998). Activity, Electrophoretic Characteristics and Heat Inactivation of Polyphenoloxidases from Apples, Avocados, Grapes, Pears and Plums. Lebensmittel-Wissenschaft und-Technologie 31 (1): 44-49.

Weibull, W. (1951). A statistical distribution function of wide applicability. Journal of Applied. Mechanics 18 293-297.

Whitaker, J. R. (1994). Enzimes: Monitors of food stability and quality. Trends in Food Science \& Technology ,2, 94-97. 
Windhab, E. J. (1995). Rheology in food processing. En: Physico-chemical aspects of food processing. S. T. Beckett (ed.), Blackie Academic and Professional, London, p. 80-116.

Wozniak, W., Radajewska, B., Reszelska-Sieciechowicz, A., Dejwor, I. (1997). Sugars and acid content influence organoleptic evaluation of fruits of six strawberry cultivars from controlled cultivation. Acta Horticultural. 439: 333-336. 
